\title{
The Respiratory System
}

\subsection{Physiology of the Upper Airway and Control in Breathing}

\author{
Alastair A. Hutchison
}

\section{Educational Aims}

- Describe the expanded concept of breathing in terms of multiple motor functions that ensure airway protection, volume homeostasis, and ventilation.

- Describe the upper airway structures and how their functions affect the entire airway.

- Describe the nasal functions involved in air conditioning, in protection, in the maintenance of airway patency, and in the consequences of nasal bypass and obstruction.

- Describe the oral cavity and pharyngeal regions and control of airway patency.

- Describe factors involved in obstructive sleep apnea and the effects of CPAP therapy.

- Describe the coordination of sucking, nutritive swallowing, and breathing during development and the relationship to apnea and bradycardia.
- Describe the importance of nonnutritive swallowing in pharyngeal clearance and how this may be influenced by CPAP.

- Describe the three major functions of the larynx involving breathing.

- Describe the triple mechanism of laryngeal closure in airway protection.

- Describe how flow and subglottic volume are controlled during eupnea.

- Describe the integrative nature of the central control of laryngeal functions.

- Describe the roles of laryngeal muscles and their coordination with pump muscles during development and in eupnea, sighs, grunting, incremental breathing, and gasping.

- Describe how this information has been/ can be applied in respiratory support.

- Describe afferent inputs that alter laryngeal muscle functions and alter breathing and cardiovascular function.

- Describe the impact of central behavioral state and induced central depression upon laryngeal function and the interactions with detected changes in the gaseous environment. 


\subsubsection{Introduction: Breathing and the Upper Airway}

It is impossible for anyone to find the correct function of a part unless he is perfectly acquainted with the action of the whole instrument. Galen, AD 120-200.

Breathing consists of multiple motor acts whose mechanical effects aim to ensure that the airway is protected, has optimal supra- and subglottic volumes, and provides vital ventilation. The upper airway extends from the nose or mouth to the larynx (Seikel et al. 2005), but its functions, in the context of ventilation, extend to the entire airway. Maintenance of airway volume and ventilation is actively controlled by the centrally coordinated activities of nasal, oral, pharyngeal, and laryngeal upper airway muscles and those of the pump muscles. These act in concert with lower airway smooth muscle. Effective breathing requires that the brain coordinates ventilatory functions with cardiovascular function and with other motor acts, e.g., swallowing, postural changes, and speech. Adaptations in breathing must occur appropriately, rapidly, and constantly. Protective and mechanical changes occur in milliseconds. Changes in circulatory gas transport alter breathing within seconds. Other adjustments optimize breathing in tune with changes in growth, aging, metabolism, and the environment. This chapter addresses how each upper airway structure plays critical roles in the dynamic processes of breathing.

\subsubsection{Nasal Functions in Breathing}

... we would do well to keep our mouths shut and reflect on the marvelous physiology of the nose. Richard Godfrey 1994

\subsubsection{Air Conditioning and Vascularity}

Normal breathing occurs via the nose (Fig. 4.1). Inspired and expired air is conditioned by the nasal mucosa, whose surface area and blood supply are such that particles are filtered and temperature and humidity are modified. The nasal vascular system can achieve a $25^{\circ} \mathrm{C}$ gradient between the nasal ostia and the nasopharynx (Godfrey 1994), a property that enables air breathing at very different environmental temperatures while maintaining a remarkable constancy of temperature and humidity in the lower airway, thereby optimizing cellular function and ciliary action. Given its vascularity, it is not surprising that the nose is a source of nitric oxide, that trauma to the nasal passages can be induced by nasal continuous positive airway pressure (NCPAP) prongs and other cannulae, and that epistaxis can require hospital admission.

\subsubsection{Nasal Reflexes and Protection}

The nose can sniff out noxious substances and protect the airway from particles by sneezing. It can increase its resistance rapidly, switching on a watery secretion "like a tap" (Godfrey 1994), and can trigger laryngeal closure and reduced ventilatory drive (Editorial 1992). The extreme protective reflex response to nasal irritation is the dive reflex that is typified by apnea with glottic closure, bradycardia, and redistribution of blood flow to the brain, heart, and adrenals (see also Sect. 47.3.1) (de Burgh Daly 1997; Editorial 1992). The dive reflex can be triggered by nasal water, tobacco smoke, or ice applied to the trigeminal area (Angell James and de Burgh Daly 1969; de Burgh Daly 1997). Water entry into the nose is dramatic even for adults who "suffer a sense of impending suffocation and the almost impossibility of voluntarily making an inspiratory effort" (de Burgh Daly 1997). Exaggerated dive reflex responses can cause total upper airway closure and cardiac arrest and have been implicated in accidental and deliberately induced deaths (de Burgh Daly 1997).

\subsubsection{Nasal Patency and Resistance}

Nasal breathing in the newborn and infant is the predominant but not obligatory form of breathing and is related to the high position of the 

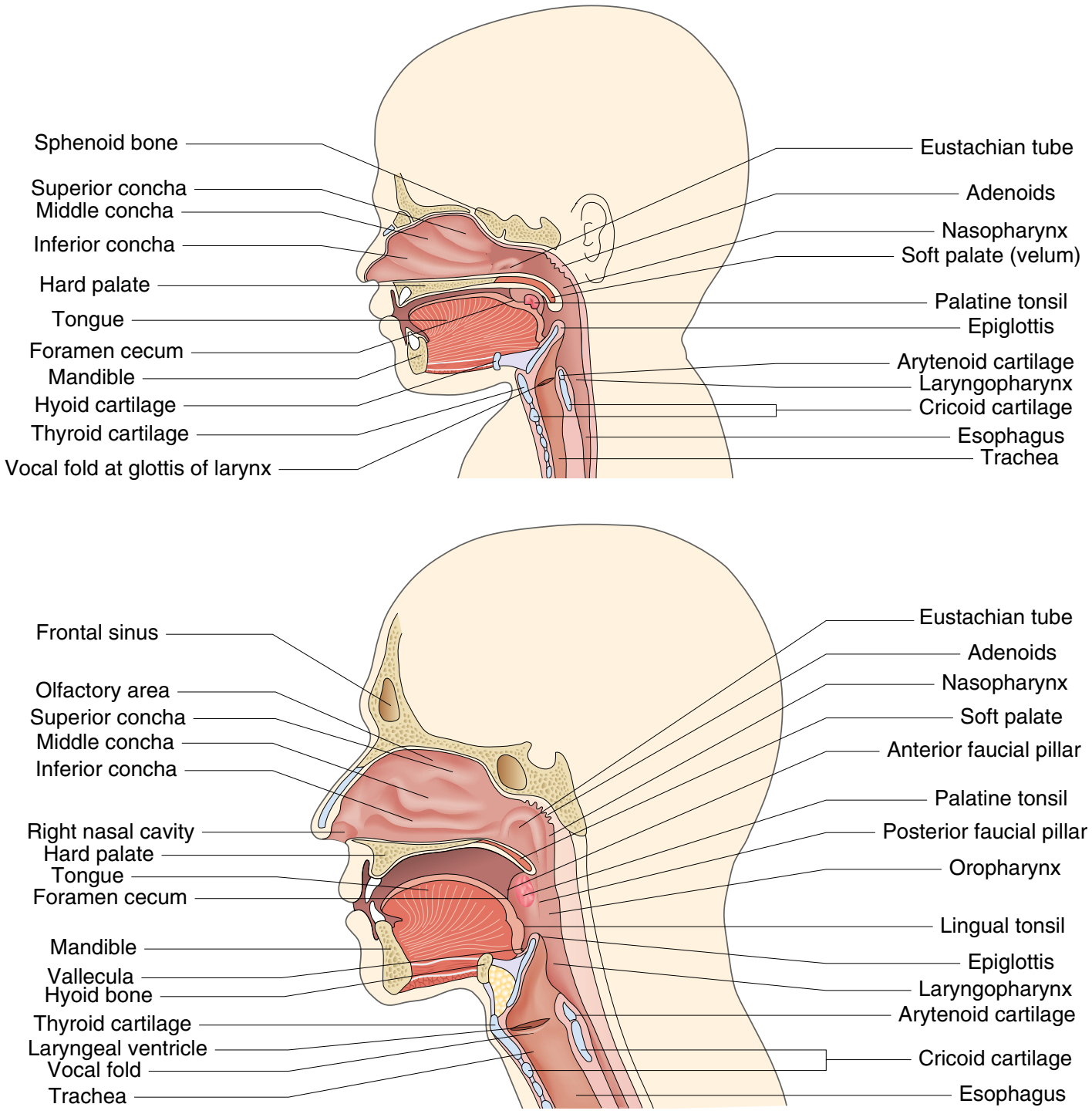

Fig. 4.1 The anatomy of the newborn (left panel) and adult (right panel) upper airways is shown

epiglottis (Fig. 4.1) (Seikel et al. 2005). There is a nasal cycle whereby resistance alternates from one nostril to the other every $2-4 \mathrm{~h}$ in $80 \%$ of humans (Widdicombe 1986). Pressure in the axilla or on the lateral chest increases ipsilateral nasal resistance (Widdicombe 1986). Resistance is highest in the regions adjacent to the external ostia, whose dimensions are altered by the alae nasi muscles that cause nasal flaring during exercise hyperpnea and respiratory distress, especially in newborns. Newborn nasal resistance exceeds that of the adult in absolute terms but is less than that of their lower airways. Nearly half of the adult's total airway resistance is nasal. Thus, minor increases in nasal resistance can produce major overall effects on breathing (Editorial 
1992). In adult humans, nasal occlusion results in a switch to mouth breathing in $<5 \mathrm{~s}$ (Editorial 1992). Both this switch to oral breathing and the resumption of nasal breathing following release of the occlusion are delayed by nasal and pharyngeal anesthesia. Occlusion of the nasal passages in infants results in mouth breathing in $\sim 8 \mathrm{~s}$ (range <1-32 s) (Editorial 1992; Rodenstein 2004). The response is quicker with advancing age but is decreased in rapid eye movement (REM) sleep, more so at 6 weeks than in the newborn period (Editorial 1992). These observations led to a proposal that the response may be related to the sudden infant death syndrome (SIDS) (Editorial 1992). In premature infants, the change to oral breathing results in a sixfold increase in pulmonary resistance, which over time might result in fatigue with hypoventilation (Miller et al. 1987). Oral breathing places an increased burden on the lower airway to modify the temperature and humidity of inspired gas, presumably via changes in lower airway vascularity. Preventing nasal breathing can decrease gas exchange and functional residual capacity (FRC) (Editorial 1992). Postoperative nasal packing in adults can lead to arterial hypoxemia, apnea, and sleep disturbance, with the latter also occurring in normal volunteers after local anesthesia of the nasal passages (Editorial 1992). In newborn lambs, nasal obstruction also affects gas exchange, with hypoxemia, hypercapnia, and acidosis being observed. These effects are aggravated by carotid body denervation. The impact of nasal obstruction diminishes with advancing age (Editorial 1992). Blockage of the nose (choanal stenosis being an extreme example) can cause obstructive sleep apnea (OSA) (Marcus 2000). Human neonates whose nasal resistance is increased by birth trauma or trauma secondary to repeated suctioning breathe orally. They can have cyanotic episodes, stridor, and hypercapnia; these problems disappear with resolution of the nasal injury (Miller et al. 1987).

In summary, the nose provides air conditioning, and its sensory receptors initiate reflexes that alter upper airway patency and mediate extended ventilatory changes in response to a challenge.

\subsubsection{Oral Cavity and Pharyngeal Functions in Breathing}

\begin{abstract}
...after relaxing, many sword swallowers are able to relax and breathe while swallowing a sword. From swordswallow.com 2009.
\end{abstract}

The oral cavity extends from the lips to the plane of the faucial pillars, where it joins the pharynx (Fig. 4.1). The three pharyngeal regions are the nasopharynx, from the posterior nares to the uvula; the oropharynx, from the uvula to the epiglottis; and the laryngopharynx, from the epiglottis to the esophagus. The pharynx is a conduit for air and/or food.

\subsubsection{Oral Cavity and Pharyngeal Patencies and Obstructive Apnea}

The muscles of the tongue, especially the genioglossi, maintain patency of the oral cavity. Pharyngeal patency is a function of the cavity dimensions (Rodenstein 2004) and the balance between the opening forces exerted by pharyngeal muscle activities and the collapsing ones exerted by the tissue-intrapharyngeal pressure gradient and by pharyngeal mucosal adhesion (Fig. 4.2). Patency is critically influenced by posture. Narrowing occurs with neck flexion and hyperextension and can alter cavity pressures required to achieve flow. Narrowing can also follow an inspiratory occlusion of the mouth/nose (a load) that augments diaphragmatic activity and thus negative pressure within the pharynx. Upper and lower airway afferents induce reflex compensatory change in glossopharyngeal muscles to offset the load effect (Fig. 4.2) (Bailey and Fregosi 2006).

Obstructive apnea occurs during sleep in $\sim 1-4 \%$ of children and adults (Marcus 2000). In children, a persistent partial form of upper airway obstruction, obstructive hypoventilation, is 
Fig. 4.2 This diagram shows the factors that determine pharyngeal patency - please see text (Modified from Patil et al. (2007))

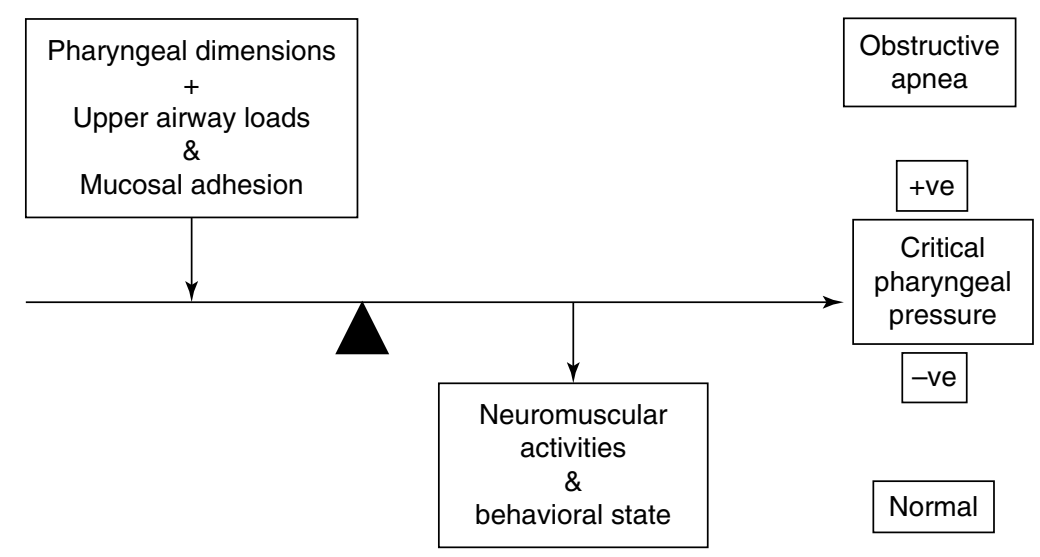

seen (Marcus 2000). In adults, a spectrum of decreased inspiratory airflow is seen in snoring, upper airway resistance syndrome, and OSA. Pharyngeal OSA occurs when a critical tissue pressure $\left(P_{\text {crit }}\right)$ exceeds the intrapharyngeal opening pressure (Fig. 4.2) (Marcus 2000; Dempsey et al. 2010) and is influenced by factors that alter pharyngeal dimensions, namely, adenotonsillar hypertrophy, obesity (less common in children than adults), low subglottic airway volume, and craniofacial structural abnormalities. The major role played by the central motor output to the oral cavity and pharyngeal muscles that modify $P_{\text {crit }}$ is emphasized by the fact that OSA occurs only in sleep, predominantly in REM sleep in children (Marcus 2000). The following factors also stress the importance of central control in OSA. Obstructive apnea occurring during mixed apnea in preterm newborns involves a direct central mechanism, as shown by the onset of pharyngeal and/or laryngeal closure before diaphragmatic activation (Idiong et al. 1998) (see Sect. 47.3.1). In adults pharyngeal closure can accompany central apnea (Marcus 2000). Central arousal patterns during OSA differ between children and adults (Marcus 2000). Other factors affecting the incidence of OSA are gender, a familial tendency, and racial/ethnic factors (Marcus 2000). Anti-inflammatory medications can benefit OSA, suggesting a role for inflammation in its etiology (Praud and Dorion 2008). Therapy with NCPAP improves OSA by increas- ing intrapharyngeal pressure and its transverse diameter (Rodenstein 2004), by augmenting lower airway volume and probably by stimulating breathing via pharyngeal pressure sensors (Angell James and de Burgh Daly 1969). In children and adults with OSA, CPAP therapy can improve their metabolism.

\subsubsection{Sucking, Nutritive Swallowing, and Breathing}

The abilities to suck, swallow, and breathe are developed during fetal life (Harding 1986). At all ages, swallowing is accompanied by laryngeal closure. Term newborns and infants up to 12-18 months of age can lock the larynx into the nasopharynx (Figs. 4.1 and 4.3). This separation of the nasopharyngeal-laryngeal air passage from the oropharyngeal nutritive passage enables the term infant to breathe and feed simultaneously but with decreased ventilatory drive. This ability is not developed in the preterm neonate whose sucking pattern is also immature (Lau 2006). Coordination of sucking-swallowing-breathing is defined by the ability to feed "by mouth with no overt signs of aspiration, oxygen desaturation, apnea, or bradycardia" and when "a ratio of $1: 1: 1$ or $2: 2: 1$ suck: swallow: breathe" is attained (Lau 2006). Safe swallowing occurs at end-expiration and end-inspiration (Lau 2006). In term newborns, $55 \%$ of swallows occur at these points of the breathing cycle. In preterm infants, $55 \%$ of swallows occur during deglutition apnea (Lau 2006). 


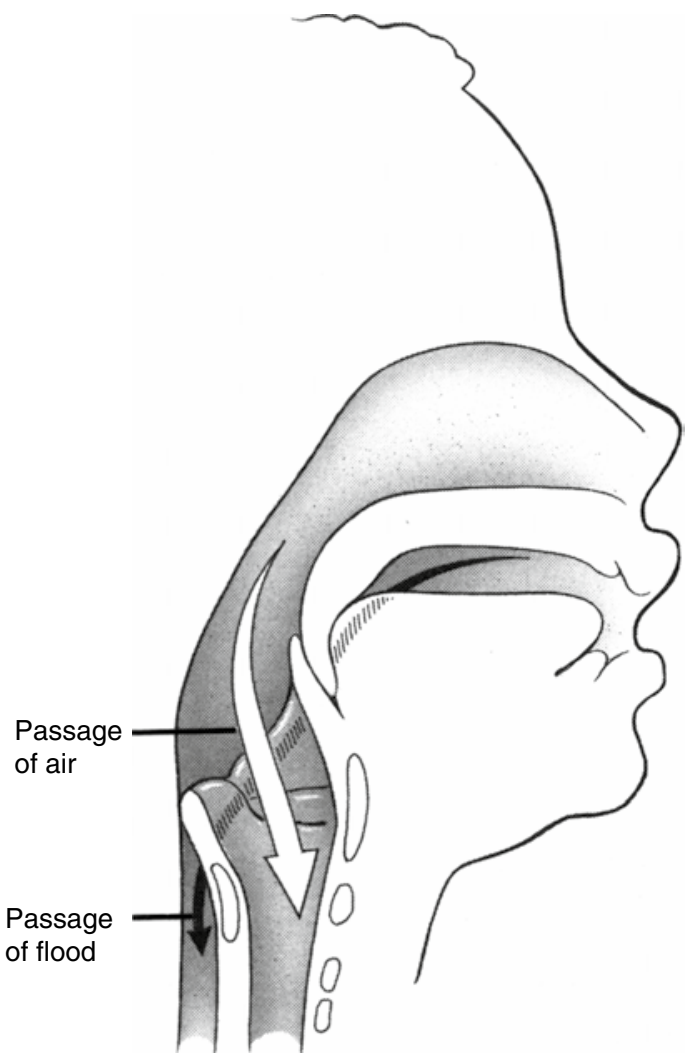

Fig. 4.3 The high position of the infantile larynx allows the epiglottis and uvula to lock, separating the nasopharyngeal-laryngeal air passage from the oropharyngeal nutritive one (From O'Connor, D. Reproduced with permission from Myer et al. (1995). Redrawn by agreement with Springer-Verlag)

\subsubsection{Nonnutritive Swallowing, Aspiration, and Swallow Breaths}

Nonnutritive swallowing (NNS) is "essential for survival," since $>2 \mathrm{~L}$ of oral and nasal secretions are produced daily. Without NNS, "the lungs rapidly fill with these secretions, producing death within a few days" (Thach 2005). When pharyngeal secretions reach a critical volume, neural receptors, in the interarytenoid notch, stimulate the laryngochemoreflex which triggers NNS (Thach 2005). The critical pharyngeal volume for NNS may be increased by applied positive pharyngeal pressure, providing an explanation for the decrease in NNS frequency with CPAP (Thach 2005). In adult humans NNS occurs mainly during expiration. In infants NNS occurs at any time in the respiratory cycle (Thach 2005). Volitional swallowing in adults clears the pharynx and reduces the protective laryngeal adductor reflex. During sleep, the protection provided by NNS and glottic closure is imperfect, and some aspiration is common in normal individuals (Thach 2005). Swallow breaths are short inspirations that precede a swallow, occurring when the upper pharyngeal sphincters are closed (Thach 2005). These breaths are thought to result in pharyngeal air being inhaled as opposed to being swallowed (Thach 2005). The increased gastric air found when positive pharyngeal pressure is applied suggests that CPAP can alter normal pharyngeal clearance mechanisms and infers the need to titrate the applied pressure carefully (Thach 2005). Finally, swallowing may be related to sleep apnea and be part of recovery from sleep apnea (see Sect. 47.3.1) (Thach 2005).

In summary, patency of the oral cavity and the pharynx and the coordination with swallowing and sucking are critical for breathing. The term, but not preterm, newborn can suck and breathe simultaneously, although ventilatory drive is decreased. Physiological control of breathing and swallowing involves important sensory input that limits aspiration and protects the lower airway. Intensive care therapies can alter normal protective, breathing and swallowing functions.

\subsubsection{Laryngeal Functions in Breathing and Control in Breathing}

Like a Swiss watch, ... our vocal tract depends on the precise functioning of many structures and muscles." Jared Diamond, 1992 (The Third Chimpanzee).

The larynx has three major functions involving breathing. It serves as a protective structure guarding the subglottic airway; as a flow controller of subglottic absolute and tidal volumes during eupnea and complex coordinated movements; and as a vibratory modulator of flow that generates speech, song, and laughter (Fig. 4.4). 


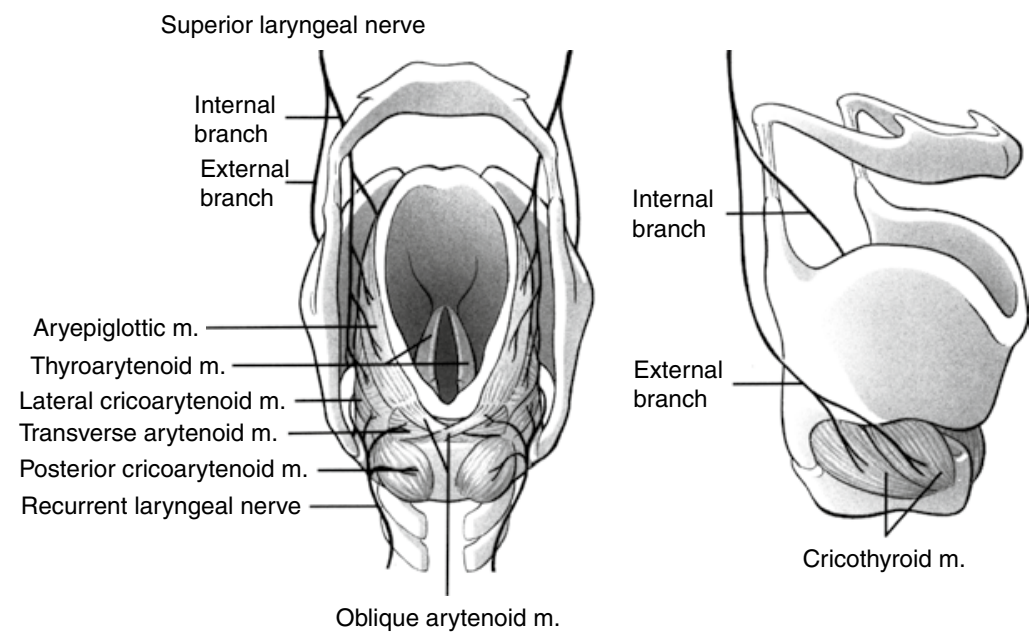

Fig. 4.4 The intrinsic laryngeal muscles and their innervation are shown. The left panel shows from bottom to top the posterior cricoarytenoids, the sole abductors of the larynx, and the abductors: the thyroarytenoids, the lateral cricoarytenoids, the transverse and oblique arytenoids, and the aryepiglottic muscles. All of these muscles are

\subsubsection{Laryngeal Opening and Closure in Airway Protection and Breathing}

\subsection{Laryngeal Closure and Airway Protection}

Protection of the subglottic airway is a centrally controlled major task of "breathing." Laryngeal stimulation can trigger a clearing response, e.g., an expiration reflex or a cough, or can result in airway closure. Laryngeal closure occurs at the level of the epiglottis, at the vestibular folds, and at the vocal folds. This triple mechanism has been likened to closure of a nutcracker, an analogy whose accuracy is all too evident to intensivists faced with laryngospasm (Fink 1973).

\subsection{Eupnea: Glottic Aperture Size and Flow/Volume Control}

In adult humans the glottis opens maximally during inspiration, closes gradually to a minimum about three quarters through expiration, and then opens again in late expiration (England et al. 1982a). Glottic resistance is least at peak inspiration, increases as expiration progresses, and then decreases in late expiration to minimize inspiratory flow resistance with the onset of pump supplied by the recurrent laryngeal nerve (X). The internal branch of the SLN is sensory, while the external SLN branch is motor for the cricothyroid muscles (right panel) (From O'Connor, D. Reproduced with permission from Myer et al. (1995). Redrawn by agreement with Springer-Verlag)

muscle activity (England et al. 1982a). There is no sensation of expiratory glottic closure in eupnea. Accurate, rapid laryngeal opening and closure maintains an optimal subglottic airway volume, ensures tidal volume changes that enable gas exchange, and enhances airway patency and surfactant secretion. The smooth tidal flow pattern, produced by laryngeal and diaphragmatic activities interacting with the mechanics of the respiratory system, avoids tissue exposure to acceleration or deceleration injuries.

\subsection{Integrative Central Control and Effects}

The same laryngeal intrinsic muscles are involved in all laryngeal functions emphasizing that the central coordinations of the motor acts of breathing are truly integrative, a fact also stressed by the impacts that laryngeal sensory inputs and the resultant vagal outputs have on the cardiovascular system. Laryngeal closure is important for other motor acts, e.g., effective lifting. Central control of breathing is linked to emotions. It is of note that in laughter the order of abductor-adductor activities seen in breathing is reversed (Luschei et al. 2006). Eastern philosophies combine 


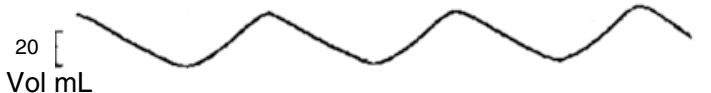

Vol $\mathrm{mL}$

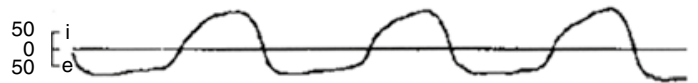

Flow $\mathrm{mL} / \mathrm{s}$

3 .

$i_{+}^{-}$

Pua $\mathrm{cm} \mathrm{H}_{2} \mathrm{O}$

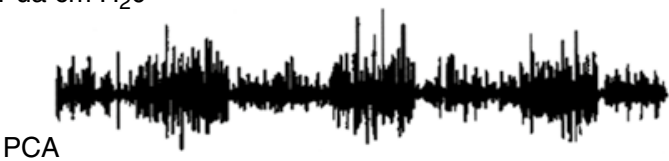

TA

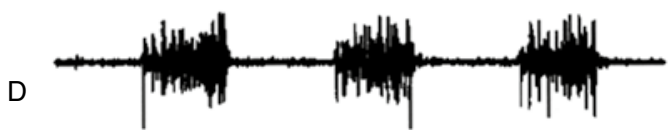

Fig. 4.5 This figure demonstrates the breathing cycles during eupnea and grunting in newborn lambs, showing the relationships between the EMGs of the posterior cricoarytenoid ( $P C A$ ) muscles, those of the major adductors,

breathing and vocalizations in practices aiming to augment metabolic and mental well-being.

\subsubsection{Laryngeal Intrinsic Muscles and Control in Breathing}

Understanding the actions of the laryngeal intrinsic muscles is a necessary first step in gaining insights into the nature of the central control of breathing. The posterior cricoarytenoids (PCA) are the sole abductors of the vocal cords. There are several adductors, with the thyroarytenoids (TA) being the major ones (Fig. 4.4). Some adductors, the cricothyroid and the vocalis part of TA, enhance abduction by tensing the vocal cords. This restricts vertical movement, improving flow control in the more horizontal plane. The magnitude of abductor activity exceeds that of the adductors when glottic size is increased and vice versa, consistent with relationships between glottic size and flow resistance (England et al. 1982a; Insalaco et al. 1990; Kuna et al. 1988). Animal (m)
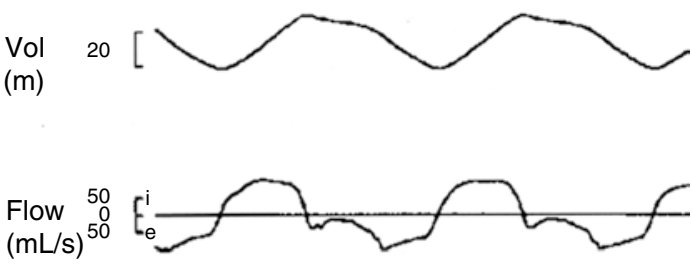

$\begin{array}{lr}\text { Pua } & 3 \\ \left(\mathrm{~cm} \mathrm{H}_{2} \mathrm{O}\right) & 0 \\ 3\end{array}$

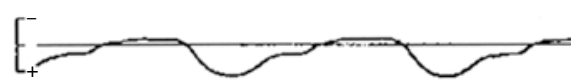

PCA

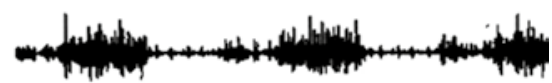

TA

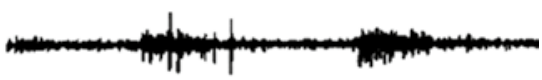

D

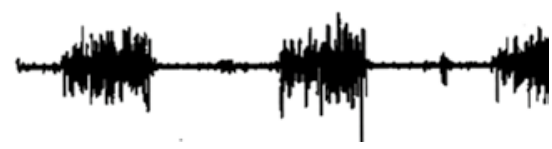

the thyroarytenoid (TA) muscles, and those of the diaphragm $(D)$, together with flow, volume, and trans-upper airway pressure changes (Reproduced with permission from Hutchison et al. (1993))

studies indicate that, in general, glottic opening and closing are achieved by reciprocal laryngeal abductor and adductor activities (Fig. 4.5) (Bartlett 1989; Harding 1986; Hutchison et al. 1993). Concurrent actions of laryngeal abductor and adductor muscles during inspiration and expiration may occur in adult humans, but their nature is unknown (Insalaco et al. 1990; Kuna et al. 1988, 1990).

\subsection{Laryngeal Intrinsic Muscles in Eupnea and Grunting}

During eupnea the inspiratory outline of the PCA EMG resembles the flow pattern, while the ramp shape of the diaphragm EMG relates to the inspired volume trace (Hutchison et al. 1993). In animals little expiratory TA activity is seen, and trans-upper airway pressure is minimal (Fig.4.5). In eupneic expiration in adult humans, PCA activity diminishes, but some TA activity is present "rounding off" the early expiratory volume 

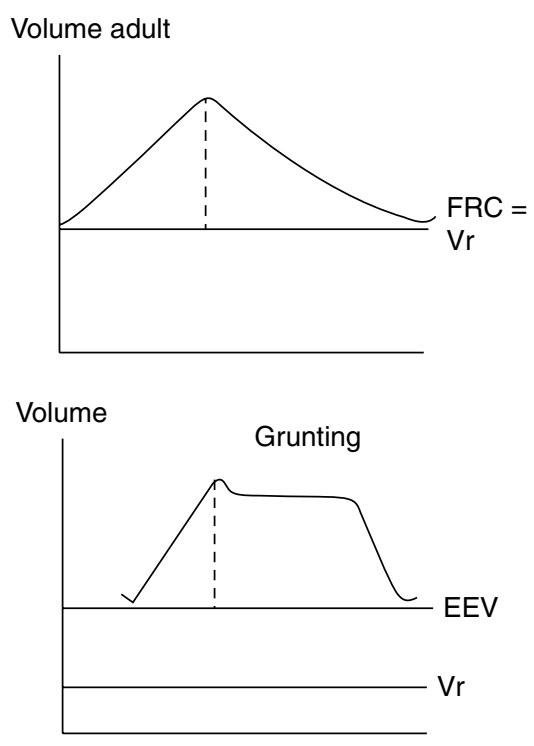

Time

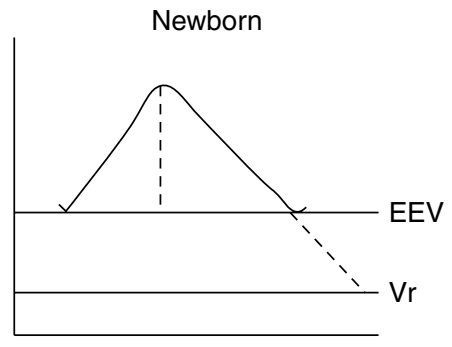

Incremental breath

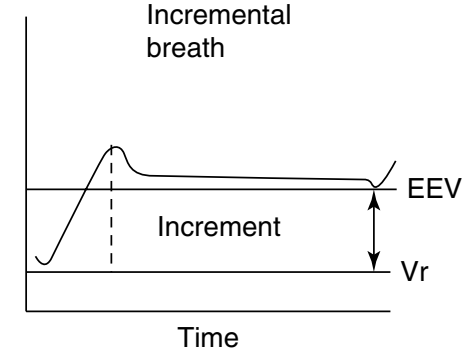

grunting breathing pattern (bottom left) maintains lung volume above the EEV for variable periods of expiration before the volume returns to the EEV. The incremental pattern of breathing (bottom right) maintains lung volume above the EEV throughout expiration and, using laryngeal and diaphragmatic activities, achieves a true increment in lung volume (Reproduced with permission from Hutchison and Bignall (2008))

(PEEP), their oxygenation worsened (Harrison et al. 1968). This finding established the role of airway PEEP and likely influenced the introduction of CPAP therapy. Harrison et al. also focused on venous return (Harrison et al. 1968), stressing the importance of cardiac function in grunting. The outline of the volume-time trace in grunting (Figs. 4.5 and 4.6) resembles that of a volume with a prolonged inspiratory time, as used in artificial ventilation to improve oxygenation. Pre-surfactant, this strategy reduced the required peak inspiratory pressure and decreased the incidence of bronchopulmonary dysplasia. Today, the maintenance of subglottic volume, the "open lung" approach, is a fundamental tenet of all ventilatory support. In keeping with the concept of alveolar interdependence, airway volume recruitment is achieved not by a maximal prolonged inflation but with an augmented breath (sigh) followed by an expiratory hold, mimicking the volume-time profile of grunting or of airway pressure release ventilation. Spontaneous sighs can be biphasic, with inspiration being grunting was prevented by endotracheal intubation, without positive end-expiratory pressure 
interrupted briefly by laryngeal closure. This mechanism may reset vagal afferent feedback, avoiding a Hering-Breuer inflation reflex and possible loss of the acquired volume (see Sect. 47.3.1). In summary, human and animal data emphasize the importance of laryngeal control of expiratory subglottic airway volume. This central control strategy whereby airway pressure is dependent upon volume control has been shown by the study of bubble physics to produce a more stable mechanical system (Hildebrandt 1974). Thus, coordinated central control of laryngeal and pump muscles is a major focus in the control of breathing. This knowledge can be applied in respiratory support (Hutchison and Bignall 2008).

\subsubsection{Laryngeal and Pump Muscle Breathing Patterns in the Fetus and Newborn}

Behavioral state is a major controlling factor of breathing pattern. In fetal lambs, during the highvoltage electrocorticogram (ECoG) state, apnea (no phasic laryngeal abductor or diaphragmatic activities) and tonic laryngeal adductor activity occur. Laryngeal adductor activity can be enhanced by laryngeal contact with cooled lung liquid, by fetal movements, by "arousals," by swallowing, by uterine contractures, and by fetal hypoxemia. In the low-voltage ECoG state, laryngeal and diaphragmatic activities are similar to those seen postnatally (Harding 1986). Hypercapnia mainly enhances fetal breathing in the low-voltage ECoG state (Harding 1986). In general, active laryngeal retardation of lung liquid egress is reported in the absence of fetal breathing movements and is related to lung growth (Harding 1986). Stimulation of the superior laryngeal nerve (SLN) produces laryngeal closure (Harding 1986) that will prevent aspiration of noxious material, e.g., meconium. The coordination of the acts of fetal swallowing (Harding 1986) and "inspiratory" activities of the respiratory muscles stresses the developmental importance of the controller's ability to switch patterns rapidly between upper airway closure (laryngeal adduction) with lack of diaphragmatic activity (apnea) and laryngeal abductor and pump activities (see Sect. 47.3.1).
Airway volume is high in the fetus compared to the newborn. It has been speculated that during different fetal behavioral states, the brain is setting the homeostatic limits for high and low airway volume to prepare the fetus for the major needs of subglottic volume control at birth (Hutchison 2007) (see also Sect. 47.3.1). Life's greatest airway volume challenge, the establishment and maintenance of an air-filled airway at birth, is usually overcome without a hitch by breathing patterns whose complexities exceed those used during the majority of adult life. At birth, an incremental breathing pattern retains more inspired volume than is expired (Fig. 4.6) (Hutchison et al. 1994). Incremental breathing shares features with grunting with the addition of timing changes in laryngeal and pump muscle activities at end-expiration when the onset of pump muscle activity occurs before laryngeal muscles open the glottis fully. The result is a decrease in expired volume and an increase in EEV (Hutchison et al. 1994). This incremental mechanical process is aided by the airway stability accrued from the increased end-expiratory positive subglottic pressure that limits the development of a negative airway pressure during inspiration. Given their tendency to chest wall distortion, it is not surprising that incremental breathing can occur in preterm neonates (Eichenwald et al. 1992). Incremental breathing is also seen in gasping during acute cerebral hypoxia-ischemia (Hutchison et al. 2002). Gasping is typified by brief laryngeal abductor and pump muscle activities followed by long periods of laryngeal adductor activity with apnea (Hutchison et al. 2002). Subglottic pressure is increased, maintaining airway volume and likely promoting autoresuscitation (Hutchison et al. 2002).

\subsubsection{Control of Coordinated Laryngeal and Pump Muscle Activities}

\subsubsection{Laryngeal Protective, Lower Airway and Chest Wall Afferents}

Nasal and laryngeal afferent inputs alter laryngeal abductor and adductor activities and thus glottic size. The laryngochemoreflex (LCR), whose afferent pathway is the SLN, results in 
protective responses, including swallowing, apnea, obstructed respiratory efforts, cough, hypertension, and arousal from sleep (Thach 2008). An obstructive apnea with bradycardia results if the LCR stimulus is persistent, especially in the immature or depressed brain. This LCR response alters with age - coughing becomes the major response. However, acquisition of a viral infection in infancy can rekindle its potency (Thach 2008). It is augmented by hypoxemia and anemia and has been implicated in apnea of prematurity and SIDS (Thach 2008) (see Sect. 47.3.1).

Other laryngeal SLN afferents, including those from mechanoreceptors, drive receptors, and temperature receptors, affect laryngeal intrinsic muscle activities. Although SLN section does not alter the eupneic breathing pattern, these afferents are important. Upper airway bypass can alter the inspiration-inhibition Hering-Breuer reflex. Application of acid to the larynx in animals, mimicking chronic aspiration, alters the subsequent response to an applied airway load (see Sect. 47.3.1). During noninvasive ventilation, nonsynchronous delivery of airflow to the upper airway in neural expiration results in laryngeal closure (Rodenstein 2004; Scharf et al. 1978). Thus, noninvasive ventilation and pacing of a paralyzed diaphragm should be applied synchronously with neural inspiration (Rodenstein 2004; Scharf et al. 1978).

In intact animals, compensatory glottic abduction follows single-breath total occlusion of inspiration or expiration at the mouth/nose. During the unimpeded expiration following a single inspiratory occlusive load, unopposed TA activity can produce laryngeal closure. Thus when no air enters the lung, a compensatory reflex mechanism can prevent expiratory volume loss, maintaining absolute subglottic volume. Lower airway afferent inputs affect glottic size (Bailey and Fregosi 2006). Stretch receptor discharges, induced by PEEP, decrease expiratory TA activity (Harding 1986). By contrast increased expiratory glottic adduction follows rapidly adapting receptor stimulation, e.g., with deflation or irritant stimulation secondary to a pneumothorax (Bartlett 1989), or follows C-fiber stimulation, e.g., with experimental pulmonary edema (Bartlett 1989). Direct and indirect stimulation of chest wall muscle afferents can invoke several flow patterns involving glottic closure (Bartlett 1989; Stecenko and Hutchison 1991).

While pseudoasthma can be fabricated by partial glottic closure (Rodenstein 2004), matching laryngeal control of flow pattern to maintain optimal subglottic airway volume may explain changes reported with true increased airway resistance. Subglottic inspiratory flow limitation in croup is associated with expiratory flow resistance, probably glottic in origin (Argent et al. 2008). Increased lower airway resistance in adult asthmatic patients induces a breathing pattern characterized by laryngeal expiratory flow retardation (Collett et al. 1983; Sekizawa et al. 1987). In adults, resistive loads applied at the mouth also decrease expiratory glottic size (Brancatisano et al. 1985). This change may occur immediately, suggesting that resistive loading, unlike total occlusive (elastic) loading, produces sudden flow changes that stimulate airway receptors to cause laryngeal adduction (Brancatisano et al. 1985). Therapy with CPAP reverses the expiratory laryngeal adduction in some asthmatic subjects, suggesting that airway pressure changes may alter the dynamics between stretch receptor and irritant receptor stimulations, thus changing the breathing pattern (Collett et al. 1983). In normal adults a voluntary deep breath can decrease laryngeal resistance and lower airway resistance (Sekizawa et al. 1987). By contrast, bronchoconstrictive stimulation in normal adults can result in inspiratory and expiratory glottic narrowing (Higenbottam 1980). An increased resistance to inspiratory flow may be advantageous in that more transpulmonary pressure is applied to opening a constricted peripheral airway. If lower airway volume and resistance changes affect laryngeal function, can absence of laryngeal control affect lower airway resistance? Laryngeal bypass during invasive ventilation is associated with atelectasis and with the development of increased lower airway resistance (Hutchison and Bignall 2008). The latter effect may stiffen the conducting airways and thus stabilize total airway volume but demand increased effort. In summary, the data reflect the importance of laryngeal subglottic volume control as a 
determinant of lower airway resistance and point to interactions between lower airway afferents and coordinated laryngeal and pump muscle activities in this dynamic process (see also Sect. 47.3.1).

\subsubsection{Central and Chemical Control}

Central control of coordinated laryngeal and diaphragmatic muscle activities is determined by developmental stage, behavioral states, metabolism (temperature), central inputs, and centrally acting chemicals. Postnatally in lambs, increased expiratory TA activity with decreased PCA activity occurs during the NREM state. By contrast, expiratory TA activity in REM is mainly absent, while PCA activity is variable (Harding 1986). In normal adult humans, expiratory TA activity is absent during stable NREM, while expiratory PCA activity decreases in NREM and is variable in REM (Kuna et al. 1988, 1990). At all ages, expiratory TA activity occurs at arousal. Thus behavioral state is a key factor in subglottic airway volume control that, in turn, is important in sleep apnea.

Increased central drive, with hyperventilation and/or hypercapnia, promotes laryngeal abduction in inspiration and expiration in adults and term newborns, in whom increased PCA, diaphragmatic and intercostal muscle activities occur (Bartlett 1989; Insalaco et al. 1990; Kuna et al. 1994; Wozniak et al. 1993). Laryngeal adduction can occur during hypercapnic hyperventilation in preterm neonates, probably due to chest wall distortion (but see also Sect. 47.3.1) (Eichenwald et al. 1993). This adduction also occurs in adults at the mechanical limits of airway volume (Brancatisano et al. 1983). In general, however, increased central drive decreases laryngeal resistance unless mechanical limitations are present.

Decreased central drive with hypocapnia diminishes expiratory glottic size and is associated with periodic breathing in adults (Kuna et al. 1993; Rodenstein 2004). Laryngeal closure has been noted in human newborns and infants with apnea or suspected apparent life-threatening events (Ruggins and Milner 1991, 1993). During central apnea and periodic breathing in lambs, expiratory TA activity is noted (Praud 1999). In depressed human infants at birth, laryngeal closure can block intubation, and, in lambs, acute cerebral hypoxia-ischemia results in expiratory TA activity with laryngeal closure (Hutchison et al. 2002). Centrally acting depressant drugs diminish central drive and, in lambs, produce laryngeal closure with apnea (Praud 1999). In former preterm infants, up to 55-60 postmenstrual weeks, exposure to anesthesia and/or operative stress can result in apnea postoperatively (see Sect. 47.3.1). Thus, the intensivist should avoid hypocapnia during noninvasive ventilation and be aware that central depression can result in apnea with glottic closure.

Hypoxia stimulates expiratory laryngeal abduction and increases ventilation in human adults and newborn lambs (England et al. 1982b; Insalaco et al. 1990; Praud et al. 1992). In lambs, the increase in ventilation is dependent upon carotid body input - a sudden decrease in that input induces expiratory TA activity (Praud et al. 1992). However, animal and human data indicate that the effects of carotid body input vary depending upon central state and the presence/absence of other inputs (de Burgh Daly et al. 1979). If animals are vagotomized and paralyzed, direct carotid body stimulation can induce expiratory TA activity, and exposure to hypoxia after airway vagal blockade or intrathoracic vagal section results in laryngeal adduction (Bailey and Fregosi 2006). In adult humans, the degree of expiratory glottic adduction with hypoxia exceeds that during hypercapnia (England et al. 1982b). Thus, it is argued that the "pure" carotid body reflex response is laryngeal expiratory adduction that will retain airway volume and promote oxygenation. This pure response can be countered by the presence of ventilation which increases airway stretch receptor feedback that results in an overall expiratory laryngeal abduction response. In the author's view, a unifying explanation for the diverse findings with hypoxia is that the effect of carotid body input is to augment the central coordinated output to laryngeal and pump muscles that is selected under different conditions (see Sect. 47.3.1). When central depression exists, protective inputs and/or absence of volume-related inputs produce an apneic response 
with glottic closure that is augmented by hypoxia. This can be seen in the "vagal" preterm infant who is sedated for a surgical procedure. At intubation laryngeal closure and apnea/bradycardia can be triggered. If hypoxemia ensues, the problems are aggravated. When tidal ventilation and airway volume feedback are restored, the impact of any ongoing hypoxemia is to augment breathing. Hering and Breuer found that their volumerelated reflexes were active even with hydrogen breathing. This fits the modern focus on ventilation for resuscitation from asphyxia.

\section{Conclusion}

This chapter of upper airway physiology for the pediatric intensivist has focused on motor and specifically on laryngeal aspects relevant to the control of breathing patterns. The major message is that upper airway physiology is involved in all aspects of "breathing": protection, volume homeostasis, and ventilation; its functional impact covers the entire airway, from the nose to the alveolus. Understanding upper airway physiology can guide and improve therapy, while therapy can aid a return to normal homeostasis or detract from it. Current knowledge of upper airway physiology has had major implications for the application of invasive and noninvasive ventilatory support. Much remains to be learned from the interactions between physics and biochemistry in the entire airway and how they affect breathing patterns.

\section{Essentials to Remember}

- The upper airway plays roles in all the extended functions of breathing, namely, in airway protection, in the control of supra- and subglottic volumes, and in tidal ventilation.
- Nasal functions include air conditioning and airway protection. Stimulation can result in profuse secretions, altered patency, and the cardiorespiratory dive reflex. Obstruction can affect gas exchange markedly; thus, a rapid switch to oral breathing is advantageous.

- Pharyngeal patency can be altered in sleep. Nonnutritive swallowing is vital to minimize aspiration. Therapy with CPAP improves pharyngeal patency in OSA but may alter pharyngeal clearing mechanisms and increase gastric air.

- Laryngeal closure can protect the airway rapidly. Laryngospasm can be hard to treat.

- Controlled expiratory laryngeal closure modifies airflow and subglottic airway volume in normal breathing, at the establishment of airway volume at birth or when airway volume is threatened by mechanical, chemical, or central changes.

- Intrinsically or extrinsically induced changes in central state alter the laryngeal motor outputs in response to mechanical or chemical inputs.

- Understanding how laryngeal motor functions affect breathing patterns, airway pressures, and gas exchange is at the core of many technical and procedural advances in the provision of resuscitative measures and of invasive and noninvasive respiratory support.

Acknowledgements The author thanks L. S. Segers, PhD; B. G. Lindsey, PhD; and B. M. Schnapf, DO, for critical review and J.D. Carver, $\mathrm{PhD}$ and M-F. Hutchison, MA for editorial input. 


\subsection{Mechanics of the Lung, Airways, and the Chest Wall}

\author{
Paul D. Robinson and J. Jane Pillow
}

\section{Educational Aim}

To describe the principal components of respiratory mechanics of the airways, lungs, and the chest wall and the developmental and environmental considerations that impact on these measurements in the neonatal and young child

\subsubsection{Background}

The mechanical properties of the respiratory system are a critical component of the chain of events that result in translation of the output of the respiratory rhythm generator to ventilation. A comprehensive understanding of respiratory mechanics is therefore essential to the delivery of optimized and individualized mechanical ventilation. This chapter describes the basic elements of respiratory mechanics and reviews the developmental changes in the airways, lungs, and chest wall that impact on measurement of respiratory mechanics with advancing postnatal age.

During spontaneous breathing, the forces driving inspiration are generated by the inspiratory muscles, whereas during mechanical ventilation, the forces are generated by the ventilator or by a combination of the ventilator with spontaneous inspiratory muscle contributions. The inspiratory muscle pressure needs to be sufficient to overcome three major mechanical properties of the respiratory system: elastance $(E)$ (to overcome tissue forces required to change the lung volume $(V)$ ), resistance $(R)$ (to overcome resistance to flow $\left(V^{\prime}\right)$ ), and inertance $(I)$ (for acceleration $\left(V^{\prime \prime}\right)$ of gas volumes). Elastance is often considered in terms of its inverse, the compliance $(C)$. The total pressure $\left(P_{\text {total }}\right)$ generated is equal to the sum of the elastic ( $P_{\mathrm{el}}$, proportional to volume and $1 /$ compliance), resistive ( $P_{\text {res }}$, proportional to flow and resistance), and inertive $\left(P_{\text {in }}\right.$, proportional to acceleration and inertance) components:

$$
\begin{aligned}
P_{\text {total }}= & P_{e l}+P_{r e s}+P_{i n}=(V \times 1 / C)+ \\
& \left(V^{\prime} \times R\right)+\left(V^{\prime \prime} \times I\right)
\end{aligned}
$$

Although pressure losses to inertia are considerable during high-frequency ventilation, the inertive component is normally a small portion of $P_{\text {total }}$ at normal breathing frequencies and can be effectively neglected. Thus the equation driving flow during normal respiration can be simplified:

$$
P_{\text {total }}=P_{e l}+P_{r e s}+P_{\text {in }}=(V \times 1 / C)+\left(V^{\prime} \times R\right)
$$

Nonetheless, the linearized relation of driving pressure to volume and flow does not fully characterize the pediatric respiratory system: Resistance and compliance are both dependent on volume, volume history, and flow, particularly in the very small or premature neonate. Further, the simplified equation does not fully incorporate the complexities of the respiratory system.

Almost all the tests used to measure respiratory mechanics in the infant and pediatric population have been developed in adults and then adapted for younger subjects. Measurements of respiratory mechanics are most appropriately corrected to lung volume, such as functional residual capacity (FRC). In the absence of a measure of FRC, measurements of respiratory mechanics made in infancy are often related to body size (e.g., height/length or weight). Measurements at the body surface are necessary to include the contributions of the chest wall. The chest wall contribution to respiratory mechanics can be isolated, by subtraction of the pleural measurements from those obtained at the body surface (e.g., airway opening).

\subsubsection{Passive Tests of Respiratory Mechanics}

The respiratory system is in a passive state when there is no inspiratory muscle activity $\left(P_{\text {mus }}=0\right)$. A passive condition is present in the paralyzed patient but can also occur without paralysis following hyperventilation (Mortola 2004). Under passive conditions, resting lung volume is determined by 
two opposing forces. The outward recoil of the chest wall results from the elastic characteristics of the diaphragm/abdomen and of the rib cage. The outward recoil of the chest wall directly opposes the inward recoil of the lung. Inward recoil is determined by the viscoelastic properties of the lung, including the mechanical properties of the lung tissues, and the collapsing pressure generated at the alveolar air-liquid interface.

During spontaneous breathing, the passive respiratory mechanics can be measured using occlusion techniques. Occlusion of the airways at lung volumes above the resting lung volume relaxes the respiratory muscles by stimulating the slowly adapting stretch receptors and the vagally mediated Hering-Breuer inflation reflex. Passive tests assess the mechanical properties of the entire respiratory system. Simultaneous measurement of transpulmonary pressure allows measurement of respiratory system compliance $\left(C_{\mathrm{rs}}\right)$ to be partitioned into lung $\left(C_{\mathrm{L}}\right)$ and chest wall $\left(C_{\mathrm{w}}\right)$ components. Transpulmonary pressure $\left(P_{\mathrm{tp}}\right)$ is derived from the difference in pressure at the airway opening $\left(P_{\mathrm{ao}}\right)$ and pleural pressure (or elastic recoil pressure, $\left.P_{\mathrm{el}}\right)$, measured using an esophageal balloon, liquid-filled catheter, or miniature pressure transducer.

$$
P_{a o}=P_{t p}+P_{e l}
$$

Other passive measurements of respiratory mechanics include forced expiratory maneuvers to provide measures of maximal flow at FRC ( $V_{\text {max,FRC }}^{\prime}$ ) (Lum et al. 2006a). Partial forced expiratory flow-volume curves in infants are obtained by rapid compression of the chest through endinspiratory inflation of a jacket placed around the chest and abdomen. During tidal breathing, this rapid thoracoabdominal compression (RTC) technique provides a $V^{\prime}{ }_{\text {max,FRC }}$ that is similar to forced flows at low lung volumes (e.g., maximal expiratory flow $\mathrm{MEF}_{25} \%$,FRC). Modification of the RTC technique by raising lung volume of the infant towards total lung capacity (so-called raised volume RTC or RVRTC) allows assessment of forced expiratory flows over a more extended range of volumes. Reported measures include forced vital capacity (FVC) and forced expiratory volumes after defined time periods (e.g., 0.4, 0.5, or $1 \mathrm{~s}$, termed $\mathrm{FEV}_{0.4}, \mathrm{FEV}_{0.5}$, and $\mathrm{FEV}_{1}$, respectively) and the ratio of these values e.g., $\left(\mathrm{FEV}_{\mathrm{t}} / \mathrm{FVC}\right.$, where $t$ is the time period chosen).

\subsubsection{Dynamic Tests of Respiratory Mechanics}

In contrast, dynamic tests of respiratory mechanics allow the relative contributions of the airways and lung tissues to be partitioned, in addition to separately identifying the chest wall contribution to airway and tissue mechanical properties. Dynamic mechanics derive mechanical variables from analysis of dynamic waveforms obtained either during normal (tidal) breathing or via imposed oscillatory waveforms. During tidal breathing, multilinear regression is used to determine dynamic respiratory system compliance $\left(C_{\mathrm{dyn}, \mathrm{rs}}\right)$ and resistance $\left(R_{\mathrm{rs}}\right)$. Kano and colleagues showed that consideration of volume dependence is important when using this approach to assess dynamic mechanics during mechanical ventilation. Consideration of volume dependence is important because ventilatory settings may "push" the pressure-volume curve onto the flattened upper portion of the curve (Kano et al. 1994). In the overdistended lung, fits obtained by multilinear regression are improved by the inclusion of a volume-dependent elastance term in the regression model:

$$
P_{a o}=\left(E_{1}+E_{2} V\right) V+R_{r s} V^{\prime}+P_{\mathrm{A}, E E}
$$

where $P_{\text {ao }}$ is the airway opening pressure, $V$ is the tidal volume, $E_{1}+E_{2} V$ is the total elastance over the cycle ( $E_{1}$ and $E_{2} V$ representing the volumeindependent and volume-dependent portions of elastance, respectively), and the final term $P_{\mathrm{A}, \mathrm{EE}}$ represents the alveolar pressure at end-expiration.

An important consideration during the interpretation of dynamic respiratory mechanics is the concept of frequency dependence. Kano showed that increasing the ventilation rate from 30 to 80 breaths/min in a group of near-term newborn infants increased $E_{\mathrm{rs}}$ and $R_{\mathrm{rs}}$ by a mean of 8.3 and $17.5 \%$, respectively (Kano et al. 1994). Frequency dependence and the mechanical properties of the respiratory system under normal tidal breathing conditions are also determined using forced oscillatory techniques (FOT). These techniques are 
essentially noninvasive and are especially useful in infants and children as no active subject cooperation is required. The technique involves application of a pressure waveform (forcing function) to the airway opening and measurement of the resultant flow. The measured impedance reflects the complex viscoelastic resistance of the respiratory system $\left(Z_{\mathrm{rs}}\right)$. Simultaneous measurement of the transpulmonary pressure and hence chest wall impedance $\left(Z_{\mathrm{w}}\right)$ allows determination of the lung impedance $\left(Z_{\mathrm{L}}\right)$ by subtraction. The impedance $(Z)$ can be separated into the resistance $\left(R_{\mathrm{rs}}\right)$, the impedance component in phase with flow, and reactance $\left(X_{\mathrm{rs}}\right)$, representing the impedance components in phase with volume (elastance) and acceleration (inertance).

The low-frequency forced oscillation technique (LFOT) measures impedance over a range of frequencies (usually $\sim 0.5-20 \mathrm{~Hz}$ ). LFOT is obtained in infants by invoking the Hering-Breuer inflation reflex to inhibit temporarily any respiratory muscle activity, during which brief time (6-10 s) the LFOT signal is applied. Fitting the constant-phase model to the resultant pressure and flow data permits partitioning of respiratory mechanics into frequency-independent airway resistance $\left(R_{\mathrm{aw}}\right)$ and airway inertance $\left(I_{\text {aw }}\right)$ and a constant-phase tissue component. This constant-phase tissue component is described by $[(G-j H) / \omega \alpha$, where $G$ and $H$ are coefficients for tissue damping and elastance, respectively, $\omega$ is angular frequency, and $\alpha$ determines the frequency dependence of the real (pressure change in phase with flow) and imaginary (pressure change in phase with volume) parts of the impedance] (Hantos et al. 1992a).

The interrupter technique provides a further option to assess partitioned mechanics. The interrupter technique involves measurement of changes in airway opening pressure after a midexpiratory occlusion, which is used to calculate airway resistance $\left(R_{\mathrm{aw}}\right)$. After airway occlusion at mid-expiration, there is a biphasic change in $P_{\text {ao }}$ : the immediate rapid rise in $P_{\text {ao }}$ represents the resistive pressure drop across the conducting airways and is followed by a secondary slower increase in $P_{\text {ao }}$ (often referred to as $P_{\text {dif }}$ ) generally attributed to stress recovery in the respiratory tissues (lung and chest wall) and gas redistribution associated with ventilation inhomogeneity (Bates et al. 1988). A major limitation of this technique is that it requires mechanical ventilation and paralysis to obtain reliable data.

\subsubsection{Developmental Considerations}

Particular challenges for lung function testing in infants and children include the marked developmental changes occurring over the first months and years of life. Additional considerations include position, sleep state and sedation, and feasibility of individual tests given minimal capacity of these age groups for active cooperation and preferential nasal breathing (Stocks and Hislop 1996). Thus, in contrast to the adult and older child, tests in infants are performed using a mask instead of a mouthpiece and nose clips.

\subsubsection{Airway and Lung Development}

Lung development represents a period of considerable change in both lung architecture and volume and is affected by several factors including genetic, in utero and postnatal environmental exposures, somatic growth, puberty, changes in muscularity, and ongoing alveolarization. Our understanding of the interactions between these factors is based on a mix of pathological and physiological data, which are predominantly cross-sectional in nature. Consensus between these studies is lacking. While some of the lack of agreement is attributable to technical approaches used by different authors, a comprehensive understanding of factors influencing respiratory mechanics over time can only be answered by strong longitudinal data, which are urgently required. These tests of lung mechanics provide us with essential insight into how tissue properties change with development, and a full understanding of the changes that occur during healthy development is an important step to detect the subsequent effects of disease and response of the individual to therapeutic interventions. Measurements need to be accompanied by accurate records of height (length) and weight to facilitate interpretation of longitudinal data. 


\subsection{Dysanapsis}

Over the course of development, there is considerable remodelling of all of the structural components of the respiratory system, although the exact patterns of change in airways, alveoli, and blood vessels may differ with respect to each other. The term "dysanaptic growth" was originally introduced by Green et al. (1974) and describes the disproportionate but physiologically normal growth of the lung relative to the airways. In infancy, airway size relative to lung volume is larger than in older children and adults. There is considerable debate in the pediatric literature about the degree, extent, and stage of development to which biological variability of airway size to lung volume occurs. The data outlined in this chapter suggest that dysanapsis is a feature of all stages of postnatal lung development.

Whether disproportionate growth along the length of the airway tree occurs is less clear. Increased growth of the larger central airways, in relation to peripheral generations, has been described through the first year of life, after which point adult relative proportions are achieved and maintained through further growth (Horsfield et al. 1987). Disproportionate central and peripheral airway growth, however, is not a consistent finding in the literature (Hislop et al. 1972). The most rapid period of tracheal growth appears to occur during the first 4 years of life (Wailoo and Emery 1982). An elevated ratio of peripheral airway resistance to central airway resistance (and its contribution to total airway resistance) in young children compared to adults was originally proposed by Hogg et al. (1970), based on retrograde catheter measurements. The authors described relatively little change in the contribution of the central airways (those proximal to the 12th-15th airway generations) to conductance with age but marked increase in peripheral airway conductance from the age of 5 years of age. These changes were attributed to altered linear dimensions of the peripheral airways, based on morphometric data. The ratio of central to peripheral resistance can also be examined noninvasively by comparing measured forced expiratory flows (FEF) breathing air to FEF measured breathing a less-dense gas mixture of $80 \%$ helium $/ 20 \%$ oxygen (heliox). FEF measured breathing heliox is typically higher than during air breathing (e.g., 1.2-1.6 times at $50 \%$ FVC). In older subjects with peripheral airway disease, this pattern is lost with ratios approaching parity (Cooper et al. 1983; Dosman et al. 1975). Density dependence data during infancy, in comparison to values reported in later life, appear to challenge the findings of Hogg et al. (1970). Davis et al. examined the changes in density dependence through the first 2 years of life (Davis et al. 1999). FEF 30-40 \% higher were measured with heliox: although no relationship existed between density dependence and age, length, or FVC in the first 2 years of life (in keeping with Hogg et al. (1970)), the values obtained were similar to those reported across 16 other studies in older children ranging from school age to adulthood (summarized in Table 2 of the original manuscript (Davis et al. 1999)). These equivalent cross-sectional density dependence values suggest that there is no difference in the convective accelerative and turbulent pressure loss with age, supporting the notion that the ratio of resistance of the peripheral to the central airways is similar in infants, older children, and adults.

\subsubsection{Sex Differences in Respiratory Mechanics}

Sex-specific differences in respiratory mechanics are well recognized in infants and young children and are a particularly important consideration in forced expiratory maneuvers in infants. Airways are larger in females before puberty, and this difference is detectable from infancy (Tepper et al. 1986a; Hoo et al. 2002a): $V_{\text {max,FRC }}^{\prime}$ is approximately $20 \%$ higher in girls over the first 9 months of life (Hoo et al. 2002a). Similar sex-dependent increases in $V^{\prime}{ }_{\text {max,FRC }}$ are evident in preterm girls compared to preterm boys, suggesting such differences in lung function may be developmental rather than environmental in origin (Stocks et al. 1997). Larger lungs have been reported in males between the ages of 6 weeks and 14 years (Thurlbeck 1982). Presence and timing of the growth spurt is an important confounding factor, with lung growth occurring out of phase to somatic growth, especially in boys (Degroodt et al. 1986; 


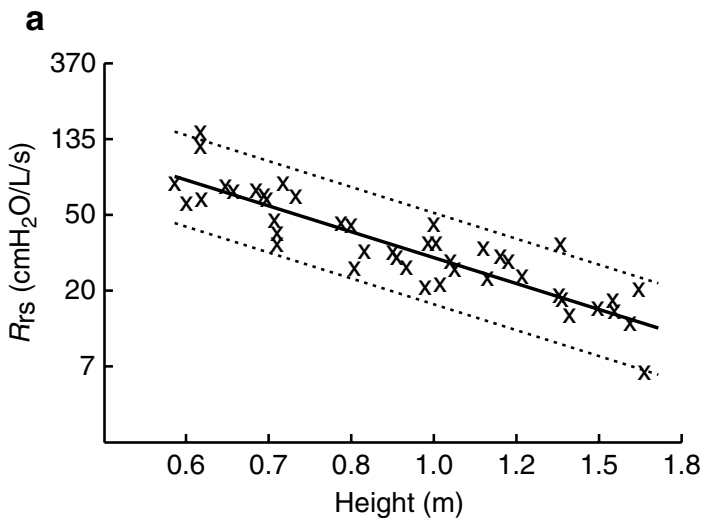

Fig. 4.7 Decreasing resistance of the respiratory system $\left(R_{\mathrm{rs}}\right)$ and airway resistance $\left(R_{\mathrm{aw}}\right)$ with increasing height. Cross-sectional data taken from 51 subjects (aged 3 weeks

Quanjer et al. 1989; Schrader et al. 1984). Lung development in females is almost complete following menarche but continues throughout puberty in males (Neve et al. 2002).

\subsubsection{Periconceptional and Intrauterine Exposures}

There is increasing evidence that the periconceptional and intrauterine exposures impact on development of the respiratory system and consequently impact on respiratory mechanics in infancy and childhood. Factors known to influence lung mechanics after birth include maternal smoking, nutritional deprivation and intrauterine growth restriction, infection and/or inflammation, and maternal glucocorticoids. Prenatal exposure to nicotine may cause abnormal airway branching and dimensions as well as increase airway smooth muscle and collagen deposition resulting in reduced lung function at birth that persists into early adulthood regardless of postnatal exposure (Hayatbakhsh et al. 2009; Svanes et al. 2004). Lung function irregularities include airflow limitation, reduced $\mathrm{FEV}_{1}$, and airway hyperreactivity (Sandberg et al. 2011; Wongtrakool et al. 2012). Chronic restriction of nutrients and/or oxygen in late pregnancy impairs development of the fetal small airways and lungs, including reduced numbers of alveoli that are also enlarged with increased septal wall thickness and basement membranes compared to nonexposed infants

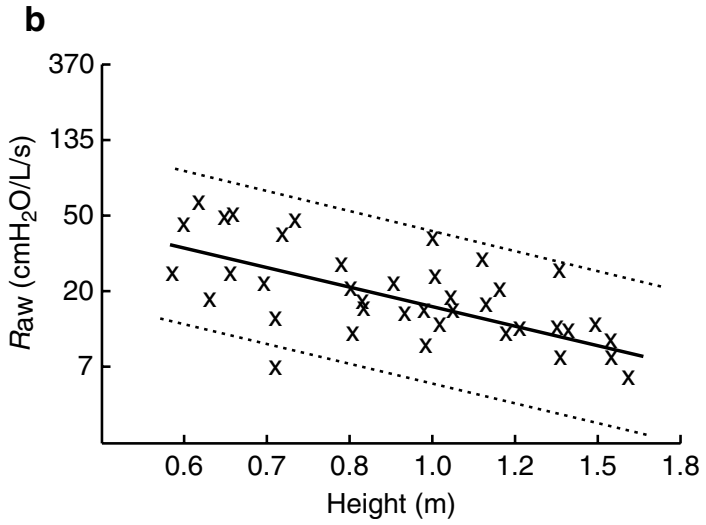

to 15 years) (Lanteri and Sly 1993). Both resistance and height are plotted as natural log values but are labeled with absolute numbers for clarity

(Pike et al. 2012). Such differences in alveolar number can influence the subsequent rate of disease progression, including an accelerated rate of decline in $\mathrm{FEV}_{1}$ with advancing age (Stocks and Sonnappa 2013).

\subsubsection{Mechanical Properties of the Airways, Lung, and Chest Wall in Infancy and Childhood}

\subsubsection{The Airways}

Several cross-sectional studies have looked at the changes in airway resistance (reflecting airway size) during childhood. Hall and colleagues using LFOT described a quasilinear decrease in $R_{\text {aw }}$ with increasing length during infancy in 37 infants, including some with repeat measurements (Hall et al. 2000). Lanteri and Sly examined changes across the pediatric age range and also reported linear decreases in both $R_{\mathrm{rs}}$ and $R_{\mathrm{aw}}$ with increasing height (when plotted on a loglog plot) in 51 children (range 3 weeks-15 years) with healthy lungs (Fig. 4.7) (Lanteri and Sly 1993). Pooled data across the preschool age range reinforces the consistent relationship seen with increasing height (Beydon et al. 2007a). In a study of 40 subjects, across the first 5 years of life, Gerhardt et al. demonstrated an increase in lung conductance (the reciprocal of resistance), of approximately fivefold over the weight range 
Fig. 4.8 Rapid increase in lung compliance (a) and rapid decrease in specific conductance (b), with increase in body length, based on cross-sectional data in 40 subjects in the first 5 years of life (Gerhardt et al. 1987a). The regression line (solid) and $95 \%$ confidence interval (dotted lines) are shown (Reproduced with permission from the publisher)

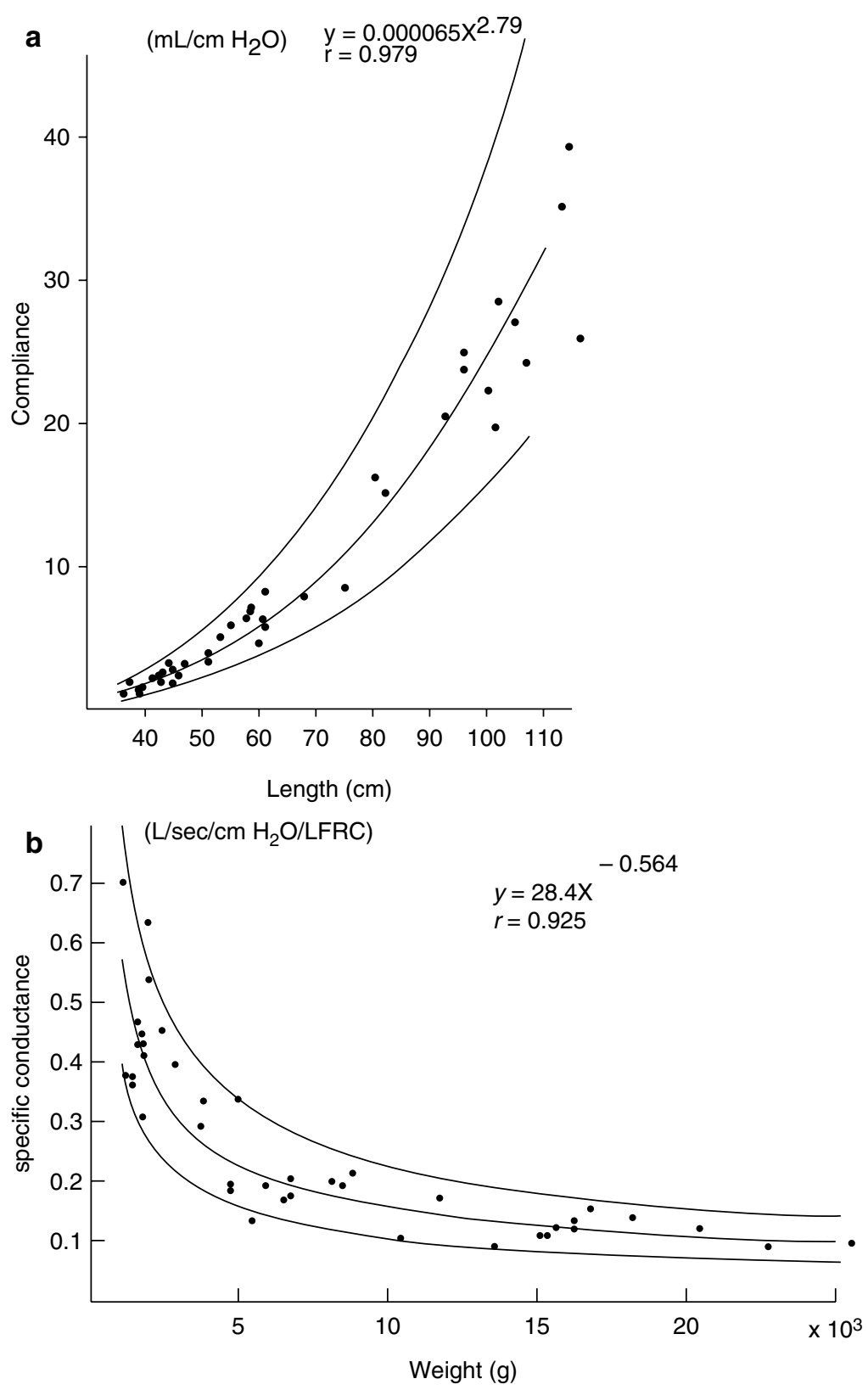

examined (Gerhardt et al. 1987a). This increase occurred at a slower rate than the increase in FRC, which led to a rapid drop in specific conductance (Fig. 4.8b). This rapid decrease in specific airway resistance or conductance through early life has been described previously (Doershuk et al. 1974; Stocks and Godfrey 1977). Tepper et al. measured maximal FEF at FRC, from partial expiratory flow-volume curves and corrected for changes in lung volume: they reported higher flows in the neonatal range which decreased to a steady value through the 2nd year of life, similar to those reported elsewhere in older children (Tepper et al. 1986a). Differential increases in anatomic dead space volume (twofold), compared to FRC (threefold), have also been shown in the pediatric population (Wood et al. 1971). 


\subsubsection{The Lungs}

Rapid postnatal increases in lung volume are reported widely. FRC increases by a magnitude of 40 times (from $80 \mathrm{~mL}$ in infants to $3,000 \mathrm{~mL}$ in adults) (Dunnill 1982) and over ten times in total lung weight (Polgar and Weng 1979). The rapid growth of the distal lung, in comparison to relatively steady changes in airway dimensions, is a major feature of respiratory system development beyond birth. After the appearance of primitive saccules at approximately 28 weeks gestation, mature alveoli with secondary septa appear from 34 weeks gestation onwards. Alveolar multiplication was initially thought to cease at around 2 years of age (Thurlbeck 1982). More recent estimates indicate that increase in alveolar number continues until at least 8 years (Dunnill 1982). Recent advanced imaging studies using hyperpolarized helium magnetic resonance imaging (MRI) provide evidence of ongoing alveolar multiplication in adolescence (Narayanan et al. 2012). Increase in alveolar size (expansion) is also evident during infancy and childhood, with recent epidemiology studies suggesting lung size increases into early adulthood, when chest wall development is complete (Quanjer et al. 1989; Reid 1977).

Based on cross-sectional studies, specific lung compliance falls during early infancy before remaining relatively constant from the early preschool years. Tepper et al., based on measurements of compliance from the linear portion of the static pressure-volume $(P V)$ curve in almost 50 infants, described an increase in lung compliance over the age range studied, but decreasing specific lung compliance with increasing body length in the first 2 years of life (Tepper et al. 2001). Gerhardt et al. examined similar changes in 40 infants and children over the first 5 years of life. Lung compliance increased markedly (by 20-25-fold) over the weight range examined (Fig. 4.8a) but in proportion to FRC, resulting in a constant-specific compliance over the first 5 years of life. The same pattern of findings was reported in 63 children aged 2-7 years (Greenough et al. 1986). This initial rapid period of alveolar growth is also supported by evidence from measurements using the interrupter technique and FOT. Lanteri and Sly showed a biphasic change in $P_{\text {dif }}$ with age: $P_{\text {dif }}$ was highest in young infants, falling rapidly over the first 12 months, before increasing again after approximately 5 years of age (Lanteri and Sly 1993). Hall and colleagues, using LFOT measures of tissue mechanics derived by fitting data to the constant-phase model, showed that both tissue parameters $G$ and $H$ decreased in a quasihyperbolic manner with increasing length between 7 weeks and 2 years of age (Hall et al. 2000). The difference in the pattern of change in $G$ and $H$ compared to the change in $R_{\text {aw }}$ with increasing length is further evidence of dysanapsis: tissue mechanical properties change more rapidly than airway mechanics over the first 2 years of life (Fig. 4.9).

\subsubsection{The Chest Wall and Respiratory Musculature}

The chest wall of the neonate and infant, and to a lesser extent the growing child, is especially compliant compared to the compliance of the chest wall in the adult subject. A highly compliant chest wall in infancy results in less opposition to the tendency of the lung to collapse, promoting a low residual lung volume and also distortion of the chest wall, resulting in a loss of volume during inspiration. The disproportionately high compliance of the chest wall compared to the compliances of the lung means that the compliance of the respiratory system $\left(C_{\mathrm{rs}}\right)$ is approximately equal to the compliance of the lung $\left(C_{\mathrm{L}}\right)$ during childhood, especially in neonates and infancy (Davis et al. 1988; Gerhardt et al. 1987a). Several active (dynamic) mechanisms of respiratory mechanics serve to partially compensate for the instability in FRC associated with a compliant chest wall and tendency for small airway closure during tidal breathing. Infants acutely increase their end-expiratory lung volume (EELV) and maintain it above resting lung volume by modulating (abbreviating) their expiratory time (Mortola and Saetta 1987) (Fig. 4.10a). In addition, they reduce expiratory flow through post-inspiratory activity of the diaphragm and inspiratory chest wall muscles (Kosch and Stark 1984) (Fig. 4.10b) (Lopes et al. 1981), stiffening the chest wall and by increasing laryngeal resistance ( \pm glottic closure) briefly (Kosch et al. 1988). Such dynamic modifications of respiratory mechanics occur via neural (vagal) 

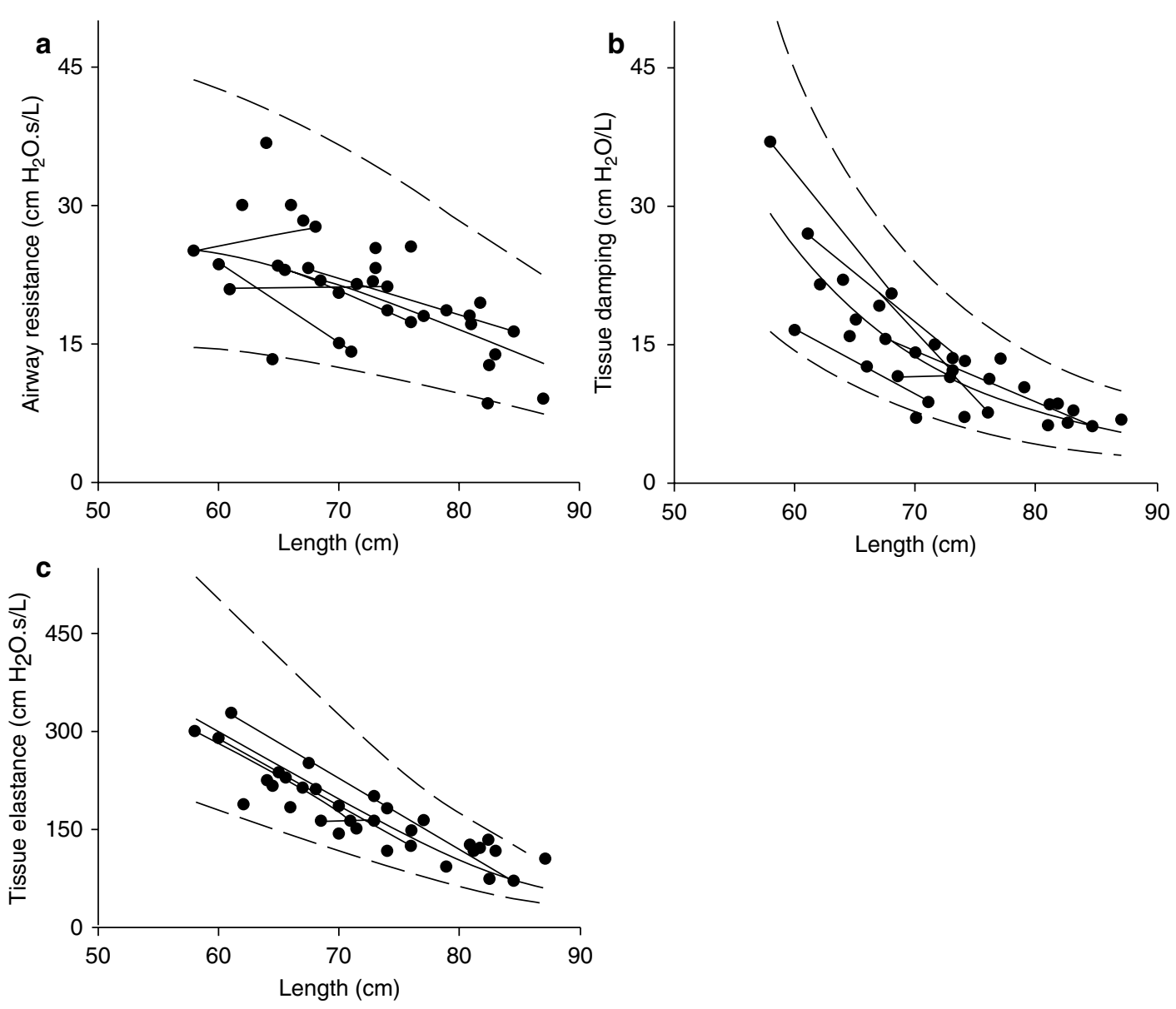

Fig. 4.9 Low-frequency FOT data plotted against length in 37 infants: airway resistance (raw, a), tissue damping (b), and tissue elastance (c). The greater rate of change suggested in tissue $(\mathbf{b}, \mathbf{c})$ compared to airway properties

receptor-mediated reflexes. Restriction of lung function measurement to periods of quiet sleep is necessary to reduce the variability in measurements resulting from such dynamic processes (Henschen and Stocks 1999).

The changes in chest wall, lung, and respiratory system mechanics over the first 4 years of life were examined by Papastamelos et al., in 40 subjects (Papastamelos et al. 1995). The authors used a modified Mead-Whittenberger technique (Cook et al. 1957): manual ventilation overrode respiratory drive and relaxed the respiratory muscles, avoiding the need for intubation or induction of a Hering-Breuer reflex. In this cohort, the ratio of chest wall to lung compliance fell from a mean (SD) of $2.9(1.1)$ to $1.3(0.4)(p<0.005)$. Chest (a) illustrates dysanaptic lung growth (Hall et al. 2000). Reprinted with permission of the American Thoracic Society (copyright @ 2014 American Thoracic Society)

wall to lung compliance ratios are even higher in preterm infants (Gerhardt and Bancalari 1980). The stiffening of the chest wall, due to rapid rib ossification, increasing musculature, and altered chest wall configuration (Bryan and Wohl 1986; Mead 1979; Openshaw et al. 1984; Leiter et al. 1986), is such that near-adult values, where lung and chest wall compliance are equal (Mittman et al. 1965), are reached after the first year of life.

Stiffening of the chest wall over the first year of life allows the infant to shift its maintenance of FRC from dynamic elevation of EELV to a more passive mechanism achieved by the balance of outward recoil of the chest wall and inward recoil of the lung (Colin et al. 1989). Stiffening of the chest wall likely also explains the increase 


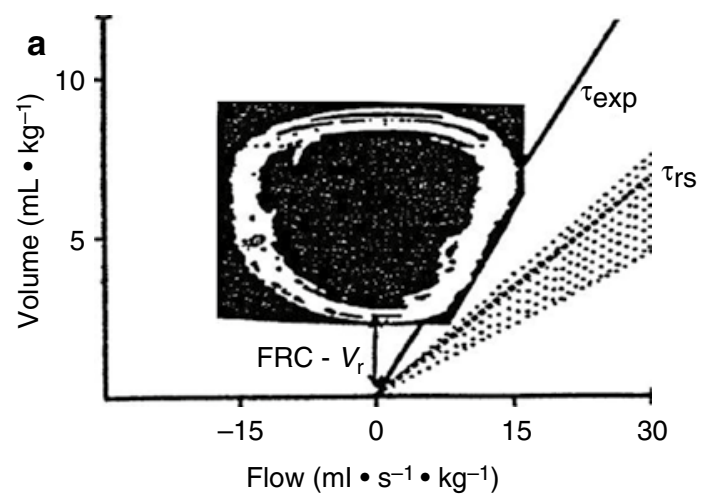

Fig.4.10 Employment of active (dynamic) mechanisms to elevate end-expiratory lung volume (EELV) in infants. In (a), active prolongation of the respiratory system time constant $(\tau)$ is shown. The expiratory time constant $\left(\boldsymbol{\tau}_{\exp }\right)$ is shown as the slope of the measured expiratory limb of the tidal flow-volume curve (solid line). This is compared to the passive expiratory time constant (slope of the dotted line) measured after an end-inspiratory occlusion. The difference between the two slopes is generated due to active use of the respiratory muscles during expiration ("braking"). The mag-

in $P_{\text {dif }}$ in children after age of 5 years observed by Lanteri and Sly (Lanteri and Sly 1993). FRC as a proportion of total lung capacity (TLC) increases with age through childhood, in the majority (Engstrom et al. 1956; Mansell et al. 1977; Weng and Levison 1969), but not all (Schrader et al. 1988), studies to date. Residual volume (RV), as a proportion of TLC, also increases with age through childhood (Merkus et al. 1993), while closing capacity (measured using single-breath nitrogen washout) decreases significantly with age, as a proportion of TLC, converging towards RV (Mansell et al. 1977). This increased RV/ TLC ratio suggests that increased stiffness of the chest wall is not entirely compensated for by increase in expiratory muscle force over time (Schrader et al. 1988). The study by Merkus et al. also highlighted the need to use TLC as a measure of lung growth and not FVC, due to the fact that an increasing RV/TLC with age led to errors in maximal expired flows due to measurement at progressively higher lung volumes (Merkus et al. 1993).

\subsubsection{Summary}

The postnatal period is characterized by ongoing rapid lung development, with differing rates of

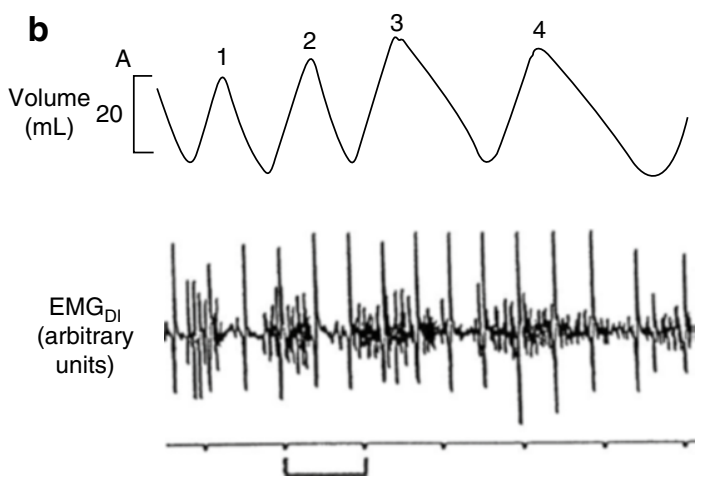

nitude of difference between the active flow-volume curvederived EELV (FRC) and the passive relaxation volume $\left(V_{\mathrm{r}}\right)$ reflects the degree of active (dynamic) mechanisms employed to elevate EELV. This active use of respiratory muscles is also illustrated in (b) from data collected in a separate infant study wherein diaphragm EMG activity of breaths three and four extends into expiration (Both figures reproduced with permission from the publishers (Mortola and Saetta 1987; Kosch and Stark 1984))

growth seen in the airway, lung parenchyma, and chest wall. The dysanapsis that occurs between the components of the respiratory system has important consequences for measurements of lung mechanics performed during infancy and childhood. Accounting for these developmental changes and dysanapsis is necessary to optimize disease detection and subsequent assessment of an individual's response to interventions. Insights into these changes are largely derived from crosssectional studies, which have identified important sources of potential error in existing methodol-

\section{Essentials to Remember}

- The postnatal period is characterized by ongoing rapid lung development in all parts of the respiratory system (airways, lung parenchyma, and chest wall). The physiologically normal rate of change of the lung relative to the airways is disproportionate. This dysanaptic growth pattern appears to be a feature of all stages of postnatal lung development. 
- Passive measures of lung mechanics provide information about the mechanics of the entire respiratory system.

- Dynamic measures of lung mechanics allow partitioning of the lung and chest wall components to separately identify the chest wall contribution to airway and tissue mechanical properties.

- Standardization of the measurement technique is essential. Results generated are corrected for either lung volume (e.g., FRC) or, in the absence of this, a measure of growth (e.g., weight).

- A number of periconceptional, intrauterine, and postnatal factors impact on the development and mechanics of the respiratory system. Important postnatal factors include maternal smoking, nutritional deprivation and intrauterine growth restriction, infection and/or inflammation, and maternal glucocorticoids.

- The rate of airway growth (detected by increases in conductance or decreases in resistance) is not as rapid as the rate of FRC increase with age. This greater relative increase in lung volume leads to a rapid decrease in specific resistance during early childhood.

- Postnatal alveolarization appears to now extend into adolescence. Rapid alveolar growth occurs during infancy leading to an initial fall in specific lung compliance, which reaches a plateau during ongoing lung growth. These changes are also evidenced by the changes seen in LFOT tissue parameters and interrupter technique-derived $P_{\text {dif }}$.

- The highly compliant chest wall of the infant leads to employment of active (dynamic) measures to maintain EELV above FRC. As the ratio of chest wall to lung compliance falls and reaches the adult values of parity beyond infancy, these gradually transition to more passive mechanisms as the chest wall stiffens through early childhood. ogy. Strong longitudinal data are now urgently required to confirm these apparent patterns and answer the important questions that remain.

\subsection{Respiratory Mechanics in Neonatal Pathologies}

\section{J. Jane Pillow}

\section{Educational Aims}

- To describe flow $(F)$, lung volumes $(V)$, and respiratory pressure $(P)$ measurements together with resistance $(R)$ and compliance $(C)$ measurements in neonatal respiratory diseases

\subsubsection{Acute Neonatal Lung Disease}

The predominant neonatal acute respiratory diseases include transient tachypnea of the newborn (TTN), respiratory distress syndrome (RDS) due to surfactant deficiency and/or structural immaturity, pulmonary interstitial emphysema (PIE), meconium aspiration syndrome (MAS), persistent pulmonary hypertension of the newborn, pneumonia, and congenital diaphragmatic hernia $(\mathrm{CDH})$. As there are no reported measurements of lung mechanics or lung function for infants with PIE and pneumonia, they are not discussed further.

\subsubsection{Transient Tachypnea of the Newborn}

Transient tachypnea of the newborn (TTN) is characterized by delayed resorption of fetal lung fluid within the distal airspaces. The mechanical consequences of TTN include reduced lung volume (functional residual capacity, FRC) and consequently also decreased lung compliance (increased elastance), tidal volume, and respiratory rate (Benito Zaballos et al. 1989). Although increased interstitial fluid might be expected to increase lung tissue resistance, there are no reported studies of tissue resistance in infants with TTN. 


\subsubsection{Respiratory Distress Syndrome}

Like TTN, RDS is predominantly a disease of the distal lung parenchyma. Surfactant deficiency promotes atelectasis, typically characterized by low lung volumes and reduced lung compliance. Lung function is also reflective of the degree of structural maturation, as surfactant deficiency is predominantly a disease of the premature infant.

In the intubated infant, lung resistance measures are highly variable and not reproducible $(22-32 \%$, ICC $<0.75)$, in contrast with less variable and more reproducible measurements of lung compliance (obtained from esophageal manometry). Hence, the clinical relevance of dynamic mechanics measurements of resistance in intubated newborn infants with respiratory distress is questionable (Gappa et al. 2006a).

Measurements of impedance, obtained using forced oscillatory mechanics (a quasistatic lung mechanics measurement), may provide a more reliable assessment of lung mechanics. Dorkin measured respiratory impedance in six paralyzed and intubated infants, three of whom also had pulmonary interstitial emphysema (Dorkin et al. 1983). The tracheal tube contributed to almost all the inertance and approximately $50 \%$ of the respiratory system resistance in the intubated infant. After subtraction of the impedance of the endotracheal tube, resistance ranged from 22 to $34 \mathrm{~cm} \mathrm{H}_{2} \mathrm{O} / \mathrm{L} / \mathrm{s}$, compliance from 0.22 to $0.68 \mathrm{~mL} /$ $\mathrm{cm}_{2} \mathrm{O}$, and inertance from 0.0056 to $0.047 \mathrm{~cm}$ $\mathrm{H}_{2} \mathrm{O} / \mathrm{L} / \mathrm{s}$ (Gappa et al. 2006a; Dorkin et al. 1983).

The low-frequency forced oscillation technique (LFOT) evaluates impedance simultaneously across a range of frequencies (usually $\sim 0.5-14 \mathrm{~Hz}$ ). Fitting of the resultant impedance data to the constant-phase model permits estimation of partitioned mechanical variables of the airways and the parenchymal tissues (Hantos et al. 1992b). Using the LFOT, impedance measurements in naïve (surfactant-deficient) newborn preterm lambs showed that respiratory system resistance $\left(R_{\mathrm{rs}}\right)$ and reactance $\left(X_{\mathrm{rs}}\right)$ are markedly frequency dependent (Pillow et al. 2001a). Respiratory system resistance in the preterm infant is also dominated by the resistive properties of the tissues, contrasting sharply with the predominant airway contribution to respiratory system resistance in later life (Pillow et al. 2005). Although compliance is also low (increased elastance), the tissue resistance is disproportionately greater, resulting in mechanical uncoupling of the parenchyma and increased hysteresivity (ratio of tissue resistance to tissue elastance) (Pillow et al. 2001a, 2005). Increased surfactant pool size (Pillow et al. 2004a) and lung volume recruitment (Pillow et al. 2004b) both enhance mechanical coupling of the tissues, evident as a lowering of the hysteresivity ratio in the lung. Increased contribution of the tissues to respiratory system mechanics, and the associated increased frequency dependence, results in elevation of the resonance frequency of the lung (Pillow et al. 2001a). Frequency dependence also becomes less marked with increasing postnatal age (Fig. 4.11) (Pillow et al. 2005).

Variability in measurements of lung mechanics in newborn infants in part reflects lung maturation associated with advancing gestation: lung compliance increases $0.17 \mathrm{~mL} / \mathrm{cm} \mathrm{H}_{2} \mathrm{O}$ /week, to reach mean (SD) values of $2.50(0.07) \mathrm{mL} / \mathrm{cm}$ $\mathrm{H}_{2} \mathrm{O}$ at term equivalent (Bhutani et al. 2005). Other factors include in utero fetal exposures such as placental nutrition, inflammation, antenatal steroids, and postnatal treatments including caffeine, glucocorticoids, surfactant, and ventilation modality. Early treatment with caffeine in surfactant-treated immature baboons increased $C_{\mathrm{rs}}$ over the first day of life and increased ventilatory efficiency index (Yoder et al. 2005).

The initial benefit of antenatal steroids on improved lung compliance at birth fades beyond 1 week after initial exposure (McEvoy et al. 2008). There is no evidence of that antenatal steroids have a persistent effect on lung mechanics: infants born at term after exposure to up to three courses of betamethasone at gestations between 25 and 33 weeks had no difference in gas mixing or lung volume/mechanics when compared to nonexposed term controls (Hjalmarson and Sandberg 2011). Like antenatal steroids, postnatal steroids also increase respiratory system compliance (Durand et al. 1995). Low-dose and high-dose postnatal dexamethasone for CLD achieve a similar increase in $C_{\mathrm{rs}}$ suggesting equal effectiveness for improvement of lung volume 

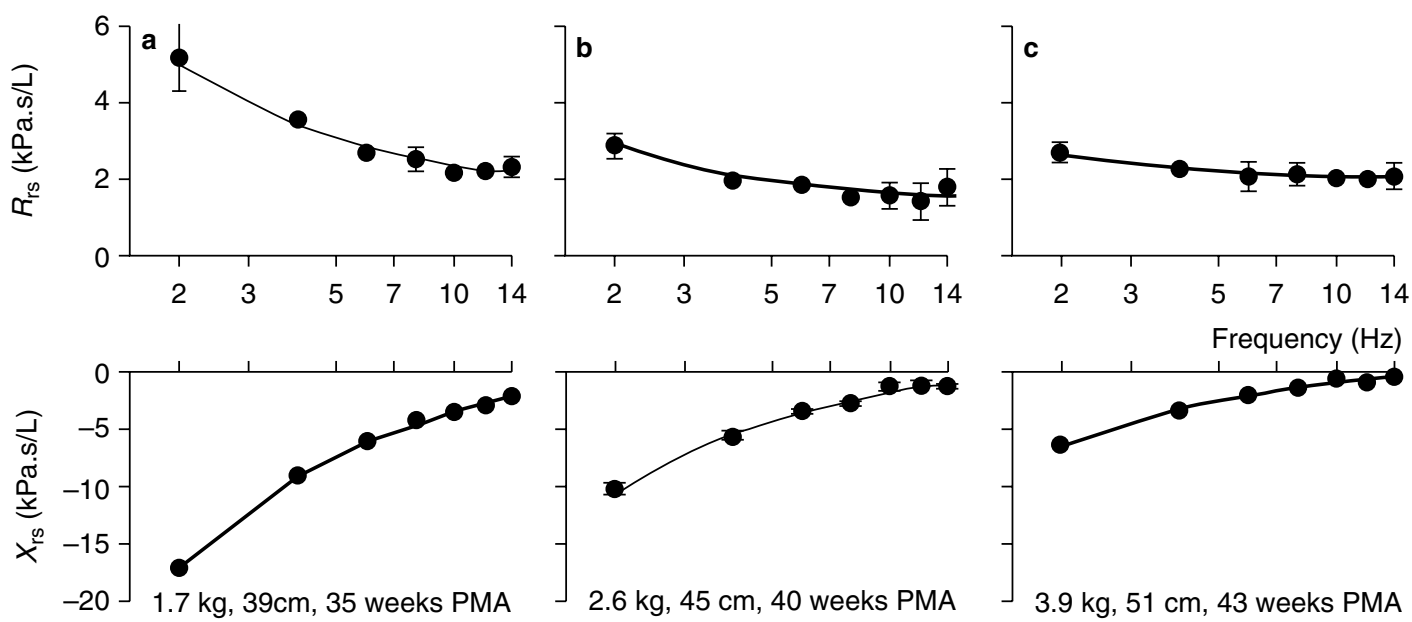

Fig. 4.11 Representative impedance spectra from two newborn infants: Panels a and b illustrate impedance spectra for a 32-week preterm infant at 35-week postmenstrual age (panel a) and on repeat measurement at 40-week PMA). Panel c shows the impedance spectra from a healthy term infant at 42-week postmenstrual age. Figure illustrates the alteration in respiratory impedance that occurs with postnatal maturation (a, b) and the marked frequency dependence of respiratory impedance in the more immature infant (a). Solid lines indicate the fit of the constant-phase model. $R_{\mathrm{rs}}$ respiratory resistance (comprising frequency-dependent tissue resistance and frequencyindependent airway resistance), $X_{\mathrm{rs}}$ respiratory reactance (incorporating tissue elastance and airway inertance), $P M A$ postmenstrual age. Symbols and bars are mean $(S D)$ values from technically acceptable measurements in the same infant (Adapted from Pillow et al. (2005))
(McEvoy et al. 2004). Early postnatal dexamethasone may be more effective than late dexamethasone in achieving lower $R_{\mathrm{aw}} / R_{\mathrm{rs}}$ and higher specific conductance ( $\mathrm{s} G_{\mathrm{aw}}$ ) (Merz et al. 1999; Vento et al. 2004), which may indicate a degree of fixed change in the airway walls in infants receiving delayed glucocorticoid treatment.

During administration, surfactant represents a fluid bolus in the airway that increases inspiratory and expiratory time constant, associated with an acute increase in respiratory system resistance. Effective delivery of surfactant to the lung thus benefits from a transient increase in the inspiratory time and potentially brief increase in the delta $P$ (peak inspiratory pressure-positive endexpiratory pressure) to overcome the increase resistance resulting from the fluid bolus. Treatment with exogenous surfactant (da Silva et al. 1994) or increases in positive end-expiratory pressure (PEEP) during recruitment from atelectasis increases lung volume: (Dimitriou et al. 1999) lung volume increases by $61 \pm 39 \%$ within a median of 4 min after surfactant administration, with altered distribution of lung volume towards the dorsal rather than ventral compartment. The increase in lung volume after surfactant or volume recruitment maneuvers increases maximal compliance of the respiratory system, with higher tidal volumes achieved at lower pressures than required prior to treatment (Miedema et al. 2011a; McEvoy et al. 2010). Importantly, the increase in compliance also impacts on the time constant ( $\left.\tau=R_{\mathrm{rs}} \times C_{\mathrm{rs}}\right)$ of the respiratory system. Changes in the inspiratory and expiratory time constants need to be monitored as they necessitate adjustment of the inspiratory and expiratory times and influence the maximal frequency that can be used during ventilation with passive expiration.

Compared to treatment of RDS with synchronized intermittent mandatory ventilation (SIMV), a small clinical trial showed that infants treated with high-frequency oscillatory ventilation (HFOV) have early and sustained improvement in pulmonary mechanics and higher dynamic respiratory compliance (Vento et al. 2005). The improvement in pulmonary mechanics in patients treated with HFOV is likely associated with enhanced lung volume recruitment. 
The neonatal lung with RDS exhibits hysteresis (Miedema et al. 2011b). Hence lung recruitment maneuvers that aim to recruit the lung and subsequently ventilate it on the most compliant part of the deflation pressure volume curve can achieve effective ventilation with minimum pressure and volume cost of ventilation. Importantly, recruitment of the lung by increasing mean distending pressure during HFOV is also associated with changes in compliance and the time constant for volume delivery during HFOV (Pillow 2012). Consequently, volume delivery can vary substantially over the time course of an HFOV volume recruitment maneuver (Miedema et al. 2012) and potentially result in rapid fluxes of the partial pressure of arterial carbon dioxide. The effect of compliance on volume delivery during HFOV is more evident at lower frequencies (Pillow 2012; Pillow et al. 2001b). The development of HFOV ventilators that incorporate volume guarantee during HFOV will provide protection from such rapid changes in ventilation during HFOV.

Infants with RDS often have their clinical course complicated by the persistence of a patent ductus arteriosus (PDA), which presents as a leftright shunt. Ligation of a PDA (left-right shunt) increased dynamic compliance by $77 \%$ in 16 newborn infants measured before and after ligation, but did not influence dynamic $R_{\mathrm{rs}}$ or mean airway pressure (Szymankiewicz et al. 2004a).

\subsubsection{Meconium Aspiration Syndrome}

Although meconium aspiration syndrome (MAS) is often considered as a high airway resistance disease due to the presence of meconium in the airways, studies in rabbits show that the acute aspiration of meconium also causes a significant reduction in the lung-thorax compliance (Sun et al. 1993). Impaired compliance after MAS is responsive to standard surfactant instillation (Sun et al. 1993). Larger volume $(15 \mathrm{~mL} / \mathrm{kg})$ surfactant lung lavage is an emerging treatment for MAS: following surfactant lung lavage, dynamic compliance approximately doubled, and airway resistance nearly halved in a group of MAS infants on mechanical ventilation (Szymankiewicz et al. 2004b). These changes in dynamic respiratory mechanics were associated with a decrease in mean (SD) airway pressure from $12.4 \pm 3.6$ to $5.4 \pm 2.1 \mathrm{~cm} \mathrm{H}_{2} \mathrm{O}$ within $48 \mathrm{~h}$ after surfactant lung lavage.

Meconium appears to have a differential effect on hyperreactivity of the airways and the lung tissue. Whereas tracheal smooth muscle reactivity increases with increasing meconium concentration in response to histamine and acetylcholine, a negative correlation was observed in the lung tissue (Mokry et al. 2007). Airway hyperresponsiveness 2 weeks after birth (approximately 5 days after cessation of ECMO) is responsive to bronchodilator treatment (Koumbourlis et al. 1995) as evidenced by percent change in $\mathrm{MEF}_{25}$ and the $\mathrm{MEF}_{25} / \mathrm{FVC}$ ratio. Airway hyperreactivity after MAS is also reduced by budesonide (Mokry et al. 2007).

Limited information is available for the longterm lung function outcomes after MAS. Neonates treated with ECMO for meconium aspiration have better long-term lung function outcomes than infants with diaphragmatic hernia treated with ECMO in the neonatal period (Spoel et al. 2012a), most likely reflecting differences in lung capacity and structure. At least $50 \%$ of children who had MAS in the neonatal period have evidence of trapped air on lung function during mid-late childhood. There are no published reports evaluating responsiveness to bronchodilators beyond infancy after neonatal MAS.

\subsubsection{Persistent Pulmonary Hypertension of the Newborn}

Persistent pulmonary hypertension of the newborn (PPHN) presents with profound hypoxia either in the absence of significant lung disease (primary PPHN) or hypoxia out of proportion with the degree of respiratory disease (secondary PPHN - complicating RDS, meconium aspiration, pneumonia, etc.). Lung function in 1-yearold infants who had PPHN and who were treated with inhaled nitric oxide (iNO) but not extracorporeal membrane oxygenation (ECMO) was compared with lung function outcomes of infants who were randomized to receive either ECMO or conventional management as part of the UK ECMO trial. $V_{\text {max,FRC }}^{\prime}$ was lower than predicted in 
Table 4.1 Longitudinal results of spirometry after neonatal ECMO after bronchodilation

\begin{tabular}{|c|c|c|c|c|c|c|}
\hline Age (year) & \multicolumn{2}{|l|}{5} & \multicolumn{2}{|l|}{8} & \multicolumn{2}{|l|}{12} \\
\hline Subjects, $n$ & \multicolumn{2}{|l|}{72} & \multicolumn{2}{|l|}{77} & \multicolumn{2}{|l|}{42} \\
\hline Bronchodilation & Pre & Post & Pre & Post & Pre & Post \\
\hline \multicolumn{7}{|l|}{ SDS FEV $_{1}$} \\
\hline MAS & $\begin{array}{l}-0.16(-0.51 \\
0.19)\end{array}$ & $\begin{array}{l}0.49(0.16 \\
0.82)^{* *}\end{array}$ & $\begin{array}{l}-0.49(-0.77 \\
-0.22)^{*}\end{array}$ & $\begin{array}{l}0.12(-0.16 \\
0.40)\end{array}$ & $\begin{array}{l}-0.69(-1.1 \\
-0.28)^{*}\end{array}$ & $\begin{array}{l}0.01(-0.45 \\
0.24)\end{array}$ \\
\hline $\mathrm{CDH}$ & $\begin{array}{l}-1.7(-2.3 \\
-1.2)^{*}\end{array}$ & $\begin{array}{l}0.01(-0.53 \\
0.47)\end{array}$ & $\begin{array}{l}-2.5(-3.0 \\
-2.0)^{*}\end{array}$ & $\begin{array}{l}-2.3(-3.0 \\
-1.5) * * *\end{array}$ & $\begin{array}{l}-3.2(-4.4 \\
-2.6) *\end{array}$ & $\begin{array}{l}-2.7(-3.9 \\
-1.5)^{*}\end{array}$ \\
\hline
\end{tabular}

Adapted with permission from Spoel et al. (2012a)

Mean $\left(95 \%\right.$ CI) standard deviation score (SDS) show for $\mathrm{FEV}_{1}$ (forced expiratory volume in $1 \mathrm{~s}$ ). Number of patients studied in each group: meconium aspiration syndrome (MAS) - 35, 46, and 26 at 5 years, 8 years, and 12 years; congenital diaphragmatic hernia $(\mathrm{CDH})-15,14$, and 5 at 5 years, 8 years, and 12 years. SDS significantly below normal (SDS $=0$; one sample $t$-test): ${ }^{*} p<0.05 ; * * p<0.01 ; * * * p<0.001$

all three groups $(p<0.001)$. There were no statistical differences between the three groups in the $Z$-scores for $V_{\text {max,FRC }}^{\prime}$ (Hoskote et al. 2008). Nonetheless, only $26 \%$ of iNO-treated infants had $V_{\text {max,FRC }}^{\prime} Z$-scores below normal compared to 37 and $56 \%$, respectively, for ECMO and CM groups. A prospective evaluation of lung function in infants with PPHN treated with/without iNO was reported by Dobyns and colleagues (1999): compared to healthy control infants of the same age, there were no differences in lung volume or passive respiratory mechanics for infants with PPHN, nor was there any effect of iNO on later pulmonary function in the PPHN group. Together, these results suggest that iNO treatment does not worsen outcome compared to ECMO or conventional management.

\subsubsection{Congenital Diaphragmatic Hernia}

Infants with congenital diaphragmatic hernia have impaired airway function in the first year of life: maximal expiratory flows at FRC were a mean $Z$-score of -1.5 lower than healthy term infants (i.e., 1.5 standard deviations below the mean FRC for healthy term infants) with no evidence of significant change between 6 and 12 months of age (Spoel et al. 2012b). Conversely, and perhaps surprisingly, given the usual association of $\mathrm{CDH}$ with pulmonary hypoplasia in at least one lung, Spoel noted that measured values of functional residual capacity were relatively high (47\% fell above the normal range) (Spoel et al. 2012b). As expected, mean $\mathrm{Z}$-score for $\mathrm{FEV}_{1}$ and $\mathrm{FVC}$ was negatively influenced by the presence of chronic lung disease, the duration of ventilation, and ECMO support (Spoel et al. 2012a). Patients with CDH develop hyperinflation, with elevated plethysmographic FRC at 1 year (Hofhuis et al. 2011) that is still evident at 8-12 years (Spoel et al. 2012a; Hamutcu et al. 2004; Majaesic et al. 2007).

Spoel showed that greater impairment was evident in infants with $\mathrm{CDH}$ who required extracorporeal membrane oxygenation (Spoel et al. 2012b). However, poorer outcome in ECMOtreated $\mathrm{CDH}$ may reflect the initial severity of disease rather than ECMO: Beardsmore showed that ECMO per se did not worsen respiratory function at 1 year of age compared to conventionally ventilated controls (Beardsmore et al. 2000).

Spoel and colleagues also noted deterioration in lung function over time (5-12 years) in patients with $\mathrm{CDH}$ who were treated with ECMO in the neonatal period (see Table 4.1) (Spoel et al. 2012a): mean (SE) SDS score for $\mathrm{FEV}_{1}$ after bronchodilation was higher at 5 years $(-0.71$ $(0.40))$ than at 8 years $(-2.27(0.36))$ and 12 years $(-2.73(0.61))$. Deterioration over time may be related to maldevelopment of the alveoli and pulmonary vessels with disturbed lung growth. It is also possible that increased susceptibility to recurrent respiratory tract infections may contribute to deterioration in lung function over time. An active lifestyle and healthy eating pattern may be especially important for children with $\mathrm{CDH}$ to counteract the deterioration in lung function over time, given the known positive effect of participation in sports and the negative interaction of 
BMI with exercise capacity (van der Cammenvan Zijp et al. 2011). Similarly, it may be especially important to treat recurrent infections of the respiratory tract and actively manage asthma to avoid limitation of exercise capacity and deterioration of lung function. Prolonged follow-up of children with $\mathrm{CDH}$ is warranted.

\subsubsection{Chronic Neonatal Lung Disease}

\subsubsection{Bronchopulmonary Dysplasia}

BPD is most commonly considered as the chronic respiratory condition complicating extreme prematurity and/or prolonged neonatal mechanical ventilation. Factors that independently influence the tidal flow-volume-derived indices include variations in disease severity, degree of alteration to airway and lung mechanics, and also the requirement for oxygen supplementation (Baldwin et al. 2006). There are, nonetheless, quantitative differences in tidal breathing function measured in BPD infants when compared with measurements obtained from healthy term and preterm controls. BPD infants are consistently more tachypneic than their healthy counterparts (Baldwin et al. 2006), but differences in other lung function variables are less consistent. Tidal volume $\left(V_{\mathrm{T}}\right)$ is either less than (Paetow et al. 1999) or similar to (Patzak et al. 1999; Schmalisch et al. 2003) values obtained in healthy infants: $V_{\mathrm{T}}$ relative to healthy infants may also decrease with advancing postnatal age (Tepper et al. 1986b), likely reflecting the altered maturational progression in lung structure and function. BPD infants have increased minute ventilation (MV). Increased MV is primarily due to increased respiratory rate rather than increases in $V$, in part reflecting increased dead space ventilation.

Infants with BPD have an increased work of breathing. Within the tidal flow-volume loop, increased work of breathing is evident from linear or concave expiratory limb morphology. BPD infants also have a less variable shape to the tidal flow-volume waveform, indicating that they are functioning near their maximum respiratory capability with minimal reserve capacity to adapt to changes in intrinsic (e.g., airway obstruction, infection, or aspiration) or extrinsic (e.g., cold stress) environment (Baldwin et al. 2006). Tidal flow indices are difficult to interpret in part due to opposing effects of neurorespiratory control and lung mechanics on the morphology of the tidal flow waveform. Whereas BPD infants have higher respiratory drive (quantified from the mean inspiratory flow: $V_{\mathrm{T}} / t_{\mathrm{I}}$ where $t_{\mathrm{I}}$ is inspiratory time), the ratio of the time to peak expiratory flow relative to expiratory time $\left(t_{\mathrm{PTEF}}: t_{\mathrm{E}}\right)$ after methacholine-induced airway obstruction can either increase or decrease (Clarke et al. 1994). Normal fluctuations in $V_{\mathrm{T}}, t_{\mathrm{I}}$, and MV seen in healthy infants in response to alternate hypoxic-normoxic breath testing are not evident in BPD infants, indicating reduced chemoreceptor sensitivity to hypoxic stimulus (Calder et al. 1994).

Lung and chest wall mechanics of infants with bronchopulmonary dysplasia (BPD) were extensively reviewed by Gappa and colleagues (2006b). Changes are reflective of maldevelopment of the lungs and airways and remodelling of the lung parenchyma and airway walls associated with increased collagen content. In preterm infants, respiratory system compliance $\left(C_{\mathrm{rs}}\right)$ increases relative to body weight over the first 2 years of life, while an initially high respiratory system resistance $\left(R_{\mathrm{rs}}\right)$ decreases over the same period (Baraldi et al. 1997a). Airway walls of preterm infants are more compliant than term infants as evidenced through measurements obtained using the high-speed interrupter technique (HIT) (Henschen et al. 2006).

Following the NICHD consensus conference in 2001 (Jobe and Bancalari 2001), some investigators evaluated differences in lung function according to whether infants had mild, moderate, or severe chronic lung disease. Using the single occlusion technique, Hjalmarson and Sandberg showed that infants with severe bronchopulmonary dysplasia (born at mean 25 weeks GA) had increased specific conductance and decreased specific compliance ( $\mathrm{s}_{\mathrm{rs}}$ ) compared to healthy preterm infants (born at mean 29 weeks gestation) (Hjalmarson and Sandberg 2005). There were no differences in lung mechanics between 
Fig.4.12 Representative flow-volume curves obtained during rapid thoracic compression from healthy (left) and flow-obstructed (right) infants. The descending portion of the expiratory flow-volume curve in the flow-obstructed infant has a characteristic concave (to the $x$-axis) shape. Dashed line indicated point at which $V_{\text {max,FRC was }}^{\prime}$ determined (Adapted with permission from Lum et al. (2006b))

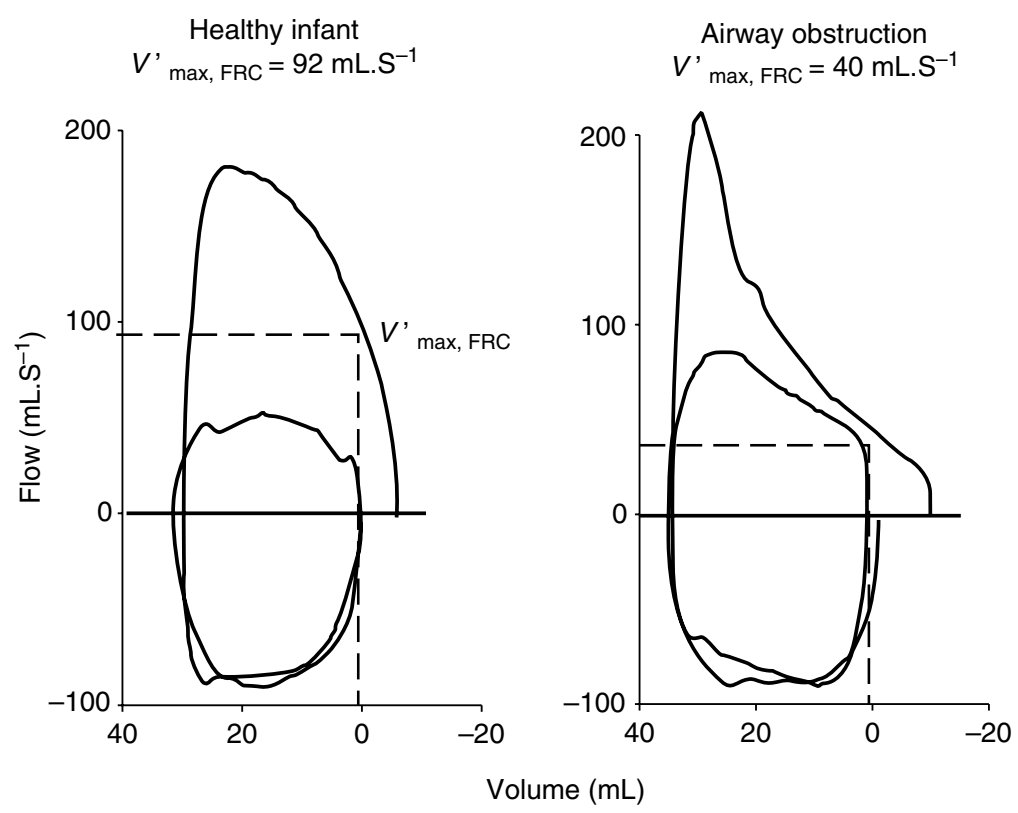

the healthy preterm infants and those with mild or moderate bronchopulmonary dysplasia. The data published by Tortorolo et al. indicate a similar trend towards lower $C_{\mathrm{rs}}$ at day 7 in infants who later went on to develop mild BPD and to a greater extent in severe BPD (Tortorolo et al. 2002). Their results contrast with the findings by Shao and colleagues in infants of similar gestations that infants with BPD had decreased $C_{\mathrm{rs}}$ (10.8 vs $16.0 \mathrm{~mL} / \mathrm{kPa} / \mathrm{Kg}$ ), but no difference in specific s $C_{\mathrm{rs}}(0.69 \mathrm{vs} 0.75 \mathrm{~mL} / \mathrm{kPa} / \mathrm{kg})$ or $R_{\mathrm{rs}}(6.6$ vs $7.3 \mathrm{~cm} \mathrm{H} \mathrm{H}_{2} \mathrm{O} / \mathrm{mL} / \mathrm{s}$ ) compared to non-ventilated preterm infants. Infants with BPD do not show an improvement in airway resistance $\left(R_{\text {aw }}\right.$, measured by plethysmography) over a 4-month period (Shao et al. 1998).

Several authors have attempted to use lung function as a predictor of BPD. The value of initial $R_{\mathrm{rS}}$ for prediction of lung disease is unclear: some have found increased initial $R_{\mathrm{rs}}$ is associated with respiratory outcome at 1 year (Choukroun et al. 2003; Lui et al. 2000; Snepvangers et al. 2004), whereas others observed that $R_{\mathrm{rs}}$ is not predictive of BPD (Tortorolo et al. 2002). Both Lui (Lui et al. 2000) and Merth (Merth et al. 1997) showed that early RDS is not an important determinant of later lung function. Serial measurements of compliance, however, show that lower $C_{\mathrm{rs}}$ values after day 5 were evident in infants who later developed severe BPD. Merth observed that BPD infants have reduced $C_{\mathrm{rs}}$ at 1 year of age irrespective of RDS (Merth et al. 1997).

$V^{\prime}{ }_{\max , \mathrm{FRC}}$ obtained using the tidal rapid thoracic compression technique is reported consistently as being lower than healthy controls throughout the first 3 years of life, regardless of the BPD era or treatment strategies (Lum et al. 2006b). Reduced expiratory flows are indicative of abnormal structural and functional development of the airways (Fig. 4.12). Serial lung function measurements in infants with both BPD and "healthy" unsedated preterm infants indicate a decline over the first year of life, suggesting that factors other than BPD may contribute to abnormal airway function in preterm infants (Hoo et al. 2002b). Raised volume rapid thoracic compression (RVRTC) measurements show similar mild-moderately severe airflow obstruction. However the predominance of airflow obstruction primarily at low lung volumes indicates the pathology is more likely to involve the small peripheral rather than larger central airways (Lum et al. 2006b). Concurrent increased residual volume (RV), FRC, and RV/ TLC (total lung capacity) ratios were more marked in infants with recurrent wheeze, indicative of a degree of hyperinflation and gas trapping. 
Intermediate values (between healthy controls and wheezy BPD infants) were observed for $\mathrm{RV}$, FRC, and RV/TLC in non-wheezy preterm infants (Robin et al. 2004), likely reflective of abnormal airway growth or the effects of preterm delivery. Forced deflation from FRC showed that preterm infants with developing BPD have severe lower airway obstruction as early as 3-4 weeks postnatal age. Increased flows and FVC following bronchodilation indicate that reopening of obstructed airways is achieved with bronchodilators (Motoyama et al. 1987).

A recent systematic review and meta-analysis assessed the effect of preterm birth on later $\mathrm{FEV}_{1}$ : (Kotecha et al. 2013) 59 studies were included in the meta-analysis, including 28 studies in children born preterm without BPD and 39 studies in children with BPD diagnosed at either 28 day of life $\left(\mathrm{BPD}_{28}\right)$ or 36 weeks postmenstrual age $\left(\mathrm{BPD}_{36}\right)$. The meta-analysis showed that just being born preterm decreased $\mathrm{FEV}_{1}$ compared to term-born controls, with further decrements in $\mathrm{FEV}_{1}$ evident for the $\mathrm{BPD}_{28}$ and $\mathrm{BPD}_{36}$ week groups. The mean differences $(95 \% \mathrm{CI})$ for $\% \mathrm{FEV}_{1}$ compared with term-born controls were $-7.2 \%(-8.7 \%$, $-5.6 \%)$ for preterm group without BPD and $-16.2 \%(-19.9$ to $-12.4 \%)$ and $-18.9 \%(-21.1$ to $-16.7 \%$ ) for the $\mathrm{BPD}_{28}$ and $\mathrm{BPD}_{36}$ groups, respectively. Including data from preterm studies not including a control group resulted in a pooled $\% \mathrm{FEV}_{1}$ estimate of $91.0 \%(88.8-93.1 \%)$ for preterm infants without BPD, $83.7 \%$ (80.2-87.2\%) for $\mathrm{BPD}_{28}$, and $79.1 \%(76.9-81.3 \%)$ for $\mathrm{BPD}_{36}$, respectively. Of interest, the authors noted that $\% \mathrm{FEV}_{1}$ for $\mathrm{BPD}_{28}$ has improved over the years. BPD survivors also have lower forced expiratory flows: $70 \%$ of children with BPD had maximal flow at functional respiratory capacity $\left(V_{\max }\right.$ FRC) below $40 \%$ of the predicted value (Baraldi et al. 1997a). Forced expiratory flow at $25 \%$ of forced vital capacity $\left(\mathrm{FEF}_{25-75)}\right.$ was reduced in young adolescents born prematurely, regardless of prior BPD or level of respiratory support (Anand et al. 2003). Of concern, Doyle and colleagues showed that airflow limitation worsened between 8 and 18 years (Doyle et al. 2006). Together, these data suggest that the preterm infant population is at risk of developing chronic obstructive disease and should receive long-term respiratory follow-up (Baraldi and Filippone 2007a; Filippone et al. 2003; Lum et al. 2011). Airway obstruction is accompanied by impaired diffusing capacity in children and adults born prematurely (Hakulinen et al. 1996; Vrijlandt et al. 2006). Similar findings in infants and toddlers with BPD in the face of normal alveolar volumes indicate parenchymal disease and impaired alveolarization (Balinotti et al. 2010).

\subsubsection{Bronchial Hyperresponsiveness}

Several studies have evaluated the effect of bronchodilators on lung mechanics in infants with BPD. Bronchodilators decrease $R_{\mathrm{rs}}$, without affecting $C_{\mathrm{rs}}$ : ultrasonic nebulizers appear to be most effective (Fok et al. 1998).

Bronchial hyperresponsiveness at 2 years of age was related to mean neonatal $C_{\mathrm{rs}}$ and $R_{\mathrm{rs}}$ over the first 3 days in ventilated preterm neonates using breath occlusion test. $C_{\mathrm{rs}}$ but not $R_{\mathrm{rs}}$ was related to bronchial hyperresponsiveness at 2 years' age (Snepvangers et al. 2004). Fifty-six percent of children in the Epicure study born at 25 weeks PMA or less had abnormal baseline spirometry at 11 years of age, with $27 \%$ showing a positive bronchodilator response: more marked responses were evident in the infants with prior BPD (Fawke et al. 2010). Less than half of the Epicure study children with abnormal lung function at 11 years were receiving treatment, suggesting more targeted respiratory follow-up is warranted. The published literature on persistence of bronchial hyperreactivity into early adulthood in the population of young adults born prior to routine antenatal glucocorticoid and postnatal surfactant treatment is conflicting: both persistence (Halvorsen et al. 2004) and resolution (Narang et al. 2008) of bronchial hyperresponsiveness are reported, although both studies report persistently abnormal baseline spirometry.

\section{Essentials to Remember}

- Measurements of dynamic mechanics are most often obtained in intubated infants, but measurements of dynamic resistance are highly variable and may 
not be reliable. Reasons for variability include the highly frequency-dependent nature of respiratory mechanics, rapidly changing nature of respiratory disease, maturation and the acute effects of antenatal exposures, and postnatal treatments and interventions.

- RDS is typically characterized by low lung volumes, reduced lung compliance, and elevated tissue resistance.

- Meconium aspiration is characterized by both increased resistance and decreased compliance. Both resistance and compliance are improved by surfactant lavage. MAS may be complicated by airway hyperreactivity and gas trapping beyond infancy.

- Infants with congenital diaphragmatic hernia have impaired airway function at 1 year of age, with evidence of continuing deterioration throughout childhood. Worse lung function is likely associated with initial severity of disease and intensity/duration of mechanical ventilation.

- BPD infants are typically more tachypneic than their healthy counterparts and have increased work of breathing. Airway walls are more compliant and may be prone to collapse. While lung function outcomes for infants with BPD have improved over the last one to two decades, airflow limitation remains an issue for long-term respiratory function after bronchopulmonary dysplasia and may worsen with time. Diffusing capacity is also impaired in children and adults born prematurely and may reflect parenchymal disease and impaired alveolarization.

- Although patients receiving ECMO generally have worse lung function than those treated without ECMO, this is likely due to the initial severity of lung disease and duration of mechanical ventilation rather than an effect of ECMO on long-term lung function per se.
Persistence of bronchial hyperreactivity into adulthood is unknown for the current population of premature infants.

\section{Educational Aim}

To describe flow $(F)$, lung volumes $(V)$, and respiratory pressure $(P)$ measurements together with resistance $(R)$ and compliance $(C)$ measurements in restrictive lung diseases, obstructive lung diseases, and neuromuscular disorders (NMD)

\subsection{Respiratory Mechanics in Pediatric Diseases}

\section{Véronique Nève and Francis Leclerc}

\subsubsection{Restrictive Lung Disease}

A restrictive ventilatory defect is observed when expansion of the lung is restricted because of alterations in lung parenchyma or as a consequence of extraparenchymal diseases affecting pleura, chest wall, or neuromuscular apparatus.

\subsubsection{Restrictive Ventilatory Defect of Pulmonary Origin}

\subsection{Chronic ILD}

Chronic ILD are characterized by derangements of the alveolar walls and loss of functional alveolar-capillary units. Pediatric ILD comprises a heterogeneous group of rare disorders with considerable mortality (Clement 2004; Fan et al. 2004; Fan and Langston 1993). Chronic ILD in immune-competent children has been defined as the presence of respiratory symptoms and/or diffuse infiltrates on chest radiographs, abnormal pulmonary function tests (PFT) with evidence of restrictive ventilatory defect and/or impaired gas exchange, and persistence of any of these findings for $>3$ months (Clement 2004). PFT, in children over 6 years, show a reduced forced $\mathrm{VC}$ (FVC) and $\mathrm{FEV}_{1}$ and a normal or elevated $\mathrm{FEV}_{1} /$ FVC ratio (Fan et al. 2004) (Fig. 4.13). The 
Fig. 4.13 In chronic insterstitial lung disease, pulmonary function tests, in children over 6 years, show a reduced forced vital capacity $(\mathrm{FVC})$ and $\mathrm{FEV}_{1}$ and $\mathrm{a}$ normal or elevated $\mathrm{FEV}_{1}$ / FVC ratio and a restrictive ventilatory defect with decreased total lung capacity (TLC)

$\begin{array}{llrrr}\text { VC } & \text { [L] } & 1.51 & 2.47 & 61 \\ \text { ERV } & \text { [L] } & 0.49 & 0.81 & 61 \\ \text { VT } & \text { [L] } & 0.45 & 0.42 & 106 \\ \text { ITGV } & \text { [L] } & 1.14 & 1.63 & 70 \\ \text { RV } & \text { [L] } & 0.65 & 0.85 & 77 \\ \text { TLC } & \text { [L] } & 2.16 & 3.32 & 65 \\ \text { RV \% TLC } & \text { [\%] } & 30.12 & 24.96 & 121\end{array}$

$\begin{array}{lcrrr}\text { FVC } & \text { [L] } & 1.46 & 2.47 & 61 \\ \text { FEV 1 } & \text { [L] } & 1.41 & 0.81 & 69 \\ \text { FEV 1 \% VC MAX } & \text { [\% ] } & 93.06 & 24.96 & 110\end{array}$

decrease in TLC, in general, is relatively less than that of VC because of normal chest wall recoil and inspiratory muscle function in most patients (Martinez and Flaherty 2006).

Functional residual capacity (FRC) and residual volume (RV) are normal or elevated resulting in increased FRC/TLC and RV/TLC (Gaultier et al. 1980; Steinkamp et al. 1990; Zapletal et al. 1985). The latter finding suggests air trapping (Fan et al. 2004). Airflow limitation has been demonstrated in some studies (Fan and Langston 1993). Diffusing capacity of carbon monoxide $\left(\mathrm{DL}_{\mathrm{CO}}\right)$, that evaluates the capacity of the lung to exchange gas across the alveolar capillary interface, is low in absolute term but normal when corrected for alveolar $V$ (Gaultier et al. 1980; Zapletal et al. 1985).
The lung $P / V$ curve is shifted down, and elastic recoil $P$ at maximum inspiration is increased (Fan and Langston 1993; Steinkamp et al. 1990; Zapletal et al. 1985). Reduced $C_{\mathrm{L}}$ is observed, with lower specific $C_{\mathrm{L}}$ in children with fibrotic changes on transbronchial lung biopsy specimen (Steinkamp et al. 1990).

The decreased $C_{\mathrm{L}}$ and increased elastic recoil can increase the retractive force exerted on the walls of lung airways and reduce the airway $R$ $\left(R_{\text {aw }}\right)$ or increase $\mathrm{FEV}_{1} \%$ and preserve the peak expiratory $F$ (PEF). However, once lung $V$ becomes severely reduced, PEF declines because it is then measured at a relatively small lung $V$ (Cotes et al. 2006).

PFT can aid in establishing disease severity and prognosis. In nonspecific interstitial pneu- 
monia and idiopathic fibrosis, $\mathrm{DL}_{\mathrm{CO}}<40 \%$ corresponds to advanced disease and predicts impaired survival. Similarly, exertional desaturation $<88 \%$ at baseline testing and a decrease in FVC $>10 \%$ over the course of the short-term follow-up identify patients at particular risk of mortality (Martinez and Flaherty 2006).

\subsection{ALI/ARDS}

ALI/ARDS are characterized by an acute onset of respiratory failure, diffuse bilateral pulmonary infiltrates on the chest radiograph, the absence of clinical evidence of left atrial hypertension, and a ratio of $\mathrm{PaO}_{2}$ to $\mathrm{FiO}_{2}(P / F)$ of less than $200 \mathrm{mmHg}$ (regardless of PEEP). Acute lung injury (ALI) is a subset of ARDS with less severe impairment in oxygenation $(P / F<300)$ (Bernard et al. 1994). $\mathrm{SpO}_{2} / \mathrm{FiO}_{2}(\mathrm{~S} / \mathrm{F})$ may be a good noninvasive surrogate marker for $P / F$ in children: $\mathrm{S} / \mathrm{F}$ ratios of 263 and 201 have been shown to correspond to $P / F$ ratios of 300 and 200, respectively, the ARDS cutoff of 201 having $84 \%$ sensitivity and $78 \%$ specificity (Bach and Bianchi 2003). Decreased $C_{\mathrm{L}}$ was associated to these items (Ware and Matthay 2000). ALI/ARDS are rare diseases in children and have mortality rates ranging from 18 to $75 \%$ (Flori et al. 2005; Zimmerman et al. 2009). Mechanical ventilation represents the main therapeutic support to maintain acceptable pulmonary gas exchange while treating the underlying disease. A "lung protective ventilation strategy" with limitation in airway $P$ and tidal volume (VT) (The Acute Respiratory Distress Syndrome Network 2000) led, in adult studies, to a reduction in mortality at day 28 and a reduction in hospital mortality (Petrucci and Iacovelli 2007; The Acute Respiratory Distress Syndrome Network 2000). No published data exist for children, but practice in PICU is derived from adult patients (Khemani and Newth 2010).

\subsection{Acute Phase}

The most characteristic alteration in acute ARDS lung is marked fall in $C_{\mathrm{L}}$ caused by loss of surfactant function, atelectatic lung regions, accumulation of interstitial/alveolar plasma leakage (Ware and Matthay 2000), and an associated fall in FRC (Hammer 2001). In adults, the decrease in $C_{\mathrm{L}}$ was shown to be more important in early ARDS from pulmonary origin (and associated with normal chest wall $C\left(C_{\mathrm{cw}}\right)$ ) than in extrapulmonary ARDS. The latter was associated with low $C_{\mathrm{cw}}$ (Gattinoni et al. 1998). A decrease in respiratory system compliance $\left(C_{\mathrm{rs}}\right)$ and a proportional decrease in TLC, FVC, and FRC were also observed in children during the acute phase of ARDS (Hammer et al. 1998; Newth et al. 1997).

ALI/ARDS may resolve completely in some patients, while in others it progresses to fibrosing alveolitis with persistent hypoxemia and a further decrease in $C_{\mathrm{L}}$ (Ware and Matthay 2000). Fibroproliferation occurs early in ARDS, and its extent may be predictive of outcome (Marshall et al. 2000). The recovery phase is characterized by the gradual resolution of hypoxemia and improved $C_{\mathrm{L}}$ (Ware and Matthay 2000). Pharmacologic interventions, such as corticosteroids, starting in the late course of ARDS may reduce fibrosis and may have a beneficial impact on pulmonary outcome (Tang et al. 2009).

\subsection{Long-Term Sequelae}

Several studies have demonstrated persistent impairment in pulmonary function of unknown long-term significance for children who required mechanical ventilation in pediatric intensive care units for respiratory failure (Khemani and Newth 2010). Most survivors of ARDS have persistent mild reductions of $\mathrm{DL}_{\mathrm{CO}}$ even as long as a year after their episode. The lung $V$ and $F$ return to normal in most instances, although a subset of patients will have persistent impairment. Both obstructive and restrictive deficits may be seen (Alberts et al. 1983; Elliott et al. 1981; Ghio et al. 1989; Hert and Albert 1994; Peters et al. 1989).

Timing of recovery occurring in the first year after ARDS was described in two prospective studies of adult survivors of ARDS (Herridge et al. 2003; McHugh et al. 1994). After discharge from the ICU, a restrictive ventilatory defect and reduced $\mathrm{DL}_{\mathrm{CO}}$ were observed in almost all patients and an obstructive defect in only $5 \%$. Improvement was observed until 6 months after discharge. A relatively static period was observed after that. By 6 months, abnormalities in FVC, TLC, and $\mathrm{DL}_{\mathrm{CO}}$ were observed in 55,45 , and $26 \%$, respectively, of patients. Patients with more severe ARDS, as determined by their higher ALI scores (corresponding to patients ventilated 
for $>2$ weeks), were more impaired for FVC throughout the follow-up and did not return to normal pulmonary function levels (McHugh et al. 1994). Patients of Herridge's study were shown to have a mild restrictive defect with mild to moderate reduction in $\mathrm{DL}_{\mathrm{CO}}$ at 3 months. Lung $V$ and spirometric measurements were normal by 6 months, but $\mathrm{DL}_{\mathrm{CO}}$ remained low throughout the 12-month follow-up (Herridge et al. 2003).

For the pediatric age group, a few small-sized observational cohort studies have reported sequelae in 10-100 \%, in mostly asymptomatic subjects (Ben-Abraham et al. 2002; Fanconi et al. 1985; Golder et al. 1998; Lyrene and Truog 1981; Weiss et al. 1996). Obstructive (reversible and nonreversible airflow obstruction) and restrictive abnormalities have been observed after discharge. Like in adults, recovery during the following months reached plateau levels at 12 months with no further improvement (Golder et al. 1998).

Decrease in $C_{\mathrm{L}}$ was shown to persist in $\geq 50 \%$ of children and adults, evaluated 1-2 months (Aggarwal et al. 2000), or 34 months after ARDS (Klein et al. 1976), and was associated with a restrictive defect in some patients. Symptomatic upper airway obstruction as a result of laryngotracheal injury from long-term intubation has been described in minority $(10 \%)$ of adults after ARDS with evidence of upper airway obstruction on inspiratory and expiratory $F / V$ curves (Elliott et al. 1988).

\subsubsection{Restrictive Defect Arising in the Chest Wall}

\subsection{Obesity}

The prevalence of childhood obesity is increasing in developed countries. Obese children have more respiratory symptoms than their normal-weighted peers, and respiratory-related disorders increase with increasing weight. The prevalence of asthma has also increased in children. Both obesity and asthma have their beginnings in early childhood (Litonjua and Gold 2008). Wheezing, asthma, and obesity seem to be associated (Guerra et al. 2002; Hancox et al. 2005; Schachter et al. 2001). However, three large studies (Bibi et al. 2004; Schachter et al. 2003; Wickens et al. 2005) showed a clear increase in symptoms of asthma in association with obesity but not more frequent airway hyperresponsiveness in obese children (Deane and Thomson 2006).

$C_{\mathrm{CW}}$ is reduced in obesity, because of increased adiposity in the abdomen and around the thoracic cage that restricts rib expansion and because the decreased total thoracic and pulmonary $V$ may pull the chest wall below its resting level to a flatten portion of its $P / V$ curve. $C_{\mathrm{CW}}$ decrease correlated with $\mathrm{CO}_{2}$ retention, independent of body fat, and with shortness of breath (Subramaian and Strohl 2004). $C_{\mathrm{L}}$ may be decreased in some obese individuals because of a large pulmonary blood volume and intrinsic alterations of elastic characteristics of lung tissues (Subramaian and Strohl 2004).

As additional fat in the abdomen raises the diaphragm, the FRC and expiratory reserve volume (ERV) are reduced in the erected position and further reduced in the supine position (Koenig 2001). The lung bases are poorly ventilated which contributes to hypoxemia. TLC and VC may also be reduced, but RV is usually maintained (therefore $\mathrm{RV} / \mathrm{TLC}$ ratio may be increased). In morbidly obese individuals, an increase in body mass correlates with reduced $\mathrm{FEV}_{1}$ (Carey et al. 1999) and $\mathrm{FVC}\left(\mathrm{FEV}_{1} /\right.$ FVC ratio remains normal) (Zerah et al. 1993).

Data in children and adolescents confirm the reduced FRC and static lung $V$ (Li et al. 2003) and the decrease in FVC and $\mathrm{FEV}_{1}$ with increasing proportions of body fat as a percentage of body weight (Lazarus et al. 1997).

All these effects were shown to be reversible in morbidly obese patients (with body mass index (BMI) >40) following weight loss (Camargo et al. 1999; Carey et al. 1999; Deane and Thomson 2006).

In seated patients with simple morbid obesity, inspiratory and expiratory muscle strength is normal (Yap et al. 1995). When patients are supine, maximal inspiratory $P$ (PImax) decreases by about half as a result of overstretching of the diaphragm, causing it to operate on the descending limb of its length-tension curve (Laghi and Tobin 2003).

Morbidly obese patients without hypoventilation (simple obesity) compensate for the respiratory load by increasing respiratory drive and diaphragmatic pressure output (Pankow et al. 1998) and increasing rib cage contribution to tidal breathing. 


\subsection{Scoliosis}

Scoliosis is the most common abnormality of the spine with direct effect on the thoracic cage. Idiopathic scoliosis (including infantile, juvenile, and adolescent) accounts for $80-85 \%$ of scoliosis. Neuromuscular scoliosis (as in Duchenne muscular dystrophy (DMD) or spinal muscular atrophy (SMA)) and scoliosis associated with congenital vertebral abnormalities account each for $5 \%$ of scoliosis. Infantile and congenital scoliosis, untreated, results in severe spinal deformities and is at risk of cardiopulmonary insufficiency before adulthood (Canet and Bureau 1990).

Patients with scoliosis and a Cobb angle $<70^{\circ}$ are usually asymptomatic, those with an angle between $70^{\circ}$ and $100^{\circ}$ often experience dyspnea on exertion, and those with the angle $>100^{\circ}$ are at risk for chronic respiratory failure (Estenne et al. 1998).

Scoliosis can produce severe reductions in lung $V$ and restrictive ventilatory defect with decrease in FVC, $\mathrm{FEV}_{1}$, and TLC as well as a normal $\mathrm{FEV}_{1} / \mathrm{FVC}$ ratio (Gagnon et al. 1989; Muirhead and Conner 1985; Upadhyay et al. 1993; Weber et al. 1975). Among patients with moderate to severe scoliosis $\left(35-100^{\circ}\right)$, the VC decrease is related to the Cobb angle. When the Cobb angle exceeds $100^{\circ}$ (severe scoliosis), VC falls to about $50 \%$ of predicted (Laghi and Tobin 2003). Impaired lung growth (Davies and Reid 1971), significant decrease in $C_{\mathrm{L}}$ and $C_{\mathrm{CW}}$ (at about $25-50 \%$ of predicted in children and adults with scoliosis) (Laghi and Tobin 2003), and/or impaired muscle strength as a consequence of inefficient coupling between the respiratory muscles and the thoracic cage account for the effect of scoliosis on lung function. In adults with scoliosis and Cobb angles of $66-136^{\circ}$, PImax was about 50-76 \% (Estenne et al. 1998; Laghi and Tobin 2003).

Decreased TLC is often associated with increased RV resulting in very high RV/TLC ratio (Day et al. 1994), probably reflecting the dysfunction of expiratory muscles, which do not allow full exhalation.

Significant gas trapping with elevated plethysmographic FRC/helium FRC ratio can occur with response to bronchodilators, indicating airway hyperresponsiveness that results from chronic airway inflammation secondary to the poor clearance of secretions (Boyer et al. 1996). The chest distortion causes airway distortion thereby contributing to a slight increase in airway $R\left(R_{\mathrm{aw}}\right)$ (Canet and Bureau 1990). Scoliosis, by inducing significant displacement/rotation of the intrathoracic trachea and/or main stem bronchi, can cause mechanical obstruction as shown on the $F / V$ loop with flattening of the initial portion of the expiratory loop suggesting central airway obstruction (Borowitz et al. 2001).

The decreased $C_{\mathrm{rs}}$ may account for the increased work of breathing, with increased transdiaphragmatic pressure during tidal breathing; increased rib cage contribution to tidal breathing; transversus abdominis recruitment during exhalation, as observed in most patients with severe scoliosis (Laghi and Tobin 2003); and the associated increased risk of respiratory muscle fatigue and eventual respiratory failure.

\subsection{Neuromuscular Scoliosis}

In contrast to idiopathic scoliosis which tends to stabilize (or progress at a lower rate) after the person reaches skeletal maturity, neuromuscular scoliosis (such as in DMD or SMA) continues to worsen because of the progressive worsening of the muscle weakness. Recurrent aspiration and pneumonias secondary to impaired clearance of airway secretions are potential complications. Due to the severity of their primary muscle weakness, patients with neuromuscular scoliosis may not be able to maintain adequate ventilation and may develop severe atelectasis (Koumbourlis 2006).

Scoliosis is reported in 60-100\% of SMA children and is due to the inability of the trunk muscles to support spine in the upright position. All children with type 2 SMA develop scoliosis starting from around 3 years. The average curve is more than $54^{\circ}$ at 10 years of age (Mullender et al. 2008). As the scoliosis progresses, respiratory function deteriorates, and the risk of life-threatening complications increases (Rodillo et al. 1989). Spinal fusion is recommended when scoliosis progresses and reaches a Cobb angle of between $40^{\circ}$ and $60^{\circ}$ in children $\geq 10$ years of age (Tsirikos and Baker 2006).

In DMD, scoliosis incidence ranges from 75 to $95 \%$ (Muntoni et al. 2006). DMD develop 
scoliosis after losing independent ambulation (in the second decade of life). Once scoliosis reaches $30^{\circ}$, it progresses with age and growth. Corticosteroids may delay the development and progression of scoliosis in DMD (Muntoni et al. 2006). Optimal timing for surgical intervention is while lung function is satisfactory and before cardiomyopathy becomes severe enough to risk arrhythmia under anesthesia (Cobb angle between $30^{\circ}$ and $50^{\circ}$ ). Best prognosis for recovery seems to be FVC $>40 \%$, although others use the absolute $\mathrm{VC}$ of $<1.9 \mathrm{~L}$ as an indicator of rapid progression of scoliosis and poor prognosis (Finder et al. 2004). Comparison between preand postoperative pulmonary function reveals no improvement due to correction of scoliosis. Long-term studies show that decline of pulmonary function in DMD patients is unchanged in operated patients compared to patients who had no surgery (Muntoni et al. 2006).

\subsubsection{Obstructive Lung Disease}

\subsubsection{Childhood Asthma and Wheezing Disorders}

Asthma is the most frequent chronic disease observed in children (prevalence ranging from 8 to $12 \%$ (ISAAC 1998)). Asthma is difficult to diagnose in children $\leq 5$ years. Children presenting with wheeze at an early age belong to a heterogeneous group: early transient, late onset, and persistent wheezers (Martinez and Helms 1998). Half of the "early" wheezing children become asymptomatic by school age. They may have diminished lung function early on, but by 6 years lung function is improved (Martinez et al. 1995). Children who had wheezing that began in infancy and continued at 6 years demonstrated normal pulmonary function initially with reduced lung function by 6 years. Those children with "persistent wheezing" have some ongoing chronic inflammatory process that results in airway alterations and some loss of lung function in early childhood, which extends to varying degrees in adulthood (Oswald et al. 1997).

Respiratory syncytial virus (RSV) bronchiolitis in infancy is often associated with recurrent wheezing and asthma during subsequent years. However, wheezing tends to diminish by school age or adolescence. Most follow-up studies of RSV bronchiolitis in infancy show that forced expiratory flow (FEF) rates and $\mathrm{FEV}_{1}$ are lower at school age compared with control groups (Hall et al. 1984; Pullan and Hey 1982). Children who had been hospitalized for RSV bronchiolitis as infants later had lung function abnormalities similar to those found in children with asthma (Kattan et al. 1977; Wennergren and Kristjansson 2001).

Increased $\mathrm{R}$ to airflow is the basis of the clinical manifestations of asthma, including dyspnea and wheeze. Usually, airflow limitation is reversible. Fixed airway obstruction may be seen in later disease stage (Strachan et al. 1996) or be a component of a specific asthma phenotype (Bush 2004). Airway obstruction in childhood is associated with a reduced $\mathrm{FEV}_{1}$ in adulthood (Jenkins et al. 1994; Roorda et al. 1994).

Airflow obstruction (AFO) can be assessed by body plethysmography, spirometry, forced oscillation technique (FOT), and interrupter technique, but these are more difficult to perform in children $<6$ years. Incentive spirometry can be performed in the majority of children $\geq 3$ years (Beydon et al. 2007b) together with FRC helium measurement and $\mathrm{R}$ measurement (using interrupter technique $\left(R_{\text {int }}\right)$ ) (Beydon et al. 2007b), FOT, or plethysmography for measurement specific $R_{\text {aw }}\left(\mathrm{s} R_{\text {aw }}\right.$ ) (Dab and Alexander 1976). Infant PFTs are mainly research tools.

\subsection{Forced Expiratory Volumes (FEV) and FIV Curves}

The $\mathrm{FEV}_{1}$ is the "gold standard" of measuring airway obstruction in children over 6 years (Miller et al. 2005; Pellegrino et al. 2005). Preschoolers often do not exhale for more than $1 \mathrm{~s}$. Therefore $\mathrm{FEV}_{1}$ may not be an accurate index of bronchial obstruction in this age group, and the utility of $\mathrm{FEV}_{0.5}$ or $\mathrm{FEV}_{0.75}$ as outcome measure in this age group has been explored (Aurora et al. 2004; Beydon et al. 2007b; Neve et al. 2006; Vilozni et al. 2005).

International guidelines (NHLBI 2002) recommend an initial evaluation and regular reeval- 
uation for the assessment of the severity and the control of asthma. Asthma severity describes the underlying disease state as evaluated by $\mathrm{FEV}_{1}$ and daytime and nighttime symptoms, all measured before treatment. Patients with moderate and severe persistent asthma are said to have values of $60-80 \%$ and $<60 \%$ of predicted, respectively. $\mathrm{FEV}_{1}$ may not be the best measure of severity in childhood asthma because most asthmatic children have $\mathrm{FEV}_{1}$ values in the normal range independent of disease severity when clinically stable (Spahn et al. 2004). Diminished $\mathrm{FEV}_{1}$ values in school-age children should identify children at risk of fixed airway obstruction at adulthood (Rasmussen et al. 2002). For children, FEV1/FVC appears to be a more sensitive measure of severity in the impairment domain (NHLBI 2007)

A concave shape on the $F / V$ curve may be observed as a result of small airway obstruction (Pellegrino et al. 2005). It may be observed in asthmatic children with a normal $\mathrm{FEV}_{1}$, together with a significant improvement following administration of a bronchodilator (Basek et al. 2005; Brand and Roorda 2003). A concave shape is associated with impairment in the FEF between 25 and $75 \%$ of $\mathrm{FVC}\left(\mathrm{FEF}_{25-75 \%}\right)$ that is believed to measure peripheral airway obstruction. $\mathrm{FEF}_{25-}$ $75 \%$ is among the first parameters to be abnormal in pediatric asthma and often the most significantly impaired of all spirometric measures (Paull et al. 2005; Spahn and Chipps 2006). A $\mathrm{FEF}_{25-75 \%} \leq 65 \%$ is well correlated with bronchodilator responsiveness in asthmatic children with normal $\mathrm{FEV}_{1}$ and may suggest suboptimal asthma control (Simon et al. 2010).

\subsection{Lung $V$}

Plethysmography may show lung distension/air trapping with larger RV and TLC in children than in adults (Jenkins et al. 2003). The RV is a sensitive parameter of airway obstruction in children, and a decrease in RV after bronchodilator administration appears to be specific for asthma diagnosis (Walamies 1998). Air trapping may be observed when FVC and $\mathrm{FEV}_{1}$ values are normal in mild or moderate asthma (Cooper et al. 1977) or in controlled asthma (Vilozni et al. 2009).
Indeed, the principal event taking place in the asthmatic lung is the closure of small airways with increase in RV that is associated to a protective increase in TLC to preserve the functional range of FVC. Once the limit of the chest wall expansion has been reached, further increase in $\mathrm{RV}$ will result in falls in both FVC and $\mathrm{FEV}_{1}$ (Irvin and Bates 2009).

FRC may be elevated, due to airway closure and/or dynamically elevated with an increased expiratory time constant (Stanescu 1999). It is a compensatory mechanism that minimizes the increase in $R_{\text {aw }}$ and the expiratory flow limitation in obstructive airway disease. Hence, at an early stage of the disease, an isolated increase in lung $V$ may be the sole functional abnormality (Landau et al. 1979; Paton 2000). In asthmatic children, FRC increases with severity of asthma (Greenough et al. 1987) and is more elevated in symptomatic children (Pool et al. 1988). Trapped air is associated with hypoxemia (Wolf et al. 1983) but correlates poorly with F limitation and may be lacking in patients with severe asthma (Basek et al. 2005; Desmond et al. 1986). In preschool children with asthma, a 6-week inhaled corticosteroid therapy is associated with reduced hyperinflation as indicated by lower FRC helium (Greenough et al. 1988). Bronchodilators were shown to decrease helium FRC in $80 \%$ of children aged 2-7 years, and the decrease was correlated to baseline FRC. Some children exhibited an increase in FRC after bronchodilation when baseline value was low (Greenough et al. 1989).

\subsection{R Measurement in Preschool Children}

Higher baseline $R_{\text {int }}$ measurement was shown in young preschool asthmatics (Beydon et al. 2003; Nielsen and Bisgaard 2001) and children with a history of wheeze (McKenzie et al. 2000) compared with healthy children. Children with persistent wheeze were shown to have higher $R_{\text {int }}$ value than those with transient or no previous wheeze, but there was an overlap in $R_{\text {int }}$ values between the three groups (Brussee et al. 2004). Using FOT, increased $R$ of the respiratory system at $5 \mathrm{~Hz}$ has been reported in asymptomatic asthmatic preschool children as 
compared with healthy subjects in some studies (Nielsen and Bisgaard 2001). Plethysmographic specific $R_{\text {aw }}\left(\mathrm{s} R_{\text {aw }}\right)$, product of $R_{\text {aw }}$, and plethysmographic thoracic gas volume (TGV) may be altered by both hyperinflation and decreased airway diameter. In preschool children, it was shown to be increased in children with a history of wheeze (Lowe et al. 2002); it was able to identify responses to bronchodilators (Nielsen and Bisgaard 2001) and inhaled steroids (Nielsen and Bisgaard 2000). $\mathrm{s} R_{\mathrm{aw}}$ was more strongly related to FEF after $50 \%$ of FVC has been exhaled $\left(\mathrm{FEF}_{50 \%}\right)$ than to $\mathrm{FEV}_{1}$ and could be used in preschool children to predict mild airflow limitation (Mahut et al. 2009). However, there is no established cutoff for $\mathrm{s} R_{\mathrm{aw}}$ to separate healthy subjects from asthmatics (Marchal and Schweitzer 2005).

\subsubsection{Cystic Fibrosis (CF)}

In $\mathrm{CF}$, the combination of mucus retention, bacterial infections, and inflammation results in obstructive lung disease primarily involving the small airways (Bedrossian et al. 1976; Fox et al. 1974; Ratjen and Grasemann 2005). Restrictive alterations develop secondary to the damage of lung parenchyma by inflammatory changes and by neutrophil degradation products. Chronic airway infection, progressing to bronchiectasis, gas trapping, and hypoxemia and hypercarbia, is the hallmark of CF lung disease. Pulmonary insufficiency is responsible for at least $80 \%$ of CF-related death (Cystic Fibrosis Foundation 2008).

\subsection{FEVs and FEFs}

$\mathrm{FEV}_{1}$ is the gold standard for lung function in $\mathrm{CF}$. $\mathrm{FEV}_{1}$ reflects the progression of pulmonary disease and correlates with mortality. An $\mathrm{FEV}_{1}$ of less than $30 \%$ predicted in conjunction with other clinical indicators is used for selecting suitable candidates for lung transplantation (Kerem et al. 1992).

In CF, obstruction primarily affects the small airways. An early change associated with airflow obstruction in small airways is a concave shape on the $F / V$ curve and a reduction in the $\mathrm{FEF}_{25-75 \%}$ (Pellegrino et al. 2005) such as reported in CF patients (Corey et al. 1997; 1976). This FEF often shows abnormalities in patients in whom $\mathrm{FEV}_{1}$ is in the normal range. However, the large interindividual variability of this FEF must be taken into account in its interpretation.

Diminished FEVs and FEFs have also been reported in sedated infants with CF (including infants considered to be asymptomatic by their physician) using the raised volume rapid thoracoabdominal compression technique (Ranganathan et al. 2002; 2001) and in preschool children using incentive spirometry (Kozlowska et al. 2008; Marostica et al. 2002; Vilozni et al. 2007).

\subsection{Lung $V$ Measurements and Other Techniques Detecting Small Airway Obstruction}

AFO in small airways is associated with lung hyperinflation as indicated by increased RV, RV/ TLC, and TLC.

A small airway obstruction syndrome with decreased $\mathrm{VC}$ and $\mathrm{FEV}_{1}$ increased $\mathrm{RV}$, but a normal $\mathrm{FEV}_{1} / \mathrm{VC}$ ratio and TLC has also been described (Stanescu 1999). The condition is attributed to premature closing of airway leading to air trapping as demonstrated by high-resolution computed tomography (HRCT) scans (Cotes et al. 2006).

Studies using body plethysmography have provided evidence for trapped gases in the majority of patients with CF (Beier et al. 1966). The ratio of RV to TLC that indicates hyperinflation, a key feature of CF lung disease, has been found to correlate with disease severity in numerous studies (Beier et al. 1966; Landau et al. 1979; Landau and Phelan 1973a). Percentage of children with hyperinflation and trapped gas increases with age, and children with severe hyperinflation at 6-8 years showed the most severe disease progression over time (Kraemer et al. 2006).

In children $<6$ years, FRC is the only lung volume that can be measured routinely. Hyperinflation is one of the earliest features of CF (Gappa et al. 2001). Elevated TGV has been found in CF infants (Beardsmore et al. 1988), and hyperinflation has been detected by the helium dilution technique in preschool children (Beydon et al. 2002). Multiplebreath washout methods (MBW) may be particu- 


$\begin{array}{lccccccc} & & \text { Pre } & \text { Pred } & \text { \%Pred } & \text { Post } & \text { \%Pred } & \text { Post/Pre } \\ & & & & & & & \\ \text { FVC } & \text { [L] } & 3.00 & 3.28 & 92 & 3.22 & 98 & 107 \\ \text { FEV 1 } & \text { [L] } & 1.98 & 2.73 & 73 & 2.66 & 97 & 134\end{array}$

Fig.4.14 A concave shape on the $F / V$ curve may be observed in airflow obstruction. Airflow obstruction is often reversible in asthma with improvement in

$\mathrm{FEV}_{1} \geq 12 \%$ of baseline

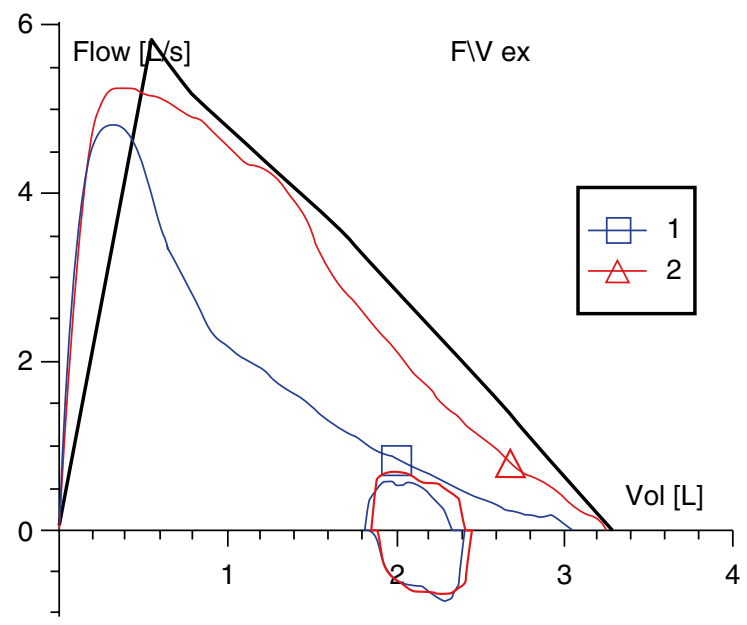

larly sensitive to changes in peripheral lung function and detect early functional abnormalities in infant and preschool children with CF (Aurora et al. 2005; Ranganathan et al. 2008).

Frequency dependence of lung $C$ as indicative AFO in small airways has been observed in the majority of $\mathrm{CF}$, but the invasive nature of this technique limits its clinical use (Landau and Phelan 1973a). Alterations in lung elastic recoil were found with variable frequency (Cook et al. 1959; Landau and Phelan 1973a; Mansell et al. 1974).

\subsection{Obstructive Ventilatory Defect}

As the airway disease becomes more advanced and/or more central airways become involved, $\mathrm{FEV}_{1}$ will be reduced out of proportion to the reduction in $\mathrm{VC}$ and an obstructive ventilatory defect be observed. Severity of lung disease in $\mathrm{CF}$ is classified by the degree of impairment in $\mathrm{FEV}_{1}$ (with $\mathrm{FEV}_{1}<50 \%$ of predicted having severe disease) (Pellegrino et al. 2005), (Fig. 4.14). The obstructive ventilatory defect is reversible if an improvement in FVC and/or $\mathrm{FEV}_{1}$ of at least $12 \%$ of baseline after betaadrenergic agents is observed (Pellegrino et al. 2005). Significant reversibility can be observed in $50-60 \%$ of CF patients, and 10-20\% show reduced lung function in response to short-acting inhaled bronchodilators (Brand 2000; Landau and Phelan 1973b; Shapiro et al. 1976).

Studies in CF have shown decreased $C$ and increased $R$ (Cook et al. 1959). Due to the large surface area of small airways, their contribution to $R_{\mathrm{aw}}$ is relatively small. $R_{\text {aw }}$ measurements are therefore normal in many patients with CF until they develop disease involving the larger airways (Landau and Phelan 1973a). As the disease progresses, bronchial obstruction leads to tissue destruction with bronchiectasis and the development of areas of pulmonary emphysema and fibrosis. In more advanced disease, the destruction of lung tissue leads to decreased $C$ that parallels the decline in $\mathrm{FEV}_{1}$ (Hart et al. 2002). This increases respiratory load and favors a rapid and shallow breathing pattern that further impairs gas exchange in CF patients.

The loss of lung $V$ that develops in patients due to tissue destruction as well as the hyperinflation decreases $\mathrm{FVC}$ : therefore $\mathrm{FEV}_{1} / \mathrm{FVC}$ ratio may be normal even in patients with severe disease (Landau and Phelan 1973a).

\subsection{Restrictive Ventilatory Defect}

A small proportion of CF patients also develop a restrictive lung disease with decreased plethysmo- 
graphic TLC. This restriction may be related to diffuse inflammatory obstruction of small airway and does not necessarily indicate more severe disease. It may be reversible in some (Ries et al. 1988).

\subsubsection{Long-Term Sequelae of Neonatal Lung Disease and Chronic Lung Disease of Infancy (CLD)}

Pulmonary disease resulting from a neonatal respiratory disorder is called chronic lung disease of infancy (CLD). Bronchopulmonary dysplasia (BPD) (defined as the need for supplemental oxygen for at least 28 days after birth) accounts for the vast majority of cases of CLD. What is now considered the "old" BPD was originally described in slightly preterm newborns who had been exposed to aggressive mechanical ventilation and high concentrations of inspired oxygen. Diffuse airway damage, smooth muscle hypertrophy, neutrophilic inflammation, and parenchymal fibrosis reflected extensive disruption of relatively immature lung structures. The "new" form of BPD is interpreted as a developmental disorder: despite being delivered several weeks before alveolarization begins, these infants often have only mild respiratory distress syndrome at birth, but lung development is affected with interruption of alveolarization at a very early stage with subsequent alveolar-capillary hypoplasia (Baraldi and Filippone 2007b). Most of the information on long-term lung function in survivors of BPD refers to patients who had the condition before surfactant treatment was available ("old" form of BPD).

\subsection{In the First Months of Life}

In the first months of life, survivors of BPD are severely affected. Infants with BPD at 28 days of age have increased total and expiratory $R$ and severe $F$ limitation especially at low lung $V$ (Hazinski 1990). Neonates and young infants with CLD have increased levels of FRC by plethysmography and decreased FRC values by nitrogen washout, suggesting the presence of trapped air (Wauer et al. 1998). Specific dynamic $C\left(C_{\mathrm{dyn}}\right)$ may be reduced by more than $50 \%$ (Allen et al. 2003; Gerhardt et al. 1987b) by small airway narrowing but also by interstitial fibrosis, edema, and atelectasis (Hazinski 1990). Lung mechanics measurement that reflects the severity of neonatal disease (i.e., $C_{\mathrm{rs}}$ at 10-20 days) has been shown to correlate with subsequent reduction in lung function in 2-year-old BDP (Baraldi et al. 1997b; Bhandari and Panitch 2006).

\subsection{During Infancy and Early Childhood}

During infancy and early childhood, an improvement of airway physiology is observed, and $C_{\mathrm{L}}$ improves over time (Baraldi et al. 1997b; Bhandari and Panitch 2006; Gerhardt et al. 1987b). Maximum flow rates at FRC were reported to increase significantly within the first 2 years along with a reduction in $R_{\text {aw }}$ (Farstad et al. 1995; Trachsel and Coates 2005). However analysis of FEF shows that substantial AFO persists in numerous survivors of BDP and in preterm infants without BPD during the first 3 years of life (Baraldi et al. 1997b; Tepper et al. 1986b). The degree of airflow limitation in the first years of life seems to predict later pulmonary function (at 8 years) suggesting tracking of lung function with time, negligible "catch-up" growth of the lung, and irreversible early airway-remodelling process (Baraldi and Filippone 2007b).

\subsection{School-Age Children}

Body plethysmography studies in school children and adolescents generally reveal normal TLC with hyperinflation as reflected by an increased RV and RV/TLC ratio. Consistently children diagnosed with BPD are more prone to hyperinflation than prematurely born children without BPD. FRC is normal or mildly increased. Differences between FRC determined by helium dilution technique and by plethysmography may indicate the presence of trapped air (Trachsel and Coates 2005).

At the age of 8 years, $C_{\mathrm{dyn}}$ was reported to be $57 \%$ of the control group, in BPD, and $74 \%$ in prematurely born children without CLD (Parat et al. 1995; Trachsel and Coates 2005).

School-age children with a history of BPD have lower $\mathrm{FEV}_{1}$ than children born at term or those born prematurely without lung disease. They also have a lower FVC and $\mathrm{FEV}_{1} / \mathrm{FVC}$ ratio than children born at term (Allen et al. 2003; Bhandari and Panitch 2006). Data from 18 studies in children, adolescents, and young adults 
show that spirometric values are consistently lower in survivors of BPD, at any age between 6 and 20 years, than in controls born at term with $\mathrm{FEV}_{1}$ ranging from normal to severely decreased values (Baraldi and Filippone 2007b). Patients who were born prematurely but did not have BPD usually fare better, but they too may have airflow limitation at school age and later (Baraldi and Filippone 2007b). Asthma-like symptoms are often associated to spirometric evidence of airflow limitation in children who had BPD as infants. But airflow limitation is only partially reversed by $\beta 2$-agonists in children suggesting a stabilized remodelling process. HRCT studies have documented scattered parenchymal fibrosis and architectural distortion in many survivors of BPD, findings that are unusual in children with asthma (Baraldi and Filippone 2007b).

There is noevidence that children with BPD born since the introduction of surfactant-replacement therapy (i.e., "new" BPD) have better spirometric results at school age than those born in the pre-surfactant era (i.e., "old" BPD) as shown in studies evaluating cohort of infants weighting less than $1,000 \mathrm{~g}$ at birth or who were born before a gestational age of 29 weeks (Doyle 2006; Halvorsen et al. 2006). These results suggest that prematurity itself has a very important independent influence on the long-term respiratory prognosis (Baraldi and Filippone 2007b).

\subsubsection{Obstructive Airway Disease Following Hematopoietic Stem Cell Transplantation: Bronchiolitis Obliterans (BO)}

Hematopoietic stem cell transplantation (HSCT) is an established therapy for many chemosensitive or radiosensitive malignancies in children. $\mathrm{BO}$ is the most common late noninfectious pulmonary complication (i.e., that presents after the first 100 days following transplantation) with $80 \%$ of cases occurring between 6 and 12 months. The reported incidence range is $0-48 \%$ (Soubani and Uberti 2007). BO seems to be less common in children than in adults (Cerveri et al. 2005).

The most important association with $\mathrm{BO}$ is chronic graft versus host disease (GVHD), especially progressive chronic GVHD which evolves without hiatus from active acute GVHD. Most cases of $\mathrm{BO}$ are thought to be secondary to bronchial mucosal damage from GVHD with inflammation of the small airways and subsequent obliteration. The main symptoms associated with BO are dry cough, dyspnea, and wheezing. Twenty percent of patients are asymptomatic.

Spirometry is the main tool to diagnose and follow up patients with BO following HSCT. Based on the experience of lung transplantation, a "BO syndrome" has been defined by PFT rather than histology (Estenne et al. 2002). It was suggested that the diagnosis of $\mathrm{BO}$ is made when there is evidence of (1) new onset of AFO with reduction in $\mathrm{FEV}_{1}<75 \%$ of predicted with a $\mathrm{FEV}_{1} / \mathrm{FVC}<0.70$ not responsive to bronchodilators; (2) air trapping or small airway thickening or bronchiectasis on HRCT of the chest with inspiratory and expiratory cuts with nonparenchymal involvement, RV on PFT $>120 \%$ of predicted or pathological confirmation of constrictive bronchiolitis; and (3) absence of infection in the respiratory tract documented by clinical symptoms, radiological studies, or microbiological cultures (Soubani and Uberti 2007).

There are some studies that suggested that a reduction in mean $\mathrm{FEF}_{25-75 \%}$ may precede the decline in $\mathrm{FEV}_{1}$ and is a sensitive but not specific indicator of subsequent development of BO (Estenne et al. 2000; Ouwens et al. 2002; Patterson et al. 1996; Reynaud-Gaubert et al. 2000). A pediatric study defined AFO as $\mathrm{FEV}_{1}<80 \%$ and $\mathrm{FEF}{ }_{25-75 \%}<60 \%$ of predicted (Schultz et al. 1994).

Since the evolution of the disease despite treatment is particularly negative with a progressive worsening of respiratory function and a high mortality, early diagnosis is important. This can be achieved by systematic regular monitoring of the respiratory function starting from the onset of acute GVHD (Cerveri et al. 2005).

\subsubsection{Neuromuscular Disease (NMD)}

Decrease in VC is closely linked to weakness of respiratory muscles and disease progression. $\mathrm{VC}$ below $40 \%$ predicts nocturnal alveolar hypoventilation, and $\mathrm{VC}<25 \%$ or $<1 \mathrm{~L}$, in Duchenne 
patients, is strongly associated with respiratory failure. In mild respiratory muscle weakness, $\mathrm{VC}$ is less sensitive than maximum respiratory pressures.

In patients with neuromuscular disorders, respiratory failure may present either acutely as a result of pneumonia or more slowly, as a result of progressive ventilatory decompensation. DMD and SMA account for the majority of patients seen in pediatric practice.

\subsubsection{Lung $V$}

The most frequently noted abnormality of lung $V$ in patients with respiratory muscle weakness is a reduction in VC. VC can be measured in cooperative children, usually older than 6 years. VC reflects the strength of both inspiratory and expiratory muscles but is not specific, as it can be reduced by other factors than muscle weakness, such as reduction in both $C_{\mathrm{L}}$ (Gibson et al. 1977) and $C_{\mathrm{CW}}$ in patients with chronic respiratory muscle weakness (De Troyer et al. 1980). The decreased $C_{\mathrm{Cw}}$ probably results from stiffening of tendons and ligaments of the rib cage and ankylosis of the costosternal and thoracovertebral joints (Laghi and Tobin 2003). A decrease in $C_{\mathrm{L}}$ could be related to diffuse microatelectasis in a few patients (Estenne et al. 1993).

In children younger than 4 years with NMD, higher $C_{\mathrm{Cw}}$ normalized to body weight than in controls has been reported (Papastamelos et al. 1996). Such a high $C_{\mathrm{cw}}$ results in chest wall deformation during tidal breathing and excessive work of breathing. It also predisposes to atelectasis and can result in fixed deformation of the chest wall (i.e., pectus excavatum). Absence of lung stretch with sigh breaths and chest wall deformities can also result in reduced lung growth for children with NMD (Bach and Bianchi 2003; Panitch 2009).

In patients with NMD, a decrease in VC is an early sign of respiratory impairment. Decrease in VC and TLC is closely linked to a weakness of respiratory muscles (Braun et al. 1983; Hahn et al. 1997; Ragette et al. 2002) and disease progression (Inkley et al. 1974; Samaha et al. 1994). In patients with advanced NMD, a restrictive ventilatory defect is observed with TLC reduction.
In DMD, a typical evolution of lung $V$ is observed (Hahn et al. 1997). In ambulatory DMD the lung $V$ increases with age (ascending phase), and predicted $V$ is almost normal (Tangsrud et al. 2001). With loss of ambulation between 7 and 12 years (Gozal 2000), measured VC remains stable (plateau phase), but $\%$ predicted values begin to decline. In the following years, VC declines by about $200 \mathrm{~mL}$ or $6-8 \%$ per year (descending phase) (McDonald et al. 1995; Phillips et al. 2001; Rideau et al. 1981).

In SMA, there is a characteristic pattern of involvement with intercostal muscle weakness and relative sparing of the diaphragm (Kuzuhara and Chou 1981; Perez et al. 1996). The rib cage is neither stabilized nor expanded during inspiration. Over a period of time, the retraction of the rib cage has a detrimental effect on alveolar development. In type 1 SMA, with disease beginning before birth, pulmonary hypoplasia has been described (Cunningham and Stocks 1978). The best parameter to monitor respiratory muscle strength in children with SMA over 6 years is FVC (\% predicted) (Manzur et al. 2003). In SMA, lung $V$ (\% predicted) decreases with age, with a greater $\mathrm{VC}$ decrease in type 2 than in type 3 SMA. A decline in $\mathrm{VC}$ from 87 to $73 \%$ was shown to occur in type 3 SMA from 12 to 18 years (Souchon et al. 1996). The FVC may therefore be normal or near normal in stronger ambulant type 3 SMA (Samaha et al. 1994). In type 2 SMA, FVC is more severely impaired and was shown to decline from $55 \%$ predicted to $37 \%$, from 10 to 16 years, with a yearly average decline by 2-5\% between 7 and 15 years of age (Barois et al. 2005; Herridge et al. 2003; Souchon et al. 1996). A restrictive pattern was observed in a majority (70 \%) of type 2 SMA children followed longitudinally (Carter et al. 1995). In intermediate type 1 SMA, severe impairment in FVC has also been described (Barois et al. 2005) with progressive decrease in FVC from $60 \%$ predicted (at 7 years) to $16 \%$ (at 15 years) in children without tracheotomy and from $22 \%$ predicted (at 7 years) to $14 \%$ (at 15 years) in children with tracheotomy (Ioos et al. 2004).

Progression of scoliosis seems to contribute to VC decline in children with NMD (Miller et al. 
1988), but treatment of scoliosis with spinal stabilization did not prevent further VC decline in patients with DMD (Kennedy et al. 1995; Miller et al. 1988). In type 2 SMA, beneficial effects of spinal surgery on pulmonary function remain controversial (Mullender et al. 2008; Wang et al. 2007), but the rate of pulmonary function decline may be slowed (Wang et al. 2007).

Static lung $V$ may also be affected in some NMD patients by coexistent lung or airway disease (American Thoracic Society, European Respiratory Society 2002).

Measurement of postural change in $\mathrm{VC}$ gives a simple index of weakness of the diaphragm relative to the other inspiratory muscles. A fall of $30 \%$ or more in the supine compared with the erect posture is generally associated with severe diaphragmatic weakness (American Thoracic Society, European Respiratory Society 2002). Studies in adults with generalized NMD suggest that supine VC is a simple, sensitive, and specific test for diaphragm weakness and can replace invasive diagnostic tests (Fromageot et al. 2001; Lechtzin et al. 2002).

Thresholds of VC have been identified to predict treatable complications and outcome in patients with NMD. A VC below $60 \%$ is a sensitive and specific predictor of the onset of sleep-disordered breathing; VC below $40 \%$ predicts nocturnal alveolar hypoventilation, and $\mathrm{VC}<25 \%$ or $<1 \mathrm{~L}$, in DMD, is strongly associated with respiratory failure and poor survival unless patients are treated with mechanical ventilation (Baydur et al. 1990; Canny et al. 1989; Hukins and Hillman 2000; Mellies et al. 2003; Phillips et al. 2001, 1999; Ragette et al. 2002; Simonds et al. 1998; Wallgren-Pettersson et al. 2004).

$\mathrm{RV}$ is usually normal or increased, the latter, particularly with marked expiratory weakness (Kreitzer et al. 1978). Consequently, TLC is less markedly reduced than $\mathrm{VC}$, and the RV/TLC and FRC/TLC ratios are often increased without necessarily implying airway obstruction (American Thoracic Society, European Respiratory Society 2002). A hypodynamic type of ventilatory defect with increased RV, low VC, and normal TLC can be observed early in the course of NMD. Such a presentation has recently been described in patients with DMD (Tangsrud et al. 2001). These children may later exhibit chest wall deformities leading to a true restrictive syndrome.

\subsubsection{F/V Curves}

$R_{\text {aw }}$ is normal in uncomplicated respiratory muscle weakness. The maximum expiratory and maximum inspiratory $F / V$ curves characteristically show a reduction in those $F$ that are most effort dependent, that is, maximum expiratory $F$ at large lung $V$ (including PEF) and maximum inspiratory $F$ at all lung $V$. With severe expiratory weakness, an abrupt fall in maximum expiratory $F$ is seen immediately before RV is reached (Vincken et al. 1987). Oscillations of maximum expiratory and/or inspiratory $F$, the so-called sawtooth appearance, are seen particularly when the upper airway muscles are weak and in patients with extrapyramidal disorders (American Thoracic Society, European Respiratory Society 2002; Vincken and Cosio 1989).

\subsubsection{Respiratory $P$}

In mild respiratory muscle weakness, VC is less sensitive than maximum respiratory $P$ measurement. VC is normal, or only minimally reduced, if respiratory muscle strength is more than $50 \%$ of predicted (Laghi and Tobin 2003). This finding results from the sigmoid shape of the $P / V$ relationship of the respiratory system.

Several invasive and noninvasive tests to assess respiratory muscle strength have been reported to be of value in testing respiratory muscle strength in patients with NMD. In children, normative data are only available for PImax, PEmax, and sniff nasal inspiratory pressure (SNIP).

PImax and PEmax are tests of global inspiratory and expiratory muscle strength. They were found to be reduced in NMD patients (Baydur 1991; Black and Hyatt 1971). The PImax decline was related to the decline of inspiratory reserve volume and TLC, and the PEmax decline was related to the decline of ERV and the increase of RV in children and adults with DMD (Hahn et al. 1997). 
In DMD, earlier in the course of the disease, inspiratory muscle strength evaluated by PImax remained relatively well preserved (as compared with PEmax) implying relative sparing of the diaphragm (Hahn et al. 1997; McDonald et al. 1995). In patients with diaphragm weakness, a VC decline of $25 \%$ or more following supine positioning is associated with a mean PImax decline of $18 \pm 14 \%$ (Ragette et al. 2002). Sleepdisordered breathing usually develops when PImax is less than $45 \mathrm{~cm} \mathrm{H}_{2} \mathrm{O}$. Diurnal hypercapnia is likely when respiratory muscle strength falls to $35 \mathrm{~cm} \mathrm{H}_{2} \mathrm{O}$ (Ragette et al. 2002).

The sniff is a natural maneuver which many children find much easier to perform than PImax. Inspiratory muscle strength can easily be assessed by SNIP in children with NMD (Stefanutti et al. 2000). A recent report comparing SNIP and PImax in 241 patients with NMD found that the values of PImax were at least the same or even greater than the SNIP, particularly in patients with severe ventilatory restriction. This can be explained by the fact that patients with severe neuromuscular disorders may not be able to perform a rapid sniff maneuver owing to significant muscle atrophy (Hart et al. 2003).

The reduction of PEmax is the first sign of respiratory muscle dysfunction in DMD children (Hahn et al. 1997; McDonald et al. 1995). Expiratory muscles that contribute to PEmax are primarily the abdominal muscles, and their strength normally exceeds that of inspiratory muscles (American Thoracic Society, European Respiratory Society 2002). Therefore PEmax < PImax indicates prevailing expiratory muscle weakness, a characteristic for children with type 2 and 3 SMA (Carter et al. 1995). Recurrent chest infections may therefore occur early in SMA children due to a predominance of expiratory muscle weakness with insufficient cough and retention of airway secretions. In patients with muscular dystrophies, PEmax $>45 \mathrm{~cm} \mathrm{H}_{2} \mathrm{O}$ has been found to be necessary for an effective cough
(Mellies and Dohna-Schwake 2005; Mellies et al. 2001; Szeinberg et al. 1988).

Assessment tools to measure the different components of cough include also inspiratory VC (IVC) and the peak expiratory flow or peak cough flow (PCF). Expiratory muscle weakness is often associated with a decrease in PCF and ERV. The effect of coughing can be visualized on the maximum expiratory $F / V$ curve in healthy subjects as a transient $\mathrm{F}$ exceeding the maximum achieved during forced expiration. The absence of such supramaximal $F$ transients during coughing presumably results in impaired clearance of airway secretions and is associated with more severe expiratory muscle weakness (American Thoracic Society, European Respiratory Society 2002; Polkey et al. 1998). Patients who could not generate peak $\mathrm{F}$ transients had significantly reduced PEF, FVC, and PEmax values $\leq 45 \mathrm{~cm}$ $\mathrm{H}_{2} \mathrm{O}$ (Szeinberg et al. 1988).

Impaired coughing leads to mucus retention, atelectasis, and recurrent pneumonia. In adults with NMD, PCF below 160-200 L/min is associated with insufficient clearance of airway secretions (Bach and Saporito 1996). PCF (below $160 \mathrm{~L} /$ ) and IVC $<1.1 \mathrm{~L}$ seem also to be able to identify children with NMD at high risk for severe chest infections (Dohna-Schwake et al. 2006). Baseline PCF measurements above $160 \mathrm{~L} /$ min, however, do not guarantee adequate airway clearance, because respiratory muscle function can deteriorate during respiratory infections (Labanowski et al. 1996). For this reason a peak cough expiratory flow rate of $270 \mathrm{~L} / \mathrm{min}$ has been used to identify patients who would benefit from assisted cough techniques (Finder et al. 2004; Laroche et al. 1988). In DMD, the likelihood of having a PCF value $<270 \mathrm{~L} / \mathrm{min}$ has been shown to rise significantly when FVC is $<2.1 \mathrm{~L}$ (Gauld and Boynton 2005).

The illustrations presented in this paper were captured with the Jaeger program 5.20.0.52 (Viasys Healthcare, Höchberg, Germany). 


\section{Essentials to Remember}

- A restrictive ventilatory defect of pulmonary origin is usually associated with a decrease in lung $C\left(C_{\mathrm{L}}\right)$ that can be due to an increase in the quantity of interstitial tissue in the lung, like in interstitial lung disease (ILD), pulmonary fibrosis, infiltration, or edema. Acute lung injury (ALI) and acute respiratory distress syndrome (ARDS) result from pulmonary edema and inflammation.

- Restrictive defect that arises in the chest wall as a consequence of severe obesity or disease process affecting the ribs or the vertebral column, such as kyphoscoliosis, is associated with reduction in $C_{\mathrm{Cw}}$.

- In restrictive diseases, expansion of the lung is restricted because of alterations in lung parenchyma or as a consequence of extraparenchymal diseases affecting pleura, chest wall, or neuromuscular apparatus. A restrictive ventilatory defect is observed in these diseases with reduction in total lung capacity (TLC) and normal forced expiratory volume in $1 \mathrm{~s}\left(\mathrm{FEV}_{1}\right) /$ vital capacity (VC) ratio.

- Obstructive diseases of the lung are extremely common. Airflow limitation is a functional consequence of asthma and chronic obstructive pulmonary disease (chronic bronchitis, emphysema), cystic fibrosis $(\mathrm{CF})$, bronchiectasis, and bronchiolitis. Airflow limitation is also observed in bronchiolitis obliterans (BO). An obstructive defect is defined by a reduced $\mathrm{FEV}_{1}$ / $\mathrm{VC}$ ratio. Severity of lung function impairment is based on $\mathrm{FEV}_{1} \%$ of predicted $\left(\mathrm{FEV}_{1}<50 \%\right.$ corresponding to severe impairment). Airflow obstruction (AFO) is often reversible in asthma with improvement in $\mathrm{FEV}_{1}$ and/or FVC $\geq 12 \%$ of baseline (Fig. 4.15). AFO in small airways is suspected from a concave shape on the

$\begin{array}{lcrrrrrc} & & \text { Pre } & \text { Pred } & \text { \%Pred } & \text { Post } & \text { \%Pred } & \text { Post/Pre } \\ \text { FVC } & {[\text { L] }} & 2.75 & 3.64 & 76 & 2.79 & 77 & 101 \\ \text { FEV 1 } & {[\text { L] }} & 1.39 & 3.17 & 44 & 1.48 & 47 & 107 \\ \text { FEV 1 \% VC MAX } & {[\%]} & 47.22 & 84.35 & 56 & 48.80 & 58 & 103\end{array}$

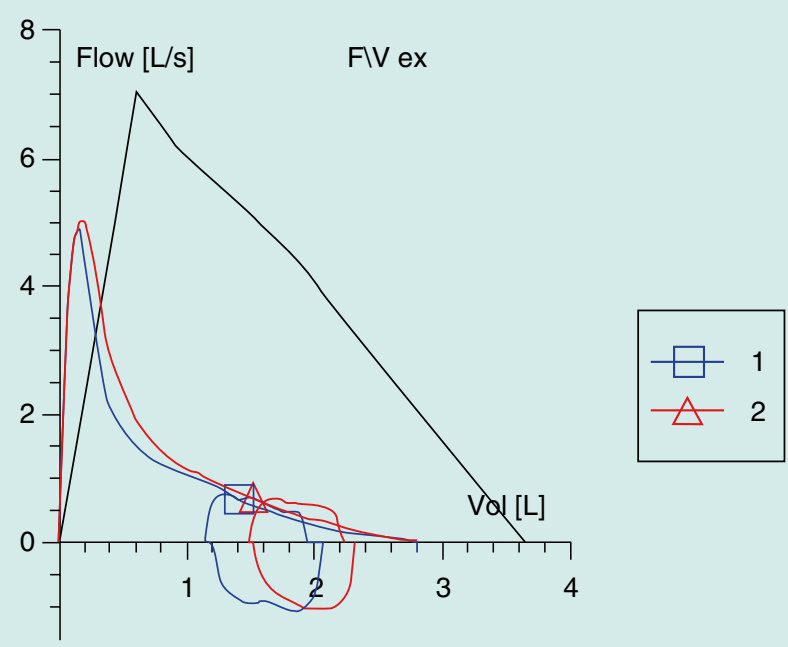

Fig. 4.15 In cystic fibrosis, as the airway disease becomes more advanced and/or more central airways become involved, $\mathrm{FEV}_{1}$ will be reduced out of proportion to the reduction in vital capacity (VC) and an obstructive ventilatory defect be observed with a reduced $\mathrm{FEV}_{1} / \mathrm{VC}$ ratio. $\mathrm{A} \mathrm{FEV}_{1}<50 \%$ predicted corresponds to severe impairement of lung function 
expiratory $F / V$ curve. AFO in small airways is associated with lung hyperinflation. In children with asthma an isolated increase in lung volume may be the sole functional abnormality. Hyperinflation is one of the earliest features of CF.

- Decrease in VC is closely linked to weakness of respiratory muscles and disease progression. VC reflects the strength of both inspiratory and expiratory muscles, but it can be reduced by other factors than muscle weakness (as decreased $C_{\mathrm{L}}$ and $C_{\mathrm{CW}}$ ). A fall of $30 \%$ or more in the supine compared with the erect posture is associated with severe diaphragmatic weakness. VC below $40 \%$ predicts nocturnal alveolar hypoventilation, and $\mathrm{VC}<25 \%$ or $<1 \mathrm{~L}$, in Duchenne patients, is strongly associated with respiratory failure. In mild respiratory muscle weakness, VC is less sensitive than maximum respiratory pressures (PImax, PEmax, sniff nasal inspiratory pressure (SNIP)).

\section{References}

Aggarwal AN, Gupta D, Behera D, Jindal SK (2000) Analysis of static pulmonary mechanics helps to identify functional defects in survivors of acute respiratory distress syndrome. Crit Care Med 28:3480-3483

Alberts WM, Priest GR, Moser KM (1983) The outlook for survivors of ARDS. Chest 84:272-274

Allen J, Zwerdling R, Ehrenkranz R, Gaultier C, Geggel R, Greenough A et al (2003) Statement on the care of the child with chronic lung disease of infancy and childhood. Am J Respir Crit Care Med 168: 356-396

American Thoracic Society, European Respiratory Society (2002) ATS/ERS Statement on respiratory muscle testing. Am J Respir Crit Care Med 166:518-624

Anand D, Stevenson CJ, West CR, Pharoah PO (2003) Lung function and respiratory health in adolescents of very low birth weight. Arch Dis Child 88(2):135-138

Angell James E, de Burgh Daly M (1969) Nasal reflexes. Proc R Soc Med 62:1287-1293

Argent AC, Newth CJ, Klein M (2008) The mechanics of breathing in children with acute severe croup. Intensive Care Med 34:324-332

Aurora P, Stocks J, Oliver C, Saunders C, Castle R, Chaziparasidis G et al (2004) Quality control for spirometry in preschool children with and without lung disease. Am J Respir Crit Care Med 169: 1152-1159

Aurora P, Bush A, Gustafsson P, Oliver C, Wallis C, Price $\mathrm{J}$ et al (2005) Multiple-breath washout as a marker of lung disease in preschool children with cystic fibrosis. Am J Respir Crit Care Med 171:249-256

Bach JR, Bianchi C (2003) Prevention of pectus excavatum for children with spinal muscular atrophy type 1 . Am J Phys Med Rehabil 82:815-819

Bach JR, Saporito LR (1996) Criteria for extubation and tracheostomy tube removal for patients with ventilatory failure. A different approach to weaning. Chest 110:1566-1571

Bailey EF, Fregosi RF (2006) Modulation of upper airway muscle activities by bronchopulmonary afferents. J Appl Physiol 101:609-617

Baldwin DN, Pillow JJ, Stocks J, Frey U (2006) Lungfunction tests in neonates and infants with chronic lung disease: tidal breathing and respiratory control. Pediatr Pulmonol 41(5):391-419

Balinotti JE, Chakr VC, Tiller C et al (2010) Growth of lung parenchyma in infants and toddlers with chronic lung disease of infancy. Am J Respir Crit Care Med 181(10):1093-1097

Baraldi E, Filippone M (2007) Chronic lung disease after premature birth. N Engl J Med 357(19): 1946-1955

Baraldi E, Filippone M, Trevisanuto D, Zanardo V, Zacchello F (1997) Pulmonary function until two years of life in infants with bronchopulmonary dysplasia. Am J Respir Crit Care Med 155(1):149-155

Barois A, Mayer M, Desguerre I, Chabrol B, Berard C, Cuisset JM et al (2005) Spinal muscular atrophy. A 4-year prospective, multicenter, longitudinal study (168 cases). Bull Acad Natl Med 189:1181-1198; discussion 98-99

Bartlett D Jr (1989) Respiratory functions of the larynx. Physiol Rev 69:33-57

Basek P, Straub D, Wildhaber JH (2005) Pediatric pulmonary function testing: childhood asthma and wheezing disorders. In: Hammer J, Eber E (eds) Progress respiratory research, vol 33. Karger, Basel

Bates JH, Ludwig MS, Sly PD, Brown K, Martin JG, Fredberg JJ (1988) Interrupter resistance elucidated by alveolar pressure measurement in open-chest normal dogs. J Appl Physiol 65(1):408-414, Epub 1988/07/01

Baydur A (1991) Respiratory muscle strength and control of ventilation in patients with neuromuscular disease. Chest 99:330-338

Baydur A, Gilgoff I, Prentice W, Carlson M, Fischer DA (1990) Decline in respiratory function and experience with long-term assisted ventilation in advanced Duchenne's muscular dystrophy. Chest 97 : 884-889 
Beardsmore CS, Bar-Yishay E, Maayan C, Yahav Y, Katznelson D, Godfrey S (1988) Lung function in infants with cystic fibrosis. Thorax 43:545-551

Beardsmore C, Dundas I, Poole K, Enock K, Stocks J (2000) Respiratory function in survivors of the United Kingdom Extracorporeal Membrane Oxygenation Trial. Am J Respir Crit Care Med 161(4 Pt 1): 1129-1135

Bedrossian CW, Greenberg SD, Singer DB, Hansen JJ, Rosenberg HS (1976) The lung in cystic fibrosis. A quantitative study including prevalence of pathologic findings among different age groups. Hum Pathol 7: 195-204

Beier FR, Renzetti AD Jr, Mitchell M, Watanabe S (1966) Pulmonary pathophysiology in cystic fibrosis. Am Rev Respir Dis 94:430-440

Ben-Abraham R, Weinbroum AA, Roizin H, Efrati O, Augarten A, Harel R et al (2002) Long-term assessment of pulmonary function tests in pediatric survivors of acute respiratory distress syndrome. Med Sci Monit 8:CR153-CR157

Benito Zaballos MF, Pedraz Garcia C, Salazar V, Villalobos A (1989) Pulmonary function in newborn infants with transitory tachypnea and pneumothorax. An Esp Pediatr 31(3):210-215

Bernard GR, Artigas A, Brigham KL, Carlet J, Falke K, Hudson L et al (1994) The American-European Consensus Conference on ARDS. Definitions, mechanisms, relevant outcomes, and clinical trial coordination. Am J Respir Crit Care Med 149:818-824

Beydon N, Amsallem F, Bellet M, Boule M, Chaussain M, Denjean A et al (2002) Pulmonary function tests in preschool children with cystic fibrosis. Am J Respir Crit Care Med 166:1099-1104

Beydon N, Pin I, Matran R, Chaussain M, Boulé M, Alain B et al (2003) Pulmonary function tests in preschool children with asthma. Am J Respir Crit Care Med 168:640-644

Beydon N, Davis SD, Lombardi E, Allen JL, Arets HG, Aurora P et al (2007) An official American Thoracic Society/European Respiratory Society statement: pulmonary function testing in preschool children. Am J Respir Crit Care Med 175(12):1304-1345, Epub 2007/06/05

Bhandari A, Panitch HB (2006) Pulmonary outcomes in bronchopulmonary dysplasia. Semin Perinatol 30: 219-226

Bhutani VK, Bowen FW, Sivieri EM (2005) Postnatal changes in pulmonary mechanics and energetics of infants with respiratory distress syndrome following surfactant treatment. Biol Neonate 87(4): 323-331

Bibi H, Shoseyov D, Feigenbaum D, Genis M, Friger M, Peled R et al (2004) The relationship between asthma and obesity in children: is it real or a case of over diagnosis? J Asthma 41:403-410

Black LF, Hyatt RE (1971) Maximal static respiratory pressures in generalized neuromuscular disease. Am Rev Respir Dis 103:641-650
Borowitz D, Armstrong D, Cerny F (2001) Relief of central airways obstruction following spinal release in a patient with idiopathic scoliosis. Pediatr Pulmonol 31: $86-88$

Boyer J, Amin N, Taddonio R, Dozor AJ (1996) Evidence of airway obstruction in children with idiopathic scoliosis. Chest 109:1532-1535

Brancatisano T, Dodd D, Engel LA (1983) Factors influencing glottic dimensions during forced expiration. J Appl Physiol 55:1825-1829

Brancatisano TP, Dodd DS, Collett PW, Engel LA (1985) Effect of expiratory loading on glottic dimensions in humans. J Appl Physiol 58:605-611

Brand PL (2000) Bronchodilators in cystic fibrosis. J R Soc Med 93(Suppl 38):37-39

Brand PL, Roorda RJ (2003) Usefulness of monitoring lung function in asthma. Arch Dis Child 88: 1021-1025

Braun NM, Arora NS, Rochester DF (1983) Respiratory muscle and pulmonary function in polymyositis and other proximal myopathies. Thorax 38:616-623

Brussee JE, Smit HA, Koopman LP, Wijga AH, Kerkhof M, Corver K et al (2004) Interrupter resistance and wheezing phenotypes at 4 years of age. Am J Respir Crit Care Med 169:209-213

Bryan AC, Wohl MEB (1986) Respiratory mechanics in children. In: Clark FJ, von Euler C (eds) Handbook of physiology the respiratory system mechanics of breathing. American Physiological Society, Bethesda, pp 179-191

Bush A (2004) Phenotype specific treatment of asthma in childhood. Paediatr Respir Rev 5(Suppl A): S93-S101

Calder NA, Williams BA, Smyth J, Boon AW, Kumar P, Hanson MA (1994) Absence of ventilatory responses to alternating breaths of mild hypoxia and air in infants who have had bronchopulmonary dysplasia: implications for the risk of sudden infant death. Pediatr Res 35(6):677-681

Camargo CA Jr, Weiss ST, Zhang S, Willett WC, Speizer FE (1999) Prospective study of body mass index, weight change, and risk of adult-onset asthma in women. Arch Intern Med 159:2582-2588

Canet E, Bureau MA (1990) Chest wall diseases and dysfunction in children. In: Chernick V (ed) Kendig's disorders of the respiratory tract in children. W.B. Saunders Company, Philadelphia

Canny GJ, Szeinberg A, Koreska J, Levison H (1989) Hypercapnia in relation to pulmonary function in Duchenne muscular dystrophy. Pediatr Pulmonol 6:169-171

Carey IM, Cook DG, Strachan DP (1999) The effects of adiposity and weight change on forced expiratory volume decline in a longitudinal study of adults. Int J Obes Relat Metab Disord 23:979-985

Carter GT, Abresch RT, Fowler WM Jr, Johnson ER, Kilmer DD, McDonald CM (1995) Profiles of neuromuscular diseases. Spinal muscular atrophy. Am J Phys Med Rehabil 74:S150-S159 
Cerveri I, Corsico A, Zoia MC, Giorgiani G (2005) Pediatric pulmonary function testing: paediatric oncology and bone marrow transplantation. In: Hammer J, Eber E (eds) Progress respiratory research, vol 33. Karger, Basel

Choukroun ML, Tayara N, Fayon M, Demarquez JL (2003) Early respiratory system mechanics and the prediction of chronic lung disease in ventilated preterm neonates requiring surfactant treatment. Biol Neonate 83(1):30-35

Clarke JR, Aston H, Silverman M (1994) Evaluation of a tidal expiratory flow index in healthy and diseased infants. Pediatr Pulmonol 17(5):285-290

Clement A (2004) Task force on chronic interstitial lung disease in immunocompetent children. Eur Respir J 24:686-697

Colin AA, Wohl ME, Mead J, Ratjen FA, Glass G, Stark AR (1989) Transition from dynamically maintained to relaxed end-expiratory volume in human infants. J Appl Physiol 67(5):2107-2111, Epub 1989/11/01

Collett PW, Brancatisano T, Engel LA (1983) Changes in the glottic aperture during bronchial asthma. Am Rev Respir Dis 128:719-723

Cook CD, Sutherland JM, Segal S, Cherry RB, Mead J, McIlroy MB et al (1957) Studies of respiratory physiology in the newborn infant. III. Measurements of mechanics of respiration. J Clin Invest 36(3):440-448, Epub 1957/03/01

Cook CD, Helliesen PJ, Kulczycki L, Barrie H, Friedlander L, Agathon S et al (1959) Studies of respiratory physiology in children. II. Lung volumes and mechanics of respiration in 64 patients with cystic fibrosis of the pancreas. Pediatrics 24:181-193

Cooper DM, Cutz E, Levison H (1977) Occult pulmonary abnormalities in asymptomatic asthmatic children. Chest 71:361-365

Cooper DM, Mellins RB, Mansell AL (1983) Ventilation distribution and density dependence of expiratory flow in asthmatic children. J Appl Physiol Respir Environ Exerc Physiol 54(4):1125-1130, Epub 1983/04/01

Corey M, Levison H, Crozier D (1976) Five- to seven-year course of pulmonary function in cystic fibrosis. Am Rev Respir Dis 114:1085-1092

Corey M, Edwards L, Levison H, Knowles M (1997) Longitudinal analysis of pulmonary function decline in patients with cystic fibrosis. J Pediatr 131:809-814

Cotes JE, Chinn DJ, Miller MR (2006) Lung function: physiology, measurement and application in medicine. Blackwell Publishing, Oxford

Cunningham M, Stocks J (1978) Werdnig-Hoffmann disease. The effects of intrauterine onset on lung growth. Arch Dis Child 53:921-925

Cystic Fibrosis Foundation Pr (2008) Annual data report 2008, Cystic Fibrosis Foundation Pr, Bethesda

da Silva WJ, Abbasi S, Pereira G, Bhutani VK (1994) Role of positive end-expiratory pressure changes on functional residual capacity in surfactant treated preterm infants. Pediatr Pulmonol 18(2):89-92

Dab I, Alexander F (1976) A simplified approach to the measurement of specific airway resistance. Pediatr Res 10:998-999
Davies G, Reid L (1971) Effect of scoliosis on growth of alveoli and pulmonary arteries and on right ventricle. Arch Dis Child 46:623-632

Davis GM, Coates AL, Papageorgiou A, Bureau MA (1988) Direct measurement of static chest wall compliance in animal and human neonates. J Appl Physiol 65(3):1093-1098, Epub 1988/09/01

Davis S, Jones M, Kisling J, Castile R, Tepper RS (1999) Density dependence of forced expiratory flows in healthy infants and toddlers. J Appl Physiol 87(5):1796-1801, Epub 1999/11/24

Day GA, Upadhyay SS, Ho EK, Leong JC, Ip M (1994) Pulmonary functions in congenital scoliosis. Spine (Phila Pa 1976) 19:1027-1031

de Burgh Daly M (1997) Clinical implications of chemoreceptor reflexes. In: Peripheral arterial chemoreceptors and respiratory-cardiovascular integration. Oxford University Press, Oxford, pp 557-589

de Burgh Daly M, Angell-James JE, Elsner R (1979) Role of carotid-body chemoreceptors and their reflex interactions in bradycardia and cardiac arrest. Lancet 1 : 764-767

De Troyer A, Borenstein S, Cordier R (1980) Analysis of lung volume restriction in patients with respiratory muscle weakness. Thorax 35:603-610

Deane S, Thomson A (2006) Obesity and the pulmonologist. Arch Dis Child 91:188-191

Degroodt EG, Quanjer PH, Wise ME, van Zomeren BC (1986) Changing relationships between stature and lung volumes during puberty. Respir Physiol 65(2):139-153, Epub 1986/08/01

Dempsey JA, Veasey SC, Morgan BJ, O'Donnell CP (2010) Pathophysiology of sleep apnea. Physiol Rev 90:47-112

Desmond KJ, Coates AL, Martin JG, Beaudry PH (1986) Trapped gas and airflow limitation in children with cystic fibrosis and asthma. Pediatr Pulmonol 2: 128-134

Dimitriou G, Greenough A, Laubscher B (1999) Appropriate positive end expiratory pressure level in surfactant-treated preterm infants. Eur $\mathrm{J}$ Pediatr 158(11):888-891

Dobyns EL, Griebel J, Kinsella JP, Abman SH, Accurso FJ (1999) Infant lung function after inhaled nitric oxide therapy for persistent pulmonary hypertension of the newborn. Pediatr Pulmonol 28(1):24-30

Doershuk CF, Fisher BJ, Matthews LW (1974) Specific airway resistance from the perinatal period into adulthood. Alterations in childhood pulmonary disease. Am Rev Respir Dis 109(4):452-457, Epub 1974/04/01

Dohna-Schwake C, Ragette R, Teschler H, Voit T, Mellies U (2006) Predictors of severe chest infections in pediatric neuromuscular disorders. Neuromuscul Disord $16: 325-328$

Dorkin HL, Stark AR, Werthammer JW, Strieder DJ, Fredberg JJ, Frantz ID 3rd (1983) Respiratory system impedance from 4 to $40 \mathrm{~Hz}$ in paralyzed intubated infants with respiratory disease. J Clin Invest 72(3): 903-910

Dosman J, Bode F, Urbanetti J, Martin R, Macklem PT (1975) The use of a helium-oxygen mixture during 
maximum expiratory flow to demonstrate obstruction in small airways in smokers. J Clin Invest 55(5):1090 1099, Epub 1975/05/01

Doyle LW (2006) Respiratory function at age 8-9 years in extremely low birthweight/very preterm children born in Victoria in 1991-1992. Pediatr Pulmonol 41: 570-576

Doyle LW, Faber B, Callanan C, Freezer N, Ford GW, Davis NM (2006) Bronchopulmonary dysplasia in very low birth weight subjects and lung function in late adolescence. Pediatrics 118(1):108-113

Dunnill MS (1982) The problem of lung growth. Thorax 37(8):561-563, Epub 1982/08/01

Durand M, Sardesai S, McEvoy C (1995) Effects of early dexamethasone therapy on pulmonary mechanics and chronic lung disease in very low birth weight infants: a randomized, controlled trial. Pediatrics 95(4): $584-590$

Editorial (1992) The nose and the respiratory system. Lancet 339:1511-1512

Eichenwald EC, Howell RG III, Kosch PC, Ungarelli RA, Lindsey J, Stark R (1992) Developmental changes in sequential activation of laryngeal abductor muscle and diaphragm in infants. J Appl Physiol 73:1425-1431

Eichenwald EC, Ungarelli RA, Stark AR (1993) Hypercapnia increases expiratory braking in preterm infants. J Appl Physiol 75:2665-2670

Elliott CG, Morris AH, Cengiz M (1981) Pulmonary function and exercise gas exchange in survivors of adult respiratory distress syndrome. Am Rev Respir Dis 123:492-495

Elliott CG, Rasmusson BY, Crapo RO (1988) Upper airway obstruction following adult respiratory distress syndrome. An analysis of 30 survivors. Chest 94: 526-530

England SJ, Bartlett D Jr, Daubenspeck JA (1982a) Influence of human vocal cord movements on airflow and resistance during eupnea. J Appl Physiol 52: 773-779

England SJ, Bartlett D Jr, Knuth SL (1982b) Comparison of human vocal cord movements during isocapnic hypoxia and hypercapnia. J Appl Physiol 53:81-86

Engstrom I, Karlberg P, Kraepelien S (1956) Respiratory studies in children. I. Lung volumes in healthy children, 6-14 years of age. Acta Paediatr 45(3):277-294

Estenne M, Gevenois PA, Kinnear W, Soudon P, Heilporn A, De Troyer A (1993) Lung volume restriction in patients with chronic respiratory muscle weakness: the role of microatelectasis. Thorax 48:698-701

Estenne M, Derom E, De Troyer A (1998) Neck and abdominal muscle activity in patients with severe thoracic scoliosis. Am J Respir Crit Care Med 158: 452-457

Estenne M, Van Muylem A, Knoop C, Antoine M (2000) Detection of obliterative bronchiolitis after lung transplantation by indexes of ventilation distribution. Am J Respir Crit Care Med 162:1047-1051

Estenne M, Maurer JR, Boehler A, Egan JJ, Frost A, Hertz $M$ et al (2002) Bronchiolitis obliterans syndrome 2001: an update of the diagnostic criteria. J Heart Lung Transplant 21:297-310
Fan LL, Langston C (1993) Chronic interstitial lung disease in children. Pediatr Pulmonol 16:184-196

Fan LL, Deterding RR, Langston C (2004) Pediatric interstitial lung disease revisited. Pediatr Pulmonol 38: 369-378

Fanconi S, Kraemer R, Weber J, Tschaeppeler H, Pfenninger J (1985) Long-term sequelae in children surviving adult respiratory distress syndrome. $\mathbf{J}$ Pediatr 106:218-222

Farstad T, Brockmeier F, Bratlid D (1995) Cardiopulmonary function in premature infants with bronchopulmonary dysplasia-a 2-year follow up. Eur J Pediatr 154:853-858

Fawke J, Lum S, Kirkby J et al (2010) Lung function and respiratory symptoms at 11 years in children born extremely preterm: the EPICure study. Am J Respir Crit Care Med 182(2):237-245

Filippone M, Sartor M, Zacchello F, Baraldi E (2003) Flow limitation in infants with bronchopulmonary dysplasia and respiratory function at school age. Lancet 361(9359):753-754

Finder JD, Birnkrant D, Carl J, Farber HJ, Gozal D, Iannaccone ST et al (2004) Respiratory care of the patient with Duchenne muscular dystrophy: ATS consensus statement. Am J Respir Crit Care Med 170: 456-465

Fink BR (1973) The curse of Adam: effort closure of the larynx. Anesthesiology 39:325-327

Flori HR, Glidden DV, Rutherford GW, Matthay MA (2005) Pediatric acute lung injury: prospective evaluation of risk factors associated with mortality. Am J Respir Crit Care Med 171:995-1001

Fok TF, Lam K, Ng PC et al (1998) Randomised crossover trial of salbutamol aerosol delivered by metered dose inhaler, jet nebuliser, and ultrasonic nebuliser in chronic lung disease. Arch Dis Child Fetal Neonatal Ed 79(2):F100-F104

Fox WW, Bureau MA, Taussig LA, Martin RR, Beaudry PH (1974) Helium flow-volume curves in the detection of early small airway disease. Pediatrics 54: 293-299

Fromageot C, Lofaso F, Annane D, Falaize L, Lejaille M, Clair B et al (2001) Supine fall in lung volumes in the assessment of diaphragmatic weakness in neuromuscular disorders. Arch Phys Med Rehabil 82:123-128

Gagnon S, Jodoin A, Martin R (1989) Pulmonary function test study and after spinal fusion in young idiopathic scoliosis. Spine (Phila Pa 1976) 14:486-490

Gappa M, Ranganathan SC, Stocks J (2001) Lung function testing in infants with cystic fibrosis: lessons from the past and future directions. Pediatr Pulmonol 32: 228-245

Gappa M, Pillow JJ, Allen J, Mayer O, Stocks J (2006) Lung function testing in neonates and infants with chronic lung disease: lung and chest wall mechanics. Pediatr Pulmonol 41(4):291-317

Gattinoni L, Pelosi P, Suter PM, Pedoto A, Vercesi P, Lissoni A (1998) Acute respiratory distress syndrome caused by pulmonary and extrapulmonary disease. Different syndromes? Am J Respir Crit Care Med 158:3-11 
Gauld LM, Boynton A (2005) Relationship between peak cough flow and spirometry in Duchenne muscular dystrophy. Pediatr Pulmonol 39:457-460

Gaultier C, Chaussain M, Boule M, Buvry A, Allaire Y, Perret L et al (1980) Lung function in interstitial lung diseases in children. Bull Eur Physiopathol Respir 16:57-66

Gerhardt T, Bancalari E (1980) Chestwall compliance in full-term and premature infants. Acta Paediatr Scand 69(3):359-364, Epub 1980/05/01

Gerhardt T, Hehre D, Feller R, Reifenberg L, Bancalari E (1987a) Pulmonary mechanics in normal infants and young children during first 5 years of life. Pediatr Pulmonol 3(5):309-316, Epub 1987/09/01

Gerhardt T, Hehre D, Feller R, Reifenberg L, Bancalari E (1987b) Serial determination of pulmonary function in infants with chronic lung disease. J Pediatr 110: $448-456$

Ghio AJ, Elliott CG, Crapo RO, Berlin SL, Jensen RL (1989) Impairment after adult respiratory distress syndrome. An evaluation based on American Thoracic Society recommendations. Am Rev Respir Dis 139: 1158-1162

Gibson GJ, Pride NB, Davis JN, Loh LC (1977) Pulmonary mechanics in patients with respiratory muscle weakness. Am Rev Respir Dis 115:389-395

Godfrey R (1994) The nose and the lower airways. Lancet 343:991-992

Golder ND, Lane R, Tasker RC (1998) Timing of recovery of lung function after severe hypoxemic respiratory failure in children. Intensive Care Med 24: 530-533

Gozal D (2000) Pulmonary manifestations of neuromuscular disease with special reference to Duchenne muscular dystrophy and spinal muscular atrophy. Pediatr Pulmonol 29:141-150

Green M, Mead J, Turner JM (1974) Variability of maximum expiratory flow-volume curves. J Appl Physiol 37(1):67-74, Epub 1974/07/01

Greenough A, Stocks J, Nothen U, Helms P (1986) Total respiratory compliance and functional residual capacity in young children. Pediatr Pulmonol 2(6):321-326, Epub 1986/11/01

Greenough A, Loftus BG, Pool J, Price JF (1987) Abnormalities of lung mechanics in young asthmatic children. Thorax 42:500-505

Greenough A, Pool J, Gleeson JG, Price JF (1988) Effect of budesonide on pulmonary hyperinflation in young asthmatic children. Thorax 43:937-938

Greenough A, Pool J, Price JF (1989) Changes in functional residual capacity in response to bronchodilator therapy among young asthmatic children. Pediatr Pulmonol 7:8-11

Guerra S, Sherrill DL, Bobadilla A, Martinez FD, Barbee RA (2002) The relation of body mass index to asthma, chronic bronchitis, and emphysema. Chest 122: 1256-1263

Hahn A, Bach JR, Delaubier A, Renardel-Irani A, Guillou C, Rideau Y (1997) Clinical implications of maximal respiratory pressure determinations for individuals with Duchenne muscular dystrophy. Arch Phys Med Rehabil 78:1-6

Hakulinen AL, Jarvenpaa AL, Turpeinen M, Sovijarvi A (1996) Diffusing capacity of the lung in school-aged children born very preterm, with and without bronchopulmonary dysplasia. Pediatr Pulmonol 21(6): 353-360

Hall CB, Hall WJ, Gala CL, MaGill FB, Leddy JP (1984) Long-term prospective study in children after respiratory syncytial virus infection. J Pediatr 105:358-364

Hall GL, Hantos Z, Petak F, Wildhaber JH, Tiller K, Burton PR et al (2000) Airway and respiratory tissue mechanics in normal infants. Am J Respir Crit Care Med 162(4 Pt 1):1397-1402, Epub 2000/10/13

Halvorsen T, Skadberg BT, Eide GE, Roksund OD, Carlsen KH, Bakke P (2004) Pulmonary outcome in adolescents of extreme preterm birth: a regional cohort study. Acta Paediatr 93(10):1294-1300

Halvorsen T, Skadberg BT, Eide GE, Roksund OD, Markestad T (2006) Better care of immature infants; has it influenced long-term pulmonary outcome? Acta Paediatr 95:547-554

Hammer J (2001) Acute lung injury: pathophysiology, assessment and current therapy. Paediatr Respir Rev 2: $10-21$

Hammer J, Numa A, Newth CJ (1998) Total lung capacity by $\mathrm{N} 2$ washout from high and low lung volumes in ventilated infants and children. Am J Respir Crit Care Med 158:526-531

Hamutcu R, Nield TA, Garg M, Keens TG, Platzker AC (2004) Long-term pulmonary sequelae in children who were treated with extracorporeal membrane oxygenation for neonatal respiratory failure. Pediatrics 114(5):1292-1296

Hancox RJ, Milne BJ, Poulton R, Taylor DR, Greene JM, McLachlan CR et al (2005) Sex differences in the relation between body mass index and asthma and atopy in a birth cohort. Am J Respir Crit Care Med 171:440-445

Hantos Z, Daroczy B, Suki B, Nagy S, Fredberg JJ (1992) Input impedance and peripheral inhomogeneity of dog lungs. J Appl Physiol 72(1):168-178, Epub 1992/01/01

Harding R (1986) The upper respiratory tract in perinatal life. In: Johnston BM, Gluckman PD (eds) Respiratory control and lung development in the fetus and newborn. Perinatology Press, Ithaca, pp 331-376

Harrison VC, Heese H de V, Klein M (1968) The significance of grunting in hyaline membrane disease. Pediatrics 41:549-559

Hart N, Polkey MI, Clement A, Boule M, Moxham J, Lofaso F et al (2002) Changes in pulmonary mechanics with increasing disease severity in children and young adults with cystic fibrosis. Am J Respir Crit Care Med 166:61-66

Hart N, Polkey MI, Sharshar T, Falaize L, Fauroux B, Raphael JC et al (2003) Limitations of sniff nasal pressure in patients with severe neuromuscular weakness. J Neurol Neurosurg Psychiatry 74:1685-1687

Hayatbakhsh MR, Sadasivam S, Mamun AA, Najman JM, Williams GM, O’Callaghan MJ (2009) Maternal smoking during and after pregnancy and lung function 
in early adulthood: a prospective study. Thorax 64(9):810-814, Epub 2009/06/16

Hazinski TA (1990) Bronchopulmonary dysplasia. In: Chernick V (ed) Kendig's disorders of the respiratory tract in children. W.B. Saunders Company, Philadelphia, pp 300-320

Henschen M, Stocks J (1999) Assessment of airway function using partial expiratory flow-volume curves: how reliable are measurements of maximal expiratory flow at frc during early infancy? Am J Respir Crit Care Med 159(2):480-486, Epub 1999/02/02

Henschen M, Stocks J, Brookes I, Frey U (2006) New aspects of airway mechanics in pre-term infants. Eur Respir J 27(5):913-920

Herridge MS, Cheung AM, Tansey CM, Matte-Martyn A, Diaz-Granados N, Al-Saidi F et al (2003) One-year outcomes in survivors of the acute respiratory distress syndrome. N Engl J Med 348:683-693

Hert R, Albert RK (1994) Sequelae of the adult respiratory distress syndrome. Thorax 49:8-13

Higenbottam T (1980) Narrowing of glottis opening in humans associated with experimentally induced bronchoconstriction. J Appl Physiol 49:403-407

Hildebrandt J (1974) Anatomy and physics of respiration. In: Ruch T, Patton H (eds) Physiology and biophysics. W B Saunders Company, Philadelphia, pp 297-324

Hislop A, Muir DC, Jacobsen M, Simon G, Reid L (1972) Postnatal growth and function of the pre-acinar airways. Thorax 27(3):265-274, Epub 1972/05/01

Hjalmarson O, Sandberg KL (2005) Lung function at term reflects severity of bronchopulmonary dysplasia. J Pediatr 146(1):86-90

Hjalmarson O, Sandberg KL (2011) Effect of antenatal corticosteroid treatment on lung function in full-term newborn infants. Neonatology 100(1):32-36

Hofhuis W, Hanekamp MN, Ijsselstijn H et al (2011) Prospective longitudinal evaluation of lung function during the first year of life after extracorporeal membrane oxygenation. Pediatr Crit Care Med 12(2): 159-164

Hogg JC, Williams J, Richardson JB, Macklem PT, Thurlbeck WM (1970) Age as a factor in the distribution of lower-airway conductance and in the pathologic anatomy of obstructive lung disease. N Engl J Med 282(23):1283-1287, Epub 1970/06/04

Hoo AF, Dezateux C, Hanrahan JP, Cole TJ, Tepper RS, Stocks J (2002a) Sex-specific prediction equations for Vmax(FRC) in infancy: a multicenter collaborative study. Am J Respir Crit Care Med 165(8):1084-1092, Epub 2002/04/17

Hoo AF, Dezateux C, Henschen M, Costeloe K, Stocks J (2002b) Development of airway function in infancy after preterm delivery. J Pediatr 141(5):652-658

Horsfield K, Gordon WI, Kemp W, Phillips S (1987) Growth of the bronchial tree in man. Thorax 42(5): 383-388, Epub 1987/05/01

Hoskote AU, Castle RA, Hoo AF et al (2008) Airway function in infants treated with inhaled nitric oxide for persistent pulmonary hypertension. Pediatr Pulmonol 43(3):224-235
Hukins CA, Hillman DR (2000) Daytime predictors of sleep hypoventilation in Duchenne muscular dystrophy. Am J Respir Crit Care Med 161:166-170

Hutchison AA (2007) Physiology of the airway. In: 5th world congress on pediatric critical care, 24-28 June. World Federation of Pediatric Intensive Critical Care Societies (WFICSS), Geneva; follow Research and Education at: www.wfpicccs.org

Hutchison AA, Bignall S (2008) Non-invasive positive pressure ventilation in the preterm neonate: reducing endotrauma and the incidence of bronchopulmonary dysplasia. Arch Dis Child Fetal Neonatal Ed 93:F64-F68

Hutchison AA, Wozniak JA, Choi HG, Conlon M, Otto RA, Abrams RM, Kosch PC (1993) Laryngeal and diaphragmatic muscle activities and airflow patterns after birth in premature lambs. J Appl Physiol 75: 121-131

Hutchison AA, Wozniak JA, Choi HG, Otto RA, Abrams RM, Kosch PC (1994) Respiratory muscle activities after birth in asphyxiated preterm lambs. Acta Paediatr 83:241-248

Hutchison AA, Burchfield DJ, Wozniak JA, Mohrman SJ (2002) Laryngeal muscle activities with cerebral hypoxia-ischemia in newborn lambs. Am J Respir Crit Care Med 166:85-91

Idiong N, Lemke RP, Lin YJ, Kwiatkowski K, Cates DB, Rigatto H (1998) Airway closure during mixed apneas in preterm infants: is respiratory effort necessary? J Pediatr 133:509-512

Inkley SR, Oldenburg FC, Vignos PJ Jr (1974) Pulmonary function in Duchenne muscular dystrophy related to stage of disease. Am J Med 56:297-306

Insalaco G, Kuna ST, Cibella F, Villeponteaux RD (1990) Thyroarytenoid muscle activity during hypoxia, hypercapnia, and voluntary hyperventilation in humans. J Appl Physiol 69:268-273

Ioos C, Leclair-Richard D, Mrad S, Barois A, EstournetMathiaud B (2004) Respiratory capacity course in patients with infantile spinal muscular atrophy. Chest 126:831-837

Irvin CG, Bates JHT (2009) Physiologic dysfunction of the asthmatic lung. What's going on down there, anyway? Proc Am Thorac Soc 6:306-311

Jenkins MA, Hopper JL, Bowes G, Carlin JB, Flander LB, Giles GG (1994) Factors in childhood as predictors of asthma in adult life. BMJ 309:90-93

Jenkins HA, Cherniack R, Szefler SJ, Covar R, Gelfand EW, Spahn JD (2003) A comparison of the clinical characteristics of children and adults with severe asthma. Chest 124:1318-1324

Jobe AH, Bancalari E (2001) Bronchopulmonary dysplasia. Am J Respir Crit Care Med 163(7):1723-1729

Kano S, Lanteri CJ, Duncan AW, Sly PD (1994) Influence of nonlinearities on estimates of respiratory mechanics using multilinear regression analysis. J Appl Physiol 77(3):1185-1197, Epub 1994/09/01

Kattan M, Keens TG, Lapierre JG, Levison H, Bryan AC, Reilly BJ (1977) Pulmonary function abnormalities in symptom-free children after bronchiolitis. Pediatrics 59:683-688 
Kennedy JD, Staples AJ, Brook PD, Parsons DW, Sutherland AD, Martin AJ et al (1995) Effect of spinal surgery on lung function in Duchenne muscular dystrophy. Thorax 50:1173-1178

Kerem E, Reisman J, Corey M, Canny GJ, Levison H (1992) Prediction of mortality in patients with cystic fibrosis. N Engl J Med 326:1187-1191

Khemani RG, Newth CJ (2010) The design of future pediatric mechanical ventilation trials for acute lung injury. Am J Respir Crit Care Med 182:1465-1474

Klein JJ, van Haeringen JR, Sluiter HJ, Holloway R, Peset $R$ (1976) Pulmonary function after recovery from the adult respiratory distress syndrome. Chest 69:350-355

Koenig SM (2001) Pulmonary complications of obesity. Am J Med Sci 321:249-279

Kosch PC, Stark AR (1984) Dynamic maintenance of end-expiratory lung volume in full-term infants. J Appl Physiol Respir Environ Exerc Physiol 57(4): 1126-1133, Epub 1984/10/01

Kosch PC, Hutchison AA, Wozniak JA, Carlo WA, Stark AR (1988) Posterior cricoarytenoid and diaphragm activities during tidal breathing in neonates. J Appl Physiol 64(5):1968-1978, Epub 1988/05/01

Kotecha SJ, Edwards MO, Watkins WJ et al (2013) Effect of preterm birth on later FEV1: a systematic review and meta-analysis. Thorax 68:760-766

Koumbourlis AC (2006) Scoliosis and the respiratory system. Paediatr Respir Rev 7:152-160

Koumbourlis AC, Mutich RL, Motoyama EK (1995) Contribution of airway hyperresponsiveness to lower airway obstruction after extracorporeal membrane oxygenation for meconium aspiration syndrome. Crit Care Med 23(4):749-754

Kozlowska WJ, Bush A, Wade A, Aurora P, Carr SB, Castle RA et al (2008) Lung function from infancy to the preschool years after clinical diagnosis of cystic fibrosis. Am J Respir Crit Care Med 178:42-49

Kraemer R, Baldwin DN, Ammann RA, Frey U, Gallati S (2006) Progression of pulmonary hyperinflation and trapped gas associated with genetic and environmental factors in children with cystic fibrosis. Respir Res 7:138

Kreitzer SM, Saunders NA, Tyler HR, Ingram RH Jr (1978) Respiratory muscle function in amyotrophic lateral sclerosis. Am Rev Respir Dis 117:437-447

Kuna ST, Insalaco G, Woodson GE (1988) Thyroarytenoid muscle activity during wakefulness and sleep in normal adults. J Appl Physiol 65:1332-1339

Kuna ST, Smickley JS, Insalaco G (1990) Posterior cricoarytenoid muscle activity during wakefulness and sleep in normal adults. J Appl Physiol 68:1746-1754

Kuna ST, McCarthy MP, Smickley JS (1993) Laryngeal response to passively induced hypocapnia during NREM sleep in normal adult humans. J Appl Physiol 75:1088-1096

Kuna ST, Vanoye CR, Griffin JR, Updegrove JD (1994) Effect of hypercapnia on laryngeal airway resistance in normal adult humans. J Appl Physiol 77: 2797-2803
Kuzuhara S, Chou SM (1981) Preservation of the phrenic motoneurons in Werdnig-Hoffmann disease. Ann Neurol 9:506-510

Labanowski M, Schmidt-Nowara W, Guilleminault C (1996) Sleep and neuromuscular disease: frequency of sleep-disordered breathing in a neuromuscular disease clinic population. Neurology 47:1173-1180

Laghi F, Tobin MJ (2003) Disorders of the respiratory muscles. Am J Respir Crit Care Med 168: 10-48

Landau LI, Phelan PD (1973a) The spectrum of cystic fibrosis. A study of pulmonary mechanics in 46 patients. Am Rev Respir Dis 108:593-602

Landau LI, Phelan PD (1973b) The variable effect of a bronchodilating agent on pulmonary function in cystic fibrosis. J Pediatr 82:863-868

Landau LI, Mellis CM, Phelan PD, Bristowe B, McLennan L (1979) "Small airways disease" in children: no test is best. Thorax 34:217-223

Lanteri CJ, Sly PD (1993) Changes in respiratory mechanics with age. J Appl Physiol 74(1):369-378, Epub 1993/01/01

Laroche CM, Carroll N, Moxham J, Green M (1988) Clinical significance of severe isolated diaphragm weakness. Am Rev Respir Dis 138:862-866

Lau C (2006) Oral feeding in the preterm infant. Neoreviews 7:e19-e26

Lazarus R, Colditz G, Berkey CS, Speizer FE (1997) Effects of body fat on ventilatory function in children and adolescents: cross-sectional findings from a random population sample of school children. Pediatr Pulmonol 24:187-194

Lechtzin N, Wiener CM, Shade DM, Clawson L, Diette GB (2002) Spirometry in the supine position improves the detection of diaphragmatic weakness in patients with amyotrophic lateral sclerosis. Chest 121:436-442

Leiter JC, Mortola JP, Tenney SM (1986) A comparative analysis of contractile characteristics of the diaphragm and of respiratory system mechanics. Respir Physiol 64(3):267-276, Epub 1986/06/01

Li AM, Chan D, Wong E, Yin J, Nelson EA, Fok TF (2003) The effects of obesity on pulmonary function. Arch Dis Child 88:361-363

Litonjua AA, Gold DR (2008) Asthma and obesity: common early-life influences in the inception of disease. J Allergy Clin Immunol 121:1075-1084; quiz 85-86

Lopes J, Muller NL, Bryan MH, Bryan AC (1981) Importance of inspiratory muscle tone in maintenance of FRC in the newborn. J Appl Physiol Respir Environ Exerc Physiol 51(4):830-834, Epub 1981/10/01

Lowe L, Murray CS, Custovic A, Simpson BM, Kissen PM, Woodcock A (2002) Specific airway resistance in 3-year-old children: a prospective cohort study. Lancet 359:1904-1908

Lui K, Lloyd J, Ang E, Rynn M, Gupta JM (2000) Early changes in respiratory compliance and resistance during the development of bronchopulmonary dysplasia in the era of surfactant therapy. Pediatr Pulmonol 30(4):282-290 
Lum S, Hulskamp G, Merkus P, Baraldi E, Hofhuis W, Stocks J (2006) Lung function tests in neonates and infants with chronic lung disease: forced expiratory maneuvers. Pediatr Pulmonol 41(3):199-214, Epub 2005/11/17

Lum S, Kirkby J, Welsh L, Marlow N, Hennessy E, Stocks J (2011) Nature and severity of lung function abnormalities in extremely pre-term children at 11 years of age. Eur Respir J 37(5):1199-1207

Luschei ES, Ramig LO, Finnegan EM, Baker KK, Smith ME (2006) Patterns of laryngeal electromyography and the activity of the respiratory system during spontaneous laughter. J Neurophysiol 96:442-450

Lyrene RK, Truog WE (1981) Adult respiratory distress syndrome in a pediatric intensive care unit: predisposing conditions, clinical course, and outcome. Pediatrics 67:790-795

Mahut B, Trinquart L, Bokov P, Le Bourgeois M, Waernessyckle S, Peiffer C et al (2009) Relationships between specific airway resistance and forced expiratory flows in asthmatic children. PLoS One 4:e5270

Majaesic CM, Jones R, Dinu IA, Montgomery MD, Sauve RS, Robertson CM (2007) Clinical correlations and pulmonary function at 8 years of age after severe neonatal respiratory failure. Pediatr Pulmonol 42(9): 829-837

Mansell A, Dubrawsky C, Levison H, Bryan AC, Crozier DN (1974) Lung elastic recoil in cystic fibrosis. Am Rev Respir Dis 109:190-197

Mansell AL, Bryan AC, Levison H (1977) Relationship of lung recoil to lung volume and maximum expiratory flow in normal children. J Appl Physiol Respir Environ Exerc Physiol 42(6):817-823, Epub 1977/06/01

Manzur AY, Muntoni F, Simonds A (2003) Muscular dystrophy campaign sponsored workshop: recommendation for respiratory care of children with spinal muscular atrophy type II and III. 13th February 2002, London, UK. Neuromuscul Disord 13:184-189

Marchal F, Schweitzer C (2005) Pediatric pulmonary function testing: Plethysmography and gas dilution techniques. In: Hammer J, Eber E (eds) Progress respiratory research, vol 33. Karger, Basel, pp 103-117

Marcus CL (2000) Pathophysiology of OSAS in children. In: Loughlin GM, Carroll JL, Marcus CL (eds) Sleep and breathing in children. Marcel Dekker, Inc., New York, pp 601-624

Marostica PJ, Weist AD, Eigen H, Angelicchio C, Christoph K, Savage J et al (2002) Spirometry in 3- to 6-year-old children with cystic fibrosis. Am J Respir Crit Care Med 166:67-71

Marshall RP, Bellingan G, Webb S, Puddicombe A, Goldsack N, McAnulty RJ et al (2000) Fibroproliferation occurs early in the acute respiratory distress syndrome and impacts on outcome. Am J Respir Crit Care Med 162:1783-1788

Martinez FJ, Flaherty K (2006) Pulmonary function testing in idiopathic interstitial pneumonias. Proc Am Thorac Soc 3:315-321

Martinez FD, Helms PJ (1998) Types of asthma and wheezing. Eur Respir J Suppl 27:3s-8s
Martinez FD, Wright AL, Taussig LM, Holberg CJ, Halonen M, Morgan WJ (1995) Asthma and wheezing in the first six years of life. The Group Health Medical Associates. N Engl J Med 332:133-138

McDonald CM, Abresch RT, Carter GT, Fowler WM Jr, Johnson ER, Kilmer DD et al (1995) Profiles of neuromuscular diseases. Duchenne muscular dystrophy. Am J Phys Med Rehabil 74:S70-S92

McEvoy C, Bowling S, Williamson K, McGaw P, Durand M (2004) Randomized, double-blinded trial of lowdose dexamethasone: II. Functional residual capacity and pulmonary outcome in very low birth weight infants at risk for bronchopulmonary dysplasia. Pediatr Pulmonol 38(1):55-63

McEvoy C, Schilling D, Spitale P, Peters D, O’Malley J, Durand M (2008) Decreased respiratory compliance in infants less than or equal to 32 weeks' gestation, delivered more than 7 days after antenatal steroid therapy. Pediatrics 121(5):e1032-e1038

McEvoy C, Schilling D, Peters D et al (2010) Respiratory compliance in preterm infants after a single rescue course of antenatal steroids: a randomized controlled trial. Am J Obstet Gynecol 202(6):544.e1-544.e9

McHugh LG, Milberg JA, Whitcomb ME, Schoene RB, Maunder RJ, Hudson LD (1994) Recovery of function in survivors of the acute respiratory distress syndrome. Am J Respir Crit Care Med 150:90-94

McKenzie SA, Bridge PD, Healy MJ (2000) Airway resistance and atopy in preschool children with wheeze and cough. Eur Respir J 15:833-838

Mead J (1979) Functional significance of the area of apposition of diaphragm to rib cage [proceedings]. Am Rev Respir Dis 119(2 Pt 2):31-32, Epub 1979/02/01

Mellies U, Dohna-Schwake C (2005) Pediatric pulmonary function testing: neuromuscular disorders. In: Hammer J, Eber E (eds) Progress respiratory research, vol 33. Karger, Basel, pp 233-246

Mellies U, Ragette R, Schwake C, Baethmann M, Voit T, Teschler H (2001) Sleep-disordered breathing and respiratory failure in acid maltase deficiency. Neurology 57:1290-1295

Mellies U, Ragette R, Schwake C, Boehm H, Voit T, Teschler H (2003) Daytime predictors of sleep disordered breathing in children and adolescents with neuromuscular disorders. Neuromuscul Disord 13: 123-128

Merkus PJ, Borsboom GJ, Van Pelt W, Schrader PC, Van Houwelingen HC, Kerrebijn KF et al (1993) Growth of airways and air spaces in teenagers is related to sex but not to symptoms. J Appl Physiol 75(5):2045-2053, Epub 1993/11/01

Merth IT, de Winter JP, Zonderland HM, Borsboom GJ, Quanjer PH (1997) Pulmonary function in infants with neonatal chronic lung disease with or without hyaline membrane disease at birth. Eur Respir J 10(7): 1606-1613

Merz U, Peschgens T, Kusenbach G, Hornchen H (1999) Early versus late dexamethasone treatment in preterm infants at risk for chronic lung disease: a randomized pilot study. Eur J Pediatr 158(4):318-322 
Miedema M, de Jongh FH, Frerichs I, van Veenendaal MB, van Kaam AH (2011a) Changes in lung volume and ventilation during surfactant treatment in ventilated preterm infants. Am J Respir Crit Care Med 184(1):100-105

Miedema M, de Jongh FH, Frerichs I, van Veenendaal MB, van Kaam AH (2011b) Changes in lung volume and ventilation during lung recruitment in highfrequency ventilated preterm infants with respiratory distress syndrome. J Pediatr 159(2):199-205.e2

Miedema M, de Jonge F, Frerichs I, van Veenendaal MB, Van Kaam AH (2012) The effect of airway pressure and oscillation amplitude on ventilation in preterm infants. Eur Respir J 40:479-484, Accepted Dec 2011

Miller M, Martin R, Carlo W, Fanaroff A (1987) Oral breathing in response to nasal trauma in term infants. J Pediatr 111:899-901

Miller F, Moseley CF, Koreska J, Levison H (1988) Pulmonary function and scoliosis in Duchenne dystrophy. J Pediatr Orthop 8:133-137

Miller MR, Hankinson J, Brusasco V, Burgos F, Casaburi $\mathrm{R}$, Coates A et al (2005) Standardisation of spirometry. Eur Respir J 26:319-338

Mittman C, Edelman NH, Norris AH, Shock NW (1965) Relationship between chest wall and pulmonary compliance and age. J Appl Physiol 20(6):1211-1216

Mokry J, Mokra D, Nosalova G (2007) Effects of meconium on airway reactivity to histamine and acetylcholine in vitro. J Physiol Pharmacol 58 Suppl 5(Pt 1): 409-417

Mortola JP (2004) Mechanics of breathing. In: Polin RA, Fox WW (eds) Fetal and neonatal physiology, 3rd edn. Saunders, Philadelphia

Mortola JP, Saetta M (1987) Measurements of respiratory mechanics in the newborn: a simple approach. Pediatr Pulmonol 3(2):123-130, Epub 1987/03/01

Motoyama EK, Fort MD, Klesh KW, Mutich RL, Guthrie RD (1987) Early onset of airway reactivity in premature infants with bronchopulmonary dysplasia. Am Rev Respir Dis 136(1):50-57

Muirhead A, Conner AN (1985) The assessment of lung function in children with scoliosis. J Bone Joint Surg Br 67:699-702

Mullender M, Blom N, De Kleuver M, Fock J, Hitters W, Horemans A et al (2008) A Dutch guideline for the treatment of scoliosis in neuromuscular disorders. Scoliosis 26:1-14

Muntoni F, Bushby K, Manzur AY (2006) Muscular dystrophy campaign funded workshop on management of scoliosis in Duchenne muscular dystrophy 24 January 2005, London, UK. Neuromuscul Disord 16:210-219

Myer CM III, Cotton RT, Shott SR (1995) The pediatric airway: an interdisciplinary approach. Philadelphia: JP Lippincott company

Narang I, Rosenthal M, Cremonesini D, Silverman M, Bush A (2008) Longitudinal evaluation of airway function 21 years after preterm birth. Am J Respir Crit Care Med 178(1):74-80

Narayanan M, Owers-Bradley J, Beardsmore CS, Mada M, Ball I, Garipov R et al (2012) Alveolarization continues during childhood and adolescence: new evidence from helium-3 magnetic resonance. Am J Respir Crit Care Med 185(2):186-191, Epub 2011/11/11

Neve V, Girard F, Flahault A, Boule M (2002) Lung and thorax development during adolescence: relationship with pubertal status. Eur Respir J 20(5):1292-1298, Epub 2002/11/27

Neve V, Edme JL, Devos P, Deschildre A, Thumerelle C, Santos C et al (2006) Spirometry in 3-5-year-old children with asthma. Pediatr Pulmonol 41:735-743

Newth CJ, Stretton M, Deakers TW, Hammer J (1997) Assessment of pulmonary function in the early phase of ARDS in pediatric patients. Pediatr Pulmonol 23: 169-175

NHLBI, WHO (2002) NHLBI/WHO workshop report. Global Initiative for asthma (GINA). Global Strategy for Asthma Management and Prevention. National institute for Health, Bethesda (updated 2006)

NHLBI. Expert panel report 3: guidelines for the diagnosis and management of asthma, full report. http:// www.nhlbi.nih.gov/guidelines/asthma/asthgdln.pdf. Accessed 29 Aug 2007

Nielsen KG, Bisgaard H (2000) The effect of inhaled budesonide on symptoms, lung function, and cold air and methacholine responsiveness in 2- to 5-year-old asthmatic children. Am J Respir Crit Care Med 162: 1500-1506

Nielsen KG, Bisgaard H (2001) Discriminative capacity of bronchodilator response measured with three different lung function techniques in asthmatic and healthy children aged 2 to 5 years. Am J Respir Crit Care Med 164:554-559

Openshaw P, Edwards S, Helms P (1984) Changes in rib cage geometry during childhood. Thorax 39(8):624627, Epub 1984/08/01

Oswald H, Phelan PD, Lanigan A, Hibbert M, Carlin JB, Bowes $G$ et al (1997) Childhood asthma and lung function in mid-adult life. Pediatr Pulmonol 23: $14-20$

Ouwens JP, van der Mark TW, Koeter GH, de Boer WJ, Grevink RG, van der Bij W (2002) Bronchiolar airflow impairment after lung transplantation: an early and common manifestation. J Heart Lung Transplant 21:1056-1061

Paetow U, Windstetter D, Schmalisch G (1999) Variability of tidal breathing flow-volume loops in healthy and sick newborns. Am J Perinatol 16(10):549-559

Panitch HB (2009) The pathophysiology of respiratory impairment in pediatric neuromuscular diseases. Pediatrics 123(Suppl 4):S215-S218

Pankow W, Podszus T, Gutheil T, Penzel T, Peter J, Von Wichert P (1998) Expiratory flow limitation and intrinsic positive end-expiratory pressure in obesity. $\mathbf{J}$ Appl Physiol 85:1236-1243

Papastamelos C, Panitch HB, England SE, Allen JL (1995) Developmental changes in chest wall compliance in infancy and early childhood. J Appl Physiol 78(1):179-184, Epub 1995/01/01

Papastamelos C, Panitch HB, Allen JL (1996) Chest wall compliance in infants and children with neuro- 
muscular disease. Am J Respir Crit Care Med 154: 1045-1048

Parat S, Moriette G, Delaperche MF, Escourrou P, Denjean A, Gaultier C (1995) Long-term pulmonary functional outcome of bronchopulmonary dysplasia and premature birth. Pediatr Pulmonol 20:289-296

Patil SP et al (2007) Adult obstructive sleep apnea: pathophysiology and diagnosis. Chest 132(1):325-337

Paton JY (2000) A practical approach to the interpretation of lung function testing in children. Paediatr Respir Rev 1:241-248

Patterson GM, Wilson S, Whang JL, Harvey J, Agacki K, Patel H et al (1996) Physiologic definitions of obliterative bronchiolitis in heart-lung and double lung transplantation: a comparison of the forced expiratory flow between $25 \%$ and $75 \%$ of the forced vital capacity and forced expiratory volume in one second. J Heart Lung Transplant 15:175-181

Patzak A, Schluter B, Mrowka R et al (1999) Rhythms and complexity of respiration during sleep in pre-term infants. Clin Physiol 19(6):458-466

Paull K, Covar R, Jain N, Gelfand EW, Spahn JD (2005) Do NHLBI lung function criteria apply to children? A cross-sectional evaluation of childhood asthma at National Jewish Medical and Research Center, 1999-2002. Pediatr Pulmonol 39:311-317

Pellegrino R, Viegi G, Brusasco V, Crapo RO, Burgos F, Casaburi R et al (2005) Interpretative strategies for lung function tests. Eur Respir J 26:948-968

Perez A, Mulot R, Vardon G, Barois A, Gallego J (1996) Thoracoabdominal pattern of breathing in neuromuscular disorders. Chest 110:454-461

Peters JI, Bell RC, Prihoda TJ, Harris G, Andrews C, Johanson WG (1989) Clinical determinants of abnormalities in pulmonary functions in survivors of the adult respiratory distress syndrome. Am Rev Respir Dis 139:1163-1168

Petrucci N, Iacovelli W (2007) Lung protective ventilation strategy for the acute respiratory distress syndrome. Cochrane Database Syst Rev (3):CD003844

Phillips MF, Smith PE, Carroll N, Edwards RH, Calverley PM (1999) Nocturnal oxygenation and prognosis in Duchenne muscular dystrophy. Am J Respir Crit Care Med 160:198-202

Phillips MF, Quinlivan RC, Edwards RH, Calverley PM (2001) Changes in spirometry over time as a prognostic marker in patients with Duchenne muscular dystrophy. Am J Respir Crit Care Med 164:2191-2194

Pike K, Jane Pillow J, Lucas JS (2012) Long term respiratory consequences of intrauterine growth restriction. Semin Fetal Neonatal Med 17(2):92-98, Epub 2012/01/27

Pillow JJ (2012) Tidal volume, recruitment and compliance in HFOV: same principles, different frequency. Eur Respir J 40(2):291-293

Pillow JJ, Hall GL, Willet KE, Jobe AH, Hantos Z, Sly PD (2001a) Effects of gestation and antenatal steroid on airway and tissue mechanics in newborn lambs. Am J Respir Crit Care Med 163(5):1158-1163
Pillow JJ, Wilkinson MH, Neil HL, Ramsden CA (2001b) In vitro performance characteristics of high-frequency oscillatory ventilators. Am J Respir Crit Care Med 164(6):1019-1024

Pillow JJ, Jobe AH, Collins RA et al (2004a) Variability in preterm lamb lung mechanics after intra-amniotic endotoxin is associated with changes in surfactant pool size and morphometry. Am J Physiol Lung Cell Mol Physiol 287(5):L992-L998

Pillow JJ, Sly PD, Hantos Z (2004b) Monitoring of lung volume recruitment and derecruitment using oscillatory mechanics during high-frequency oscillatory ventilation in the preterm lamb. Pediatr Crit Care Med 5(2): $172-180$

Pillow JJ, Stocks J, Sly PD, Hantos Z (2005) Partitioning of airway and parenchymal mechanics in unsedated newborn infants. Pediatr Res 58(6):1210-1215

Polgar G, Weng TR (1979) The functional development of the respiratory system from the period of gestation to adulthood. Am Rev Respir Dis 120(3):625-695, Epub 1979/09/01

Polkey MI, Lyall RA, Green M, Nigel Leigh P, Moxham J (1998) Expiratory muscle function in amyotrophic lateral sclerosis. Am J Respir Crit Care Med 158: 734-741

Pool JB, Greenough A, Price JF (1988) Abnormalities of functional residual capacity in symptomatic and asymptomatic young asthmatics. Acta Paediatr Scand 77:419-423

Praud JP (1999) Larynx and neonatal apneas. Pediatr Pulmonol Suppl 18:190-193

Praud JP, Dorion D (2008) Obstructive sleep disordered breathing in children: beyond adenotonsillectomy. Pediatr Pulmonol 43:837-843

Praud JP, Canet E, Bureau MA (1992) Chemoreceptor and vagal influences on thyroarytenoid muscle activity in awake lambs during hypoxia. J Appl Physiol 72: 962-969

Pullan CR, Hey EN (1982) Wheezing, asthma, and pulmonary dysfunction 10 years after infection with respiratory syncytial virus in infancy. Br Med J (Clin Res Ed) 284:1665-1669

Quanjer PH, Stocks J, Polgar G, Wise M, Karlberg J, Borsboom G (1989) Compilation of reference values for lung function measurements in children. Eur Respir J Suppl 4:184S-261S, Epub 1989/03/01

Ragette R, Mellies U, Schwake C, Voit T, Teschler H (2002) Patterns and predictors of sleep disordered breathing in primary myopathies. Thorax 57:724-728

Ranganathan SC, Dezateux C, Bush A, Carr SB, Castle RA, Madge $S$ et al (2001) Airway function in infants newly diagnosed with cystic fibrosis. Lancet 358 : 1964-1965

Ranganathan SC, Bush A, Dezateux C, Carr SB, Hoo AF, Lum $S$ et al (2002) Relative ability of full and partial forced expiratory maneuvers to identify diminished airway function in infants with cystic fibrosis. Am J Respir Crit Care Med 166:1350-1357

Ranganathan S, Linnane B, Nolan G, Gangell C, Hall G (2008) Early detection of lung disease in children with 
cystic fibrosis using lung function. Paediatr Respir Rev 9:160-167

Rasmussen F, Taylor DR, Flannery EM, Cowan JO, Greene JM, Herbison GP et al (2002) Risk factors for airway remodeling in asthma manifested by a low postbronchodilator FEV1/vital capacity ratio: a longitudinal population study from childhood to adulthood. Am J Respir Crit Care Med 165:1480-1488

Ratjen F, Grasemann H (2005) Pediatric pulmonary function testing: cystic fibrosis. In: Hammer J, Eber E (eds) Progress respiratory research, vol 33. Karger, Basel, pp 215-223

Reid LM (1977) The lung: its growth and remodelling in health and disease. 1976 Edward BD Neuhauser lecture. AJR Am J Roentgenol 129:777-788

Reynaud-Gaubert M, Thomas P, Badier M, Cau P, Giudicelli R, Fuentes P (2000) Early detection of airway involvement in obliterative bronchiolitis after lung transplantation. Functional and bronchoalveolar lavage cell findings. Am J Respir Crit Care Med 161:1924-1929

Rideau Y, Jankowski LW, Grellet J (1981) Respiratory function in the muscular dystrophies. Muscle Nerve 4: 155-164

Ries AL, Sosa G, Prewitt L, Friedman PJ, Harwood IR (1988) Restricted pulmonary function in cystic fibrosis. Chest 94:575-579

Robin B, Kim YJ, Huth J et al (2004) Pulmonary function in bronchopulmonary dysplasia. Pediatr Pulmonol 37(3):236-242

Rodenstein DO (2004) The travels of a pulmonologist through the upper airway. Arch Bronconeumol 40:178-182

Rodillo E, Marini ML, Heckmatt JZ, Dubowitz V (1989) Scoliosis in spinal muscular atrophy: review of 63 cases. J Child Neurol 4:118-123

Roorda RJ, Gerritsen J, van Aalderen WM, Schouten JP, Veltman JC, Weiss ST et al (1994) Follow-up of asthma from childhood to adulthood: influence of potential childhood risk factors on the outcome of pulmonary function and bronchial responsiveness in adulthood. J Allergy Clin Immunol 93:575-584

Ruggins NR, Milner AD (1991) Site of upper airway obstruction in preterm infants with problematical apnoea. Arch Dis Child 66:787-792

Ruggins NR, Milner AD (1993) Site of upper airway obstruction in infants following an acute lifethreatening event. Pediatrics 91:595-601

Samaha FJ, Buncher CR, Russman BS, White ML, Iannaccone ST, Barker L et al (1994) Pulmonary function in spinal muscular atrophy. J Child Neurol 9: 326-329

Sandberg KL, Pinkerton KE, Poole SD, Minton PA, Sundell HW (2011) Fetal nicotine exposure increases airway responsiveness and alters airway wall composition in young lambs. Respir Physiol Neurobiol 176(1-2):57-67, Epub 2011/01/05

Schachter LM, Salome CM, Peat JK, Woolcock AJ (2001) Obesity is a risk for asthma and wheeze but not airway hyperresponsiveness. Thorax 56:4-8
Schachter LM, Peat JK, Salome CM (2003) Asthma and atopy in overweight children. Thorax 58:1031-1035

Scharf SM, Feldman NT, Goldman MD, Haut HZ, Bruce E, Ingram RH Jr (1978) Vocal cord closure. A cause of upper airway obstruction during controlled ventilation. Am Rev Respir Dis 117:391-397

Schmalisch G, Wauer RR, Foitzik B, Patzak A (2003) Influence of preterm onset of inspiration on tidal breathing parameters in infants with and without CLD. Respir Physiol Neurobiol 135(1):39-46

Schrader PC, Quanjer PH, van Zomeren BC, Wise ME (1984) Changes in the FEV1-height relationship during pubertal growth. Bull Eur Physiopathol Respir 20(4):381-388, Epub 1984/07/01

Schrader PC, Quanjer PH, Olievier IC (1988) Respiratory muscle force and ventilatory function in adolescents. Eur Respir J 1(4):368-375, Epub 1988/04/01

Schultz KR, Green GJ, Wensley D, Sargent MA, Magee JF, Spinelli JJ et al (1994) Obstructive lung disease in children after allogeneic bone marrow transplantation. Blood 84:3212-3220

Seikel JA, King DW, Drumright DG (2005) Anatomy and physiology for speech, language, and hearing. Thomson Delmar Learning, Clifton Park

Sekizawa K, Yanai M, Sasaki H, Takishima T (1987) Effect of a previous voluntary deep breath on laryngeal resistance in normal and asthmatic subjects. J Appl Physiol 63:1406-1412

Shao H, Sandberg K, Hjalmarson O (1998) Impaired gas mixing and low lung volume in preterm infants with mild chronic lung disease. Pediatr Res 43(4 Pt 1): 536-541

Shapiro GG, Bamman J, Kanarek P, Bierman CW (1976) The paradoxical effect of adrenergic and methylxanthine drugs in cystic fibrosis. Pediatrics 58:740-743

Simon MR, Chinchilli VM, Phillips BR, Sorkness CA, Lemanske RF Jr, Szefler SJ et al (2010) Forced expiratory flow between $25 \%$ and $75 \%$ of vital capacity and FEV1/forced vital capacity ratio in relation to clinical and physiological parameters in asthmatic children with normal FEV1 values. J Allergy Clin Immunol 126:527-34.e1-8

Simonds AK, Muntoni F, Heather S, Fielding S (1998) Impact of nasal ventilation on survival in hypercapnic Duchenne muscular dystrophy. Thorax 53:949-952

Snepvangers Y, Peter de Winter JP, Burger H, Brouwers H, Van der Ent CK (2004) Neonatal respiratory mechanics and development of bronchial hyperresponsiveness in preterm infants. Early Hum Dev 78(2): $105-118$

Soubani AO, Uberti JP (2007) Bronchiolitis obliterans following haematopoietic stem cell transplantation. Eur Respir J 29:1007-1019

Souchon F, Simard LR, Lebrun S, Rochette C, Lambert J, Vanasse M (1996) Clinical and genetic study of chronic (types II and III) childhood onset spinal muscular atrophy. Neuromuscul Disord 6:419-424

Spahn JD, Chipps BE (2006) Office-based objective measures in childhood asthma. J Pediatr 148: $11-15$ 
Spahn JD, Cherniack R, Paull K, Gelfand EW (2004) Is forced expiratory volume in one second the best measure of severity in childhood asthma? Am J Respir Crit Care Med 169:784-786

Spoel M, Laas R, Gischler SJ et al (2012a) Diagnosisrelated deterioration of lung function after extracorporeal membrane oxygenation. Eur Respir J 40(6): 1531-1537

Spoel M, van den Hout L, Gischler SJ et al (2012b) Prospective longitudinal evaluation of lung function during the first year of life after repair of congenital diaphragmatic hernia. Pediatr Crit Care Med 13(3): e133-e139

Stanescu D (1999) Small airways obstruction syndrome. Chest 116:231-233

Stecenko AA, Hutchison AA (1991) Phascinating physiology. Am Rev Respir Dis 144:1008-1011

Stefanutti D, Benoist MR, Scheinmann P, Chaussain M, Fitting JW (2000) Usefulness of sniff nasal pressure in patients with neuromuscular or skeletal disorders. Am J Respir Crit Care Med 162:1507-1511

Steinkamp G, Muller KM, Schirg E, von der Hardt H (1990) Fibrosing alveolitis in childhood. A long-term follow-up. Acta Paediatr Scand 79:823-831

Stocks J, Godfrey S (1977) Specific airway conductance in relation to postconceptional age during infancy. $\mathrm{J}$ Appl Physiol Respir Environ Exerc Physiol 43(1): 144-154, Epub 1977/07/01

Stocks J, Hislop AA (1996) Structure and function of the respiratory system. In: Stocks J (ed) Infant respiratory function testing, 1st edn. Wiley-Liss, New York

Stocks J, Sonnappa S (2013) Early life influences on the development of chronic obstructive pulmonary disease. Ther Adv Respir Dis 7:161-173, Epub 2013/02/27

Stocks J, Henschen M, Hoo AF, Costeloe K, Dezateux C (1997) Influence of ethnicity and gender on airway function in preterm infants. Am J Respir Crit Care Med 156(6):1855-1862, Epub 1997/12/31

Strachan DP, Griffiths JM, Johnston ID, Anderson HR (1996) Ventilatory function in British adults after asthma or wheezing illness at ages 0-35. Am J Respir Crit Care Med 154:1629-1635

Subramaian S, Strohl KP (2004) Obesity and pulmonary function. In: Bray A, Bouchard C (eds) Handbook of obesity. Etiology and pathophysiology. Informa Health Care/Marcel Dekker Inc, New York

Sun B, Curstedt T, Song GW, Robertson B (1993) Surfactant improves lung function and morphology in newborn rabbits with meconium aspiration. Biol Neonate 63(2):96-104

Svanes C, Omenaas E, Jarvis D, Chinn S, Gulsvik A, Burney P (2004) Parental smoking in childhood and adult obstructive lung disease: results from the European Community Respiratory Health Survey. Thorax 59(4):295-302, Epub 2004/03/30

Szeinberg A, Tabachnik E, Rashed N, McLaughlin FJ, England S, Bryan CA et al (1988) Cough capacity in patients with muscular dystrophy. Chest 94 : 1232-1235
Szymankiewicz M, Hodgman JE, Siassi B, Gadzinowski J (2004a) Mechanics of breathing after surgical ligation of patent ductus arteriosus in newborns with respiratory distress syndrome. Biol Neonate 85(1):32-36

Szymankiewicz M, Gadzinowski J, Kowalska K (2004b) Pulmonary function after surfactant lung lavage followed by surfactant administration in infants with severe meconium aspiration syndrome. J Matern Fetal Neonatal Med 16(2):125-130

Tang BM, Craig JC, Eslick GD, Seppelt I, McLean AS (2009) Use of corticosteroids in acute lung injury and acute respiratory distress syndrome: a systematic review and meta-analysis. Crit Care Med 37:1594-1603

Tangsrud S, Petersen IL, Lodrup Carlsen KC, Carlsen KH (2001) Lung function in children with Duchenne's muscular dystrophy. Respir Med 95:898-903

Tepper RS, Morgan WJ, Cota K, Wright A, Taussig LM (1986a) Physiologic growth and development of the lung during the first year of life. Am Rev Respir Dis 134(3):513-519, Epub 1986/09/01

Tepper RS, Morgan WJ, Cota K, Taussig LM (1986b) Expiratory flow limitation in infants with bronchopulmonary dysplasia. J Pediatr 109(6):1040-1046

Tepper RS, Williams T, Kisling J, Castile R (2001) Static compliance of the respiratory system in healthy infants. Am J Respir Crit Care Med 163(1):91-94, Epub 2001/02/24

Thach BT (2005) Can we breathe and swallow at the same time? J Appl Physiol 99:1633

Thach BT (2008) Some aspects of clinical relevance in the maturation of respiratory control in infants. J Appl Physiol 104:1828-1834

The Acute Respiratory Distress Syndrome Network (2000) Ventilation with lower tidal volumes as compared with traditional tidal volumes for acute lung injury and the acute respiratory distress syndrome. N Engl J Med 342:1301-1308

The International Study of Asthma and Allergies in Childhood (ISAAC) Steering Committee. Worldwide variation in prevalence of symptoms of asthma, allergic rhinoconjunctivitis, and atopic eczema: ISAAC (1998) Lancet 351:1225-1232

Thurlbeck WM (1982) Postnatal human lung growth. Thorax 37(8):564-571, Epub 1982/08/01

Tortorolo L, Vento G, Matassa PG, Zecca E, Romagnoli C (2002) Early changes of pulmonary mechanics to predict the severity of bronchopulmonary dysplasia in ventilated preterm infants. J Matern Fetal Neonatal Med 12(5):332-337

Trachsel D, Coates AL (2005) Pediatric pulmonary function testing: long-term sequelae of neonatal lung disease. In: Hammer J, Eber E (eds) Progress respiratory research, vol 33. Karger, Basel, pp 255-265

Tsirikos AI, Baker ADL (2006) Spinal muscular atrophy: classification, aetiology, and treatment of spinal deformity in children and adolescents. Curr Orthop 20: 430-445

Upadhyay SS, Ho EK, Gunawardene WM, Leong JC, Hsu LC (1993) Changes in residual volume relative to vital capacity and total lung capacity after arthrodesis of the 
spine in patients who have adolescent idiopathic scoliosis. J Bone Joint Surg Am 75:46-52

van der Cammen-van Zijp MH, Gischler SJ, Hop WC, de Jongste JC, Tibboel D, Ijsselstijn H (2011) Deterioration of exercise capacity after neonatal extracorporeal membrane oxygenation. Eur Respir J 38(5): 1098-1104

Vento G, Matassa PG, Zecca E et al (2004) Effect of dexamethasone on tracheobronchial aspirate fluid cytology and pulmonary mechanics in preterm infants. Pharmacology 71(3):113-119

Vento G, Matassa PG, Ameglio F et al (2005) HFOV in premature neonates: effects on pulmonary mechanics and epithelial lining fluid cytokines. A randomized controlled trial. Intensive Care Med 31(3): $463-470$

Vilozni D, Barak A, Efrati O, Augarten A, Springer C, Yahav Y et al (2005) The role of computer games in measuring spirometry in healthy and "asthmatic" preschool children. Chest 128:1146-1155

Vilozni D, Bentur L, Efrati O, Minuskin T, Barak A, Szeinberg A et al (2007) Spirometry in early childhood in cystic fibrosis patients. Chest 131:356-361

Vilozni D, Efrati O, Hakim F, Adler A, Livnat G, Bentur L (2009) FRC measurements using body plethysmography in young children. Pediatr Pulmonol 44:885-891

Vincken WG, Cosio MG (1989) Flow oscillations on the flow-volume loop: clinical and physiological implications. Eur Respir J 2:543-549

Vincken WG, Elleker MG, Cosio MG (1987) Flowvolume loop changes reflecting respiratory muscle weakness in chronic neuromuscular disorders. Am J Med 83:673-680

Vrijlandt EJ, Gerritsen J, Boezen HM, Grevink RG, Duiverman EJ (2006) Lung function and exercise capacity in young adults born prematurely. Am J Respir Crit Care Med 173(8):890-896

Wailoo MP, Emery JL (1982) Normal growth and development of the trachea. Thorax 37(8):584-587, Epub 1982/08/01

Walamies MA (1998) Diagnostic role of residual volume in paediatric patients with chronic symptoms of the lower airways. Clin Physiol 18:49-54

Wallgren-Pettersson C, Bushby K, Mellies U, Simonds A (2004) 117th ENMC workshop: ventilatory support in congenital neuromuscular disorders - congenital myopathies, congenital muscular dystrophies, congenital myotonic dystrophy and SMA (II) 4-6 April 2003, Naarden, The Netherlands. Neuromuscul Disord 14:56-69

Wang CH, Finkel RS, Bertini ES, Schroth M, Simonds A, Wong B et al (2007) Consensus statement for standard of care in spinal muscular atrophy. J Child Neurol 22:1027-1049

Ware LB, Matthay MA (2000) The acute respiratory distress syndrome. N Engl J Med 342:1334-1349

Wauer RR, Maurer T, Nowotny T, Schmalisch G (1998) Assessment of functional residual capacity using nitrogen washout and plethysmographic techniques in infants with and without bronchopulmonary dysplasia. Intensive Care Med 24:469-475

Weber B, Smith JP, Briscoe WA, Friedman SA, King TK (1975) Pulmonary function in asymptomatic adolescents with idiopathic scoliosis. Am Rev Respir Dis 111:389-397

Weiss I, Ushay HM, DeBruin W, O’Loughlin J, Rosner I, Notterman D (1996) Respiratory and cardiac function in children after acute hypoxemic respiratory failure. Crit Care Med 24:148-154

Weng TR, Levison H (1969) Standards of pulmonary function in children. Am Rev Respir Dis 99(6):879894, Epub 1969/06/01

Wennergren G, Kristjansson S (2001) Relationship between respiratory syncytial virus bronchiolitis and future obstructive airway diseases. Eur Respir J 18:1044-1058

Wickens K, Barry D, Friezema A, Rhodius R, Bone N, Purdie G et al (2005) Obesity and asthma in 11-12 year old New Zealand children in 1989 and 2000. Thorax 60:7-12

Widdicombe J (1986) The physiology of the nose. Clin Chest Med 7:159-170

Wolf B, Gaultier C, Lopez C, Boule M, Girard F (1983) Hypoxemia in attack free asthmatic children: relationship with lung volumes and lung mechanics. Bull Eur Physiopathol Respir 19:471-476

Wongtrakool C, Wang N, Hyde DM, Roman J, Spindel ER (2012) Prenatal nicotine exposure alters lung function and airway geometry through alpha7 nicotinic receptors. Am J Respir Cell Mol Biol 46(5):695-702, Epub 2012/01/17

Wood LD, Prichard S, Weng TR, Kruger K, Bryan AC, Levison H (1971) Relationship between anatomic dead space and body size in health, asthma, and cystic fibrosis. Am Rev Respir Dis 104(2):215-222, Epub 1971/08/01

Wozniak JA, Hutchison AA, Kosch PC (1993) Laryngeal and pump muscle activities during $\mathrm{CO}_{2}$ breathing in neonates. J Appl Physiol 75:416-423

Yap JC, Watson RA, Gilbey S, Pride NB (1995) Effects of posture on respiratory mechanics in obesity. J Appl Physiol 79:1199-1205

Yoder B, Thomson M, Coalson J (2005) Lung function in immature baboons with respiratory distress syndrome receiving early caffeine therapy: a pilot study. Acta Paediatr 94(1):92-98

Zapletal A, Houstek J, Samanek M, Copova M, Paul T (1985) Lung function in children and adolescents with idiopathic interstitial pulmonary fibrosis. Pediatr Pulmonol 1:154-166

Zerah F, Harf A, Perlemuter L, Lorino H, Lorino AM, Atlan G (1993) Effects of obesity on respiratory resistance. Chest 103:1470-1476

Zimmerman JJ, Akhtar SR, Caldwell E, Rubenfeld GD (2009) Incidence and outcomes of pediatric acute lung injury. Pediatrics 124:87-95 